\title{
Exercise training undertaken by people within 12 months of lung resection for non-small cell lung cancer (Review)
}

Cavalheri V, Burtin C, Formico VR, Nonoyama ML, Jenkins S, Spruit MA, Hill K

Cavalheri V, Burtin C, Formico VR, Nonoyama ML, Jenkins S, Spruit MA, Hill K.

Exercise training undertaken by people within 12 months of lung resection for non-small cell lung cancer.

Cochrane Database of Systematic Reviews 2019, Issue 6. Art. No.: CD009955.

DOI: 10.1002/14651858.CD009955.pub3.

www.cochranelibrary.com 
TABLE OF CONTENTS

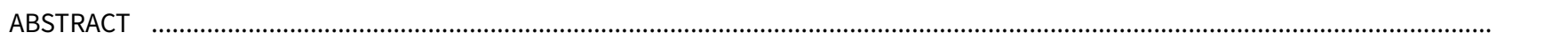

PLAIN LANGUAGE SUMMARY

SUMMARY OF FINDINGS

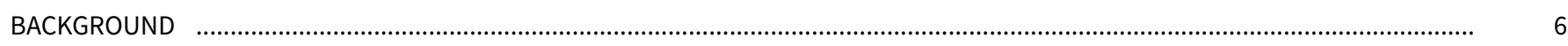

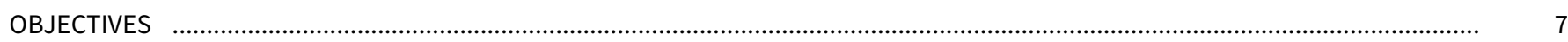

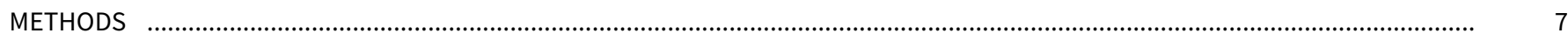

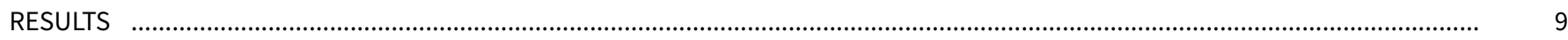

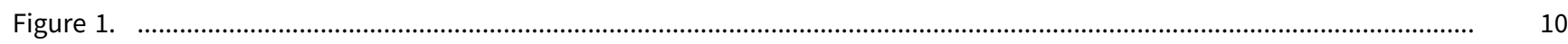

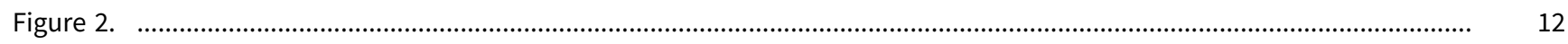

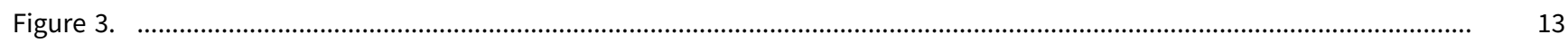

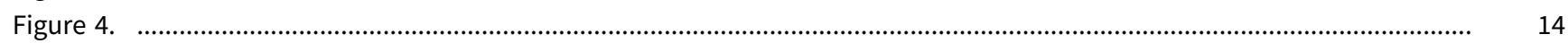

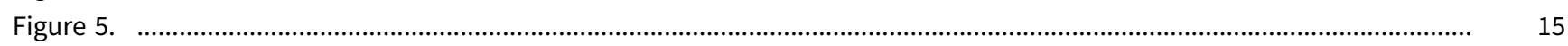

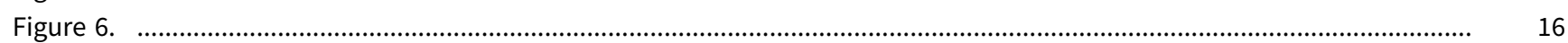

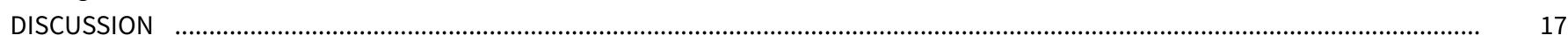

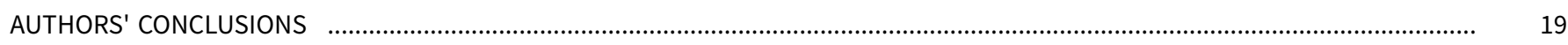

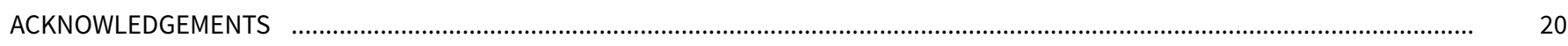

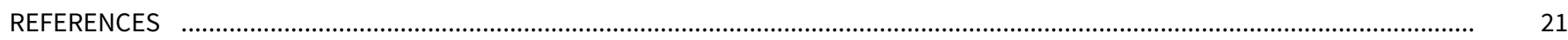

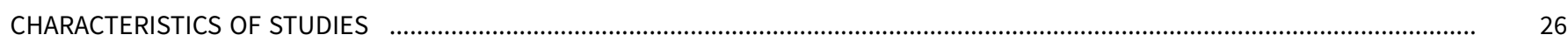

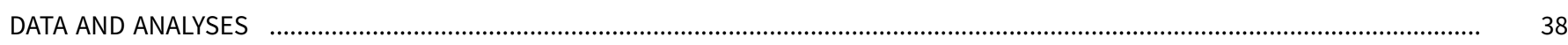

Analysis 1.1. Comparison 1 Exercise group versus control group, Outcome 1 Exercise capacity (VO2peak in $\mathrm{mL} / \mathrm{kg} / \mathrm{min}$ ). ........ 39

Analysis 1.2. Comparison 1 Exercise group versus control group, Outcome 2 Exercise capacity (6MWD in metres). .................. 39

Analysis 1.3. Comparison 1 Exercise group versus control group, Outcome 3 General health-related quality of life (SF-36 - 40

physical component score).

Analysis 1.4. Comparison 1 Exercise group versus control group, Outcome 4 General health-related quality of life (SF-36 - mental 40 component score).

Analysis 1.5. Comparison 1 Exercise group versus control group, Outcome 5 Disease-specific health-related quality of life (EORTC QLQ-C30 - global health).

Analysis 1.6. Comparison 1 Exercise group versus control group, Outcome 6 Disease-specific health-related quality of life (EORTC QLQ C30 - functional scales).

Analysis 1.7. Comparison 1 Exercise group versus control group, Outcome 7 Disease-specific health-related quality of life (EORTC QLQ-C30 - symptoms scales).

Analysis 1.8. Comparison 1 Exercise group versus control group, Outcome 8 Disease-specific health-related quality of life (EORTC QLQ-C30 - physical functioning).

Analysis 1.9. Comparison 1 Exercise group versus control group, Outcome 9 Force-generating capacity of peripheral muscle (quadriceps).

Analysis 1.10. Comparison 1 Exercise group versus control group, Outcome 10 Force-generating capacity of peripheral muscles (handgrip).

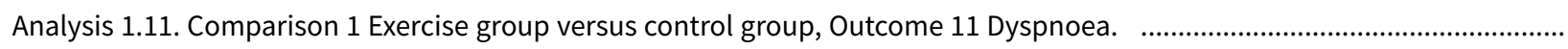

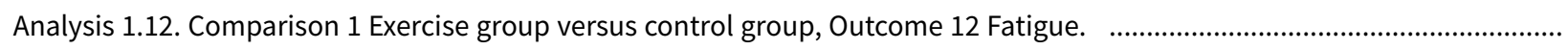

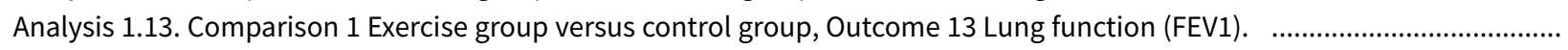

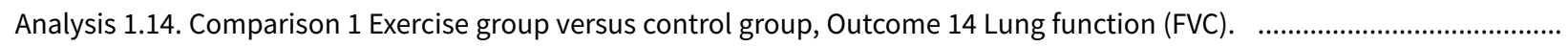

APPENDICES

FEEDBACK

WHAT'S NEW

HISTORY

CONTRIBUTIONS OF AUTHORS

DECLARATIONS OF INTEREST

SOURCES OF SUPPORT

DIFFERENCES BETWEEN PROTOCOL AND REVIEW

INDEX TERMS

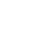
(1) 4 16 7

19

1

6

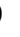


[Intervention Review]

\section{Exercise training undertaken by people within 12 months of lung resection for non-small cell lung cancer}

Vinicius Cavalheri1,2, Chris Burtin³, Vittoria R Formico4, Mika L Nonoyama5 , Sue Jenkins¹,6, Martijn A. Spruit3,7,8, Kylie Hill1,2

1School of Physiotherapy and Exercise Science, Faculty of Health Sciences, Curtin University, Perth, Australia. 2Institute for Respiratory Health, Sir Charles Gairdner Hospital, Perth, Australia. ${ }^{3}$ Reval Rehabilitation Research Center, BIOMED, Faculty of Rehabilitation Sciences, Hasselt University, Diepenbeek, Belgium. ${ }^{4}$ Physiotherapy Department, Faculdade de Ciências e Tecnologia, Universidade Estadual Paulista (UNESP), Presidente Prudente, Brazil. 5 Faculty of Health Sciences, University of Ontario Institute of Technology, Oshawa, Canada. ${ }^{6}$ Physiotherapy Department, Sir Charles Gairdner Hospital, Perth, Australia. ${ }^{7}$ Research and Education, CIRO, Horn, Netherlands. ${ }^{8}$ Respiratory Medicine, NUTRIM School of Nutrition and Translational Research in Metabolism, Maastricht University Medical Center, Maastricht, Netherlands

Contact: Vinicius Cavalheri, School of Physiotherapy and Exercise Science, Faculty of Health Sciences, Curtin University, Kent Street, Perth, Western Australia, 6102, Australia.v_cavalheri@hotmail.com, vinicius.cavalher@curtin.edu.au.

Editorial group: Cochrane Lung Cancer Group.

Publication status and date: New search for studies and content updated (no change to conclusions), comment added to review, published in Issue 6, 2019.

Citation: Cavalheri V, Burtin C, Formico VR, Nonoyama ML, Jenkins S, Spruit MA, Hill K. Exercise training undertaken by people within 12 months of lung resection for non-small cell lung cancer. Cochrane Database of Systematic Reviews 2019, Issue 6. Art. No.: CD009955. DOI: 10.1002/14651858.CD009955.pub3.

Copyright () 2019 The Cochrane Collaboration. Published by John Wiley \& Sons, Ltd.

\section{A B S T R A C T}

\section{Background}

Decreased exercise capacity and health-related quality of life (HRQoL) are common in people following lung resection for non-small cell lung cancer (NSCLC). Exercise training has been demonstrated to confer gains in exercise capacity and HRQoL for people with a range of chronic conditions, including chronic obstructive pulmonary disease and heart failure, as well as in people with prostate and breast cancer. A programme of exercise training may also confer gains in these outcomes for people following lung resection for NSCLC. This systematic review updates our 2013 systematic review.

\section{Objectives}

The primary aim of this review was to determine the effects of exercise training on exercise capacity and adverse events in people following lung resection (with or without chemotherapy) for NSCLC. The secondary aims were to determine the effects of exercise training on other outcomes such as HRQoL, force-generating capacity of peripheral muscles, pressure-generating capacity of the respiratory muscles, dyspnoea and fatigue, feelings of anxiety and depression, lung function, and mortality.

\section{Search methods}

We searched for additional randomised controlled trials (RCTs) in the Cochrane Central Register of Controlled Trials (CENTRAL) (the Cochrane Library 2019, Issue 2 of 12), MEDLINE (via PubMed) (2013 to February 2019), Embase (via Ovid) (2013 to February 2019), SciELO (The Scientific Electronic Library Online) (2013 to February 2019), and PEDro (Physiotherapy Evidence Database) (2013 to February 2019 ).

\section{Selection criteria}

We included RCTs in which participants with NSCLC who underwent lung resection were allocated to receive either exercise training, which included aerobic exercise, resistance exercise, or a combination of both, or no exercise training. 


\section{Data collection and analysis}

Two review authors screened the studies and identified those eligible for inclusion. We used either postintervention values (with their respective standard deviation (SD)) or mean changes (with their respective SD) in the meta-analyses that reported results as mean difference (MD). In meta-analyses that reported results as standardised mean difference (SMD), we placed studies that reported postintervention values and those that reported mean changes in separate subgroups. We assessed the certainty of evidence for each outcome by downgrading or upgrading the evidence according to GRADE criteria.

\section{Main results}

Along with the three RCTs included in the original version of this review (2013), we identified an additional five RCTs in this update, resulting in a total of eight RCTs involving 450 participants (180 (40\%) females). The risk of selection bias in the included studies was low and the risk of performance bias high. Six studies explored the effects of combined aerobic and resistance training; one explored the effects of combined aerobic and inspiratory muscle training; and one explored the effects of combined aerobic, resistance, inspiratory muscle training and balance training. On completion of the intervention period, compared to the control group, exercise capacity expressed as the peak rate of oxygen uptake $\left(\mathrm{VO}_{2}\right.$ peak) and six-minute walk distance $(6 \mathrm{MWD})$ was greater in the intervention group $\left(\mathrm{VO}_{2} \mathrm{peak}: \mathrm{MD} 2.97 \mathrm{~mL} / \mathrm{kg} / \mathrm{min}\right.$, 95\% confidence interval $(\mathrm{Cl}) 1.93$ to $4.02 \mathrm{~mL} / \mathrm{kg} / \mathrm{min}, 4$ studies, 135 participants, moderate-certainty evidence; $6 \mathrm{MWD}: \mathrm{MD} 57 \mathrm{~m}, 95 \% \mathrm{Cl}$ 34 to $80 \mathrm{~m}, 5$ studies, 182 participants, high-certainty evidence). One adverse event (hip fracture) related to the intervention was reported in one of the included studies. The intervention group also achieved greater improvements in the physical component of general HRQoL (MD 5.0 points, $95 \% \mathrm{Cl} 2.3$ to 7.7 points, 4 studies, 208 participants, low-certainty evidence); improved force-generating capacity of the quadriceps muscle (SMD 0.75, 95\% Cl 0.4 to 1.1, 4 studies, 133 participants, moderate-certainty evidence); and less dyspnoea (SMD -0.43, $95 \% \mathrm{Cl}-0.81$ to $-0.05,3$ studies, 110 participants, very low-certainty evidence). We observed uncertain effects on the mental component of general HRQoL, disease-specific HRQoL, handgrip force, fatigue, and lung function. There were insufficient data to comment on the effect of exercise training on maximal inspiratory and expiratory pressures and feelings of anxiety and depression. Mortality was not reported in the included studies.

\section{Authors' conclusions}

Exercise training increased exercise capacity and quadriceps muscle force of people following lung resection for NSCLC. Our findings also suggest improvements on the physical component score of general HRQoL and decreased dyspnoea. This systematic review emphasises the importance of exercise training as part of the postoperative management of people with NSCLC.

\section{PLAIN LANGUAGE SUMMARY}

\section{Exercise training after lung surgery for people with non-small cell lung cancer}

\section{Review question}

We updated the evidence about the effect of exercise training after lung surgery for non-small cell lung cancer (NSCLC) on fitness level; adverse events; quality of life; strength of the leg, hand, and breathing muscles; breathlessness; fatigue; feelings of anxiety and depression; and lung function.

\section{Background}

After lung surgery for NSCLC, people's fitness levels and quality of life decrease. We know that exercise training improves these outcomes in people with chronic lung disease and in those with prostate and breast cancer. In the 2013 version of this review, we demonstrated that exercise training improved fitness level (distance walked on the six-minute walk test) in people after lung surgery for NSCLC. Due to the limited number of studies, the effect of exercise training on quality of life and other outcomes was unclear.

\section{Search date}

The evidence is current to February 2019.

\section{Study characteristics}

We included three studies from the 2013 review and an additional five new studies from the current review, for a total of eight studies with 450 participants ( 180 women). The number of participants in the included studies ranged between 17 and 131 ; the mean age of participants was between 63 and 71 years. Six studies explored the effects of combined aerobic and strengthening exercises; one explored the effects of combined aerobic exercise and inspiratory muscle training; and one explored the effects of combined aerobic exercise, strengthening exercise inspiratory muscle training and balance training. The length of the exercise programmes ranged from four to 20 weeks, with exercises performed twice to five days a week.

\section{Key results}

Our results showed that people with NSCLC who exercised after lung surgery had better fitness level (measured using both a cycling test and the six-minute walk test) and strength in their leg muscles compared to those that did not exercise. We also showed initial evidence 
for better quality of life and less breathlessness in those who exercised. One adverse event (hip fracture) related to the intervention was reported in one study. The effect of exercise training after lung surgery on grip strength, fatigue, and lung function was uncertain. We found insufficient evidence for improvements in the strength of breathing muscles or feelings of anxiety and depression.

\section{Quality of evidence}

Overall the quality (certainty) of evidence for the outcomes was moderate, ranging between very low (for breathlessness) and high (for fitness level measured via the six-minute walk test). 
SUMMARY OF FINDINGS

\section{Summary of findings for the main comparison. Exercise group compared to control group for non-small cell lung cancer}

\section{Exercise group compared to control group for non-small cell lung cancer}

Patient or population: non-small cell lung cancer

Setting: the studies were based in the UK, Denmark, Australia, Norway, Spain, Belgium and the Netherlands

Intervention: Exercise group

Comparison: control group

\begin{tabular}{|c|c|c|c|c|c|c|}
\hline \multirow[t]{2}{*}{ Outcomes } & \multicolumn{2}{|l|}{ Anticipated absolute effects ${ }^{\star}(95 \% \mathrm{CI})$} & \multirow{2}{*}{$\begin{array}{l}\text { Relative effect } \\
(95 \% \mathrm{Cl})\end{array}$} & \multirow{2}{*}{$\begin{array}{l}\text { № of partici- } \\
\text { pants } \\
\text { (studies) }\end{array}$} & \multirow{2}{*}{$\begin{array}{l}\text { Certainty of } \\
\text { the evidence } \\
\text { (GRADE) }\end{array}$} & \multirow[t]{2}{*}{ Comments } \\
\hline & Risk with control group & $\begin{array}{l}\text { Risk with Exercise } \\
\text { group }\end{array}$ & & & & \\
\hline $\begin{array}{l}\text { Exercise capacity (VO2peak } \\
\text { in } \mathrm{mL} / \mathrm{kg} / \mathrm{min} \text { ) }\end{array}$ & $\begin{array}{l}\text { The mean exercise capacity } \\
\text { (VO2peak in } \mathrm{mL} / \mathrm{kg} / \mathrm{min} \text { ) ranged } \\
\text { from } 13.3 \text { to } 19.0 \mathrm{~mL} / \mathrm{kg} / \mathrm{min}\end{array}$ & $\begin{array}{l}\text { MD } 2.97 \mathrm{~mL} / \mathrm{kg} / \mathrm{min} \\
\text { higher } \\
\text { (1.93 higher to } 4.02 \\
\text { higher) }\end{array}$ & - & $\begin{array}{l}135 \\
(4 \mathrm{RCTs})\end{array}$ & $\begin{array}{l}\oplus \oplus \oplus \ominus \\
\text { MODERATE } 1\end{array}$ & - \\
\hline $\begin{array}{l}\text { Exercise capacity ( } 6 \mathrm{MWD} \text { in } \\
\text { metres) }\end{array}$ & $\begin{array}{l}\text { The mean exercise capacity (6MWD } \\
\text { in metres) ranged from } 452 \text { to } 491 \\
\text { metres }\end{array}$ & $\begin{array}{l}\text { MD } 57.3 \text { metres higher } \\
\text { ( } 34.3 \text { higher to } 80.2 \\
\text { higher) }\end{array}$ & - & $\begin{array}{l}182 \\
(5 \mathrm{RCTS})\end{array}$ & $\begin{array}{l}\oplus \oplus \oplus \oplus \\
\mathrm{HIGH}\end{array}$ & - \\
\hline $\begin{array}{l}\text { Safety of the intervention } \\
\text { (adverse events related to } \\
\text { the intervention) } \\
\text { assessed with: number of } \\
\text { events }\end{array}$ & \multicolumn{2}{|c|}{$\begin{array}{l}1 \text { adverse event (a hip fracture) was reported in the interven- } \\
\text { tion group of } 1 \text { RCT. }\end{array}$} & - & $\begin{array}{l}202 \\
(4 \mathrm{RCTs})\end{array}$ & $\begin{array}{l}\oplus \oplus \oplus \ominus \\
\text { MODERATE } \\
3\end{array}$ & - \\
\hline $\begin{array}{l}\text { General health-related qual- } \\
\text { ity of life (SF-36 - physical } \\
\text { component score) }\end{array}$ & $\begin{array}{l}\text { The mean general health-relat- } \\
\text { ed quality of life (SF- } 36 \text { - physical } \\
\text { component score) ranged from } \\
23.0 \text { to } 43.3\end{array}$ & $\begin{array}{l}\text { MD } 5.02 \text { higher } \\
\text { ( } 2.3 \text { higher to } 7.73 \text { high- } \\
\text { er) }\end{array}$ & - & $\begin{array}{l}208 \\
\text { (4 RCTs) }\end{array}$ & $\begin{array}{l}\oplus \oplus \odot \ominus \\
\text { LOW } 14\end{array}$ & - \\
\hline $\begin{array}{l}\text { General health-related qual- } \\
\text { ity of life (SF- } 36 \text { - mental } \\
\text { component score) }\end{array}$ & $\begin{array}{l}\text { The mean general health-related } \\
\text { quality of life (SF- } 36 \text { - mental com- } \\
\text { ponent score) ranged from } 46.6 \text { to } \\
51\end{array}$ & $\begin{array}{l}\text { MD } 2.32 \text { lower } \\
\text { (11.26 lower to } 6.62 \\
\text { higher) }\end{array}$ & - & $\begin{array}{l}208 \\
(4 \mathrm{RCTs})\end{array}$ & $\begin{array}{l}\oplus \oplus \odot \odot \\
\text { LOW } 14\end{array}$ & - \\
\hline $\begin{array}{l}\text { Force-generating capac- } \\
\text { ity of peripheral muscles } \\
\text { (quadriceps) }\end{array}$ & - & $\begin{array}{l}\text { SMD } 0.75 \text { higher } \\
\text { (0.4 higher to } 1.11 \text { high- } \\
\text { er) }\end{array}$ & - & $\begin{array}{l}133 \\
\text { (4 RCTs) }\end{array}$ & $\begin{array}{l}\oplus \oplus \oplus \ominus \\
\text { MODERATE } 5\end{array}$ & $\begin{array}{l}\text { Different mea- } \\
\text { surement meth- } \\
\text { ods (femoral }\end{array}$ \\
\hline
\end{tabular}




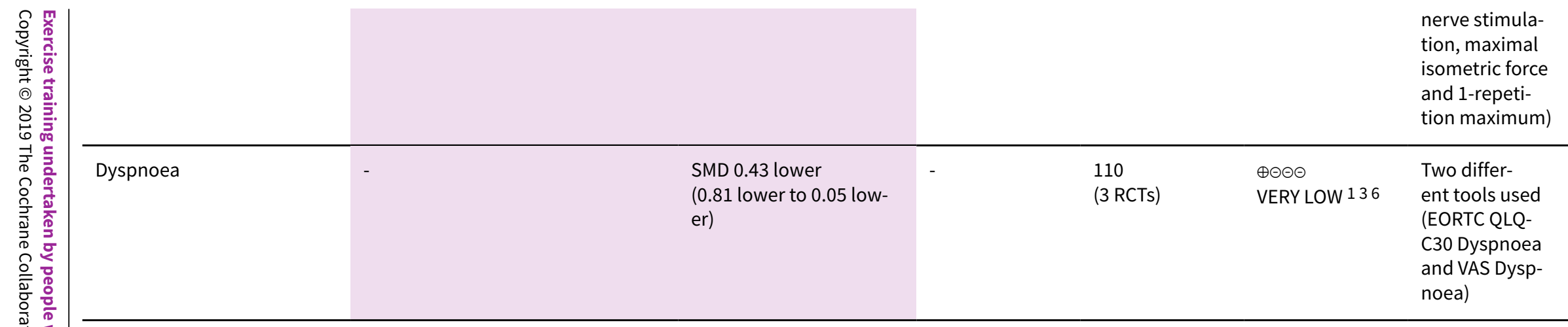

*The risk in the intervention group (and its $95 \%$ confidence interval) is based on the assumed risk in the comparison group and the relative effect of the intervention (and its $95 \% \mathrm{Cl})$.

6MWD: 6-minute walk distance; CI: confidence interval; MD: mean difference; RCT: randomised controlled trial; SF-36: Medical Outcomes Study Short Form 36 General Health Survey SMD: standardised mean difference; VAS: visual analogue scale; $\mathbf{V O}_{\mathbf{2}}$ peak: peak rate of oxygen uptake.

Minimal clinically important difference (MCID): 6MWD = 22 to 42 metres (Granger 2015); SF-36 = 3 to 5 points (Samsa 1999).

\section{GRADE Working Group grades of evidence}

High certainty: We are very confident that the true effect lies close to that of the estimate of the effect

Moderate certainty: We are moderately confident in the effect estimate: The true effect is likely to be close to the estimate of the effect, but there is a possibility that it is substantially different

Low certainty: Our confidence in the effect estimate is limited: The true effect may be substantially different from the estimate of the effect

Very low certainty: We have very little confidence in the effect estimate: The true effect is likely to be substantially different from the estimate of effect

1Some studies rated as having a high risk of detection bias.

2 Very large effect, and mean difference reached clinical important difference.

30utcome reported in only four of the eight included studies.

4Some level of inconsistency across results of studies.

${ }^{5}$ Small sample sizes across the studies, some with wide confidence intervals.

6 Imprecision of pooled estimates. 


\section{B A C K G R O U N D}

\section{Description of the condition}

Lung cancer is an important problem worldwide. Data from 2018 indicate that lung cancer is the most commonly diagnosed cancer in men and the third most commonly diagnosed cancer in women (Bray 2018). Mortality from lung cancer is high, with a five-year survival of $11 \%$ to $19 \%$, making it the leading cause of death from malignancy in high-income countries such as Australia (AlHW 2017), the USA (Jemal 2017), and the UK (Office for National Statistics 2015). Non-small cell lung cancer (NSCLC) is the most common lung cancer, accounting for approximately $85 \%$ of all cases (Sher 2008). Survival from NSCLC is considerably better than for small cell lung cancer (SCLC). Approximately $40 \%$ of people with NSCLC who undergo complete lung resection of the primary tumour survive five years (Danish Lung Cancer Registry 2009). In contrast, for people with SCLC, metastasis is common at the time of diagnosis and lung resection is rarely an option (Jett 2013).

Since the early 2000s, there has been an increased interest in outcomes other than survival for people diagnosed with NSCLC. Notably, people with this condition who require lung resection perceive physical debility as a far more important and undesirable outcome than pulmonary complications such as lung collapse and pneumonia (Cykert 2000). Earlier work has demonstrated impaired exercise capacity in people with lung cancer (Jones 2007). The reasons for this are likely to be multifactorial. Over half of all people diagnosed with lung cancer have an underlying chronic lung disease (e.g. chronic obstructive pulmonary disease (COPD)), Mouronte-Roibas 2018, that impairs exercise capacity (McCarthy 2015). Furthermore, people with lung cancer are affected by weight loss, anorexia, anaemia, protein catabolism, and muscle wasting (Baracos 2010; Murphy 2010). Dyspnoea and fatigue are also common and are likely to result in a decline in physical activity levels (Granger 2014; Granger 2016), as well as the adoption of a sedentary lifestyle (Cavalheri 2016; D'Silva 2018; O'Driscoll 1999). Failure to engage in sufficient physical activity to meet physical activity guidelines has been reported in $88 \%$ and $70 \%$ of people six months and 3.5 years after lung resection, respectively (Coups 2009), suggesting there is no spontaneous recovery in physical activity following treatment. This decline in physical activity levels results in skeletal muscle and cardiovascular deconditioning and serves to further compromise exercise capacity (Burtin 2017; Cavalheri 2015).

Treatment for lung cancer compounds the decrements in exercise capacity. Compared with preoperative measures, the peak rate of oxygen uptake $\left(\mathrm{VO}_{2}\right.$ peak) has been shown to be reduced by $13 \%$ and $28 \%$ six months following lobectomy and pneumonectomy, respectively (Nezu 1998), and it is up to $40 \%$ lower compared with healthy age-matched peers (Burtin 2017; Cavalheri 2015). Adjuvant therapy such as chemotherapy initiates a 'deconditioning storm' that further reduces the capacity to deliver or utilise oxygen and metabolic substrate during exercise, thereby contributing to exercise intolerance, Jones 2008 and fatigue, Huang 2015. Of note, the overall incidence of post-treatment fatigue in people with early stage NSCLC is $60 \%$ (Huang 2015).

Another important outcome for people with lung cancer is healthrelated quality of life (HRQoL). At the time of diagnosis, people with lung cancer present with impaired $\mathrm{HRQ}$ oL and considerable psychological distress, such as feelings of anxiety and depression
(Dagnelie 2007; Sugimura 2006). People who have undergone lung resection have been shown to have short-term (four months) and long-term (four years) impairments in HRQoL (Cavalheri 2015; Myrdal 2003). These impairments were of similar magnitude to those reported by people who have undergone coronary bypass grafting (Myrdal 2003).

\section{Description of the intervention}

Exercise training was the intervention studied in this systematic review. Training included aerobic exercises, strengthening (resistance) exercises, or a combination of these, with or without inspiratory muscle training. Earlier studies have shown that supervised exercise training is feasible for people following lung resection for NSCLC (Cesario 2007; Schneider 2007; Spruit 2006), and our original Cochrane Review demonstrated improvements in exercise capacity as measured via the six-minute walk test (6MWT) (Cavalheri 2013a).

\section{How the intervention might work}

The role of exercise training is well established in many chronic respiratory conditions, including COPD (McCarthy 2015), interstitial lung disease (Dowman 2014), and asthma (Carson 2013). There is especially abundant evidence, from over 60 randomised controlled trials (RCTs), for people with COPD. Cochrane Reviews have shown that in this population exercise training improves exercise capacity and HRQoL (McCarthy 2015; Puhan 2016), as well as reducing symptoms of dyspnoea and fatigue (McCarthy 2015). There is also evidence to suggest a reduction in healthcare utilisation (Puhan 2016). The mechanisms underlying improvements in exercise capacity and reductions in dyspnoea on exertion relate, at least in part, to an enhanced skeletal muscle function and a reduction in ventilation requirements at submaximal exercise intensities (Maltais 2014; Porszasz 2005). Previous systematic reviews have shown that exercise training confers reductions in fatigue and improvements in HRQoL in people with other forms of cancer, such as prostate and breast cancer (Lahart 2018; Mishra 2012). We hypothesised that exercise training would also be effective at improving outcomes other than exercise capacity in people following treatment for NSCLC.

\section{Why it is important to do this review}

The original version of this review in 2013 was undertaken in order to evaluate the effects of exercise training following lung resection for NSCLC, but also to identify the strengths and limitations of the published studies in this area and gaps in the literature. The original review included three RCTs (Cavalheri 2013a), and we concluded that exercise training conferred an increase in exercise capacity, measured as six-minute walk distance (6MWD), in people following lung resection for NSCLC. We also provided important considerations on how future studies could minimise bias and methodological heterogeneity. Some of the considerations for upcoming studies were to: (i) collect outcome measures immediately before and after the exercise training intervention rather than before lung resection and on completion of the exercise training intervention; (ii) choose disease-specific HRQoL questionnaires; (iii) report the values for each domain that contributes to HRQoL as well as the total score obtained from HRQoL questionnaires; and (iv) report the mean change (and standard deviation of the change) in outcomes collected immediately before and after the exercise training intervention. We 
also suggested that researchers explore other variables such as fatigue, dyspnoea, and feelings of anxiety and depression. In the current review we investigated whether exercise training following resection for NSCLC confers benefit in outcome measures other than 6MWD and also whether the certainty of the evidence found has improved compared to the original review.

\section{O B JECTIVES}

The primary aim of this review was to determine the effects of exercise training on exercise capacity and adverse events in people following lung resection (with or without chemotherapy) for NSCLC. The secondary aims were to determine the effects of exercise training on other outcomes such as HRQoL, forcegenerating capacity of peripheral muscles, pressure-generating capacity of the respiratory muscles, dyspnoea and fatigue, feelings of anxiety and depression, lung function, and mortality.

\section{METHODS}

\section{Criteria for considering studies for this review}

\section{Types of studies}

This review included RCTs in which the study participants were allocated to receive either exercise training or no exercise training following lung resection for NSCLC. Full papers and abstracts published in any language were eligible for inclusion.

\section{Types of participants}

Our inclusion criteria comprised participants following lung resection for NSCLC, performed via video-assisted thoracoscopic surgery (VATS) or thoracotomy, with or without induction or adjuvant chemotherapy. We included study participants who had undergone lung resection via either approach because earlier work has demonstrated that important outcomes such as shortterm mortality, length of hospital stay, and hospitalisation costs were similar between these groups (Gopaldas 2010). This is despite the fact that people who undergo resection via VATS or thoracotomy differ in terms of pain, HRQoL, and shoulder dysfunction (Bendixen 2016; Landreneau 1993). Participants who had undergone resections of any type (i.e. wedge resection, segmentectomy, lobectomy, or pneumonectomy) were eligible for inclusion. We excluded from this review people with SCLC because metastasis is common at the time of diagnosis, and median survival is usually less than 12 months (Dayen 2017).

\section{Types of interventions}

The intervention comprised exercise training that included aerobic exercise, resistance exercise, or a combination of both, and started within 12 months of lung resection. We did not include studies that investigated the effectiveness of inspiratory muscle training alone. Training sessions could be supervised or unsupervised, or a combination of both. Where possible, we recorded characteristics of the training programme, such as frequency, intensity, type, duration, adherence, and extent of supervision. We also documented any adverse events. Control groups received usual care with either no exercise training or only general instruction to exercise.

\section{Types of outcome measures}

\section{Primary outcomes}

1. Exercise capacity as measured either as $\mathrm{VO}_{2}$ peak during a maximal incremental exercise test or as the 6MWD.

2. Safety of the intervention as measured by numbers of adverse events.

\section{Secondary outcomes}

1. General HRQoL (e.g. the Medical Outcomes Study Short Form 36 General Health Survey (SF-36)).

2. Disease-specific HRQoL (e.g. the European Organisation for Research and Treatment of Cancer Quality of Life Questionnaire core 30 (EORTC QLQ-C30)).

3. Force-generating capacity of peripheral muscles (e.g. measures of lower limb muscle strength).

4. Pressure-generating capacity of respiratory muscles (e.g. maximal inspiratory and expiratory pressures).

5. Dyspnoea (e.g. the Borg category ratio scale, the visual analogue scale) or functional limitation during daily life resulting from dyspnoea (e.g. the Medical Research Council dyspnoea scale).

6. Fatigue (e.g. the Functional Assessment of Chronic Illness Therapy - Fatigue Subscale (FACIT-fatigue)).

7. Feelings of anxiety and depression (e.g. the Hospital Anxiety and Depression scale (HADS)).

8. Lung function (e.g. volumes and diffusing capacity).

9. Mortality.

\section{Search methods for identification of studies}

\section{Electronic searches}

We identified trials from electronic bibliographic databases including:

1. the Cochrane Central Register of Controlled Trials (CENTRAL; Issue 2, 2019) in the Cochrane Library (searched 11 February 2019);

2. MEDLINE (via PubMed) (2013 to 11 February 2019);

3. Embase (via Ovid) (2013 to 11 February 2019);

4. SCiELO (The Scientific Electronic Library Online) (2013 to 11 February 2019); and

5. PEDro (Physiotherapy Evidence Database) (2013 to 11 February 2019).

The search strategies used for MEDLINE, CENTRAL and Embase are presented in Appendix 1, Appendix 2, and Appendix 3, respectively. The search string for MEDLINE was developed according to the Cochrane Highly Sensitive Search Strategy, sensitivity maximising version (2008 version) as referenced in Section 6.4.11.1 and detailed in box 6.4.b of the Cochrane Handbook for Systematic Reviews of Interventions (Higgins 2011). We adapted the strategy for use in the other databases.

\section{Searching other resources}

We screened the reference lists of all primary studies and review articles for additional references. We contacted the authors of included trials to inquire about further published and unpublished studies. 


\section{Data collection and analysis}

\section{Selection of studies}

Two review authors (VC and $\mathrm{CB}$ ) independently examined the studies identified by the literature search using Covidence (Covidence 2017). We first excluded studies based on their title and abstract and recorded the reasons for exclusion. We subsequently obtained the full texts of the remaining studies, and the two review authors independently examined these, coding them as (i) 'include'; (ii) 'unclear'; or (iii) 'exclude' based on the review criteria. Any disagreements were resolved by consensus, and a full record was kept of the decisions.

\section{Data extraction and management}

Two review authors (VC and VRF) extracted data using a standardised form. Any disagreements were resolved by discussion or by involving a third review author (CB) when necessary. Once consensus was reached, the first review author (VC) entered data into Review Manager 5 software (RevMan 2014)). The data entered included study details, participant characteristics, and outcome measures related to the aims of this review. Where applicable, we asked the authors of the included studies to verify the data and provide details of missing data.

\section{Assessment of risk of bias in included studies}

Three review authors (VC, CB, and VRF) independently appraised the risk of bias of the included studies using the Cochrane Collaboration's 'Risk of bias' tool. Any disagreements were resolved by consensus. We judged risk of bias as high, low, or unclear for selection bias (i.e. random sequence generation and allocation concealment); performance bias (i.e. blinding of participants and personnel); detection bias (i.e. blinding of outcome assessor); attrition bias (i.e. incomplete outcome data); reporting bias (i.e. selective outcome reporting); and other potential sources of bias. The judgement was accompanied by a direct quote, specific details of the study, or both, in the 'Risk of bias' table. Where applicable, we contacted study authors to seek clarification on issues related to bias. We generated both a 'Risk of bias' graph (i.e. bar chart) and 'Risk of bias' summary (i.e. traffic lights).

\section{Measures of treatment effect}

The review did not have dichotomous outcomes. We calculated the mean differences (MD) and standardised mean differences (SMD) together with their corresponding 95\% confidence intervals (Cls) for the continuous outcomes. Mean difference was calculated for exercise capacity $\left(\mathrm{VO}_{2}\right.$ peak and 6MWD), general and diseasespecific HRQoL, handgrip force, and lung function (forced vital capacity (FVC)). Standardised mean difference was calculated for force-generating capacity of quadriceps muscle, dyspnoea, fatigue, and lung function (forced expiratory volume $\left(\mathrm{FEV}_{1}\right)$ ), as the included studies either measured these outcomes using different tools/tests or reported their findings in different ways (e.g. absolute values versus $\%$ of predicted values).

We used either postintervention values (with their respective standard deviation (SD)) or mean changes (with their respective $\mathrm{SD}$ ) in the meta-analyses that reported results as MD. When the SD of the mean change was not reported in the included study, not provided by the authors, or not able to be imputed through calculation, pre-intervention SD was used. In meta-analyses that reported results as SMD, studies that reported postintervention values (with their respective SD) and those that reported mean changes (with their respective SD) were placed in separate subgroups.

\section{Unit of analysis issues}

We planned that for studies that presented postintervention data at two or more time points (e.g. exercise capacity reported immediately postintervention and at three months postoperatively), we would not combine the results from the different time points in a single meta-analysis. We only used data collected immediately after completion of the intervention period.

\section{Dealing with missing data}

We contacted the authors of all the included studies to obtain missing data. When the specific data requested were provided, they were included in the meta-analyses. We did not impute any data.

\section{Assessment of heterogeneity}

We assessed statistical heterogeneity across the studies using the $\mathrm{I}^{2}$ statistic. We considered values of $\mathrm{I} 2$ greater than $50 \%$ as substantial heterogeneity (Higgins 2011). If we detected substantial statistical heterogeneity, we investigated whether clinical or methodological heterogeneity were the potential causes.

\section{Assessment of reporting biases}

We searched online trial registries in order to investigate potential publication bias and to assess potential outcome reporting bias in the included studies. As the number of studies included in this review was less than 10 , we did not generate funnel plots.

\section{Data synthesis}

We used Review Manager 5 to conduct the statistical analyses and generate forest plots (RevMan 2014). We initially used a randomeffects model for calculating summary estimates. However, if the studies were clinically, methodologically, and statistically homogeneous, we changed to a fixed-effect model. We metaanalysed the results of homogeneous studies using the inversevariance DerSimonian and Laird method (DerSimonian 1986). Where data aggregation was not possible due to considerable clinical, methodological, or statistical heterogeneity, we provided a narrative discussion of the data only.

\section{GRADE and 'Summary of findings' table}

In order to interpret the findings, we created a GRADE Summary of findings table (Summary of findings for the main comparison) in which we included the following outcomes: (i) exercise capacity; (ii) safety of the intervention; (iii) general HRQoL; (iv) force-generating capacity of the peripheral muscles (quadriceps); and (v) dyspnoea (Atkins 2004; Guyatt 2008). We assessed the certainty of evidence for each outcome by downgrading based on the GRADE criteria. We used the methods and recommendations described in Chapter 11 of the Cochrane Handbook for Systematic Reviews of Interventions (Higgins 2011).

\section{Sensitivity analysis}

We performed sensitivity analyses when we detected substantial heterogeneity (i.e. $I^{2}$ greater than $50 \%$ ) to investigate the effects of studies rated as having a high or unclear risk of detection or attrition bias. 


\section{RESULTS}

\section{Description of studies}

For complete details of studies classified as included or excluded, see the Characteristics of included studies and Characteristics of excluded studies sections.

\section{Results of the search}

Our search of all the databases in February 2019 yielded a total of 1380 records: 359 from CENTRAL; 401 from MEDLINE; 590 from
Embase; 29 from PEDro; and one from SciELO. We identified one extra record through other sources, therefore the total number of new records identified was 1381 (Figure 1). After removal of duplicates, 1106 records remained. Of these we excluded 1082 records based on the title and abstract and assessed 24 full-texts and conference abstracts for eligibility. We included 5 studies (9 records) identified in the current version of the review, in addition to 3 studies ( 5 records) identified in the original review (Cavalheri 2013a). We were able to contact authors of three new eligible studies to obtain missing data. 
Figure 1. Study flow diagram.

3 studies (5 records) included
from previous version
(Cavalheri 2013a)

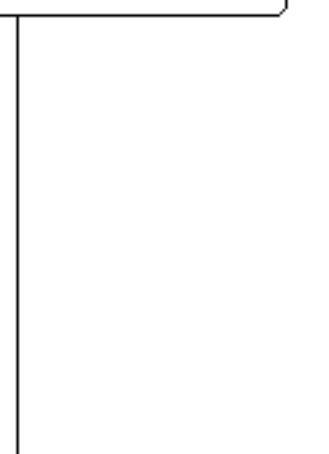

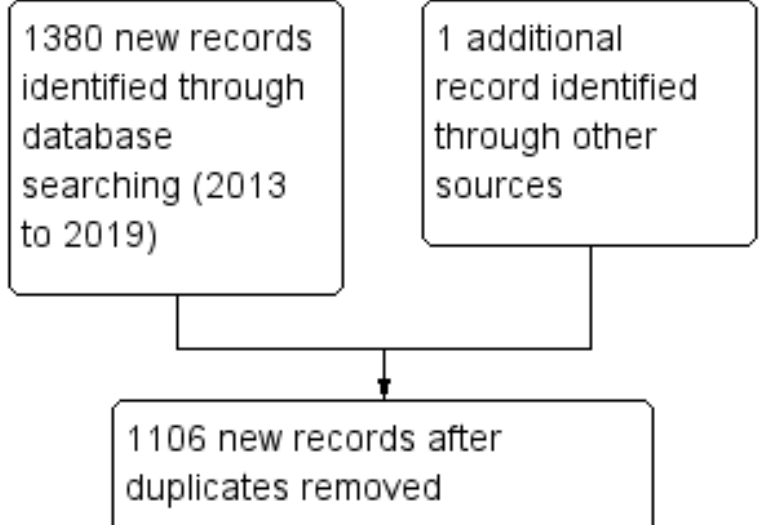

1082 records excluded on title and abstract

15 records excluded: 12 did not meet review criteria 3 authors did not reply to contact attempts 


\section{Included studies}

See Characteristics of included studies.

\section{Study}

We included the three RCTs, Arbane 2011; 'Brocki 2010'; Stigt 2013, from the 2013 version of this review (Cavalheri 2013a). We included five new RCTs for this update, therefore a total of eight RCTs (14 records) contributed data to the meta-analyses (Arbane 2014; Cavalheri 2017; Edvardsen 2015; Messaggi-Sartor 2018; Salhi 2015). The eight RCTs included 450 participants. The study named 'Brocki 2010 ' in the original version of the review is now named Brocki 2014. The record from 2010 was a conference proceeding, and the final full text of that study, Brocki 2014, was found through the database search for this update review.

\section{Population}

Six studies included only participants with NSCLC following lung resection. Two studies also included a small number of participants who either had thoracic cancers other than NSCLC or who did not undergo lung resection (Brocki 2014; Salhi 2015). We contacted the authors of these two studies, and they provided data specific to the participants with NSCLC who underwent lung resection. The sample size of the included studies ranged between 17 and 131 , with the mean age of the participants ranging between 63 and 71 years. Of the 450 participants, $180(40 \%)$ were female. At baseline, the intervention and control groups in all included studies were balanced for age. Both baseline $\mathrm{VO}_{2}$ peak and baseline 6MWD were also balanced between the intervention and control groups in the studies that included these measures $\left(\mathrm{VO}_{2}\right.$ peak: Cavalheri 2017; Edvardsen 2015; Messaggi-Sartor 2018; Salhi 2015. 6MWD: Arbane 2011; Brocki 2014; Cavalheri 2017; Salhi 2015; Stigt 2013). Six studies reported on extent of lung resection (i.e. wedge resection, lobectomy/bilobectomy, pneumonectomy) and demonstrated balanced numbers between groups (Arbane 2011; Brocki 2014; Edvardsen 2015; Messaggi-Sartor 2018; Salhi 2015; Stigt 2013). Four studies reported on type of surgical procedure (i.e. VATS or thoracotomy) (Arbane 2011; Arbane 2014; Cavalheri 2017; Messaggi-Sartor 2018); three of these studies demonstrated no between-group difference in type of surgical procedure (Arbane 2014; Cavalheri 2017; Messaggi-Sartor 2018). One study mentioned that only two participants had undergone VATS (Arbane 2011), but did not report the group allocation of these participants.

\section{Setting}

The studies were based in the UK (Arbane 2011; Arbane 2014), Denmark (Brocki 2014), Australia (Cavalheri 2017), Norway (Edvardsen 2015), Spain (Messaggi-Sartor 2018), Belgium (Salhi 2015), and the Netherlands (Stigt 2013). The studies were published between 2011 and 2018.

\section{Intervention}

There was considerable variation in length, type, frequency, and intensity of the exercise programmes that were investigated. Interventions ranged in length from four weeks, Arbane 2014, to 20 weeks, Edvardsen 2015. The exercise programmes in all studies had a supervised component, whilst in four studies they also had a home-based component (Arbane 2011; Arbane 2014; Brocki 2014; Cavalheri 2017). The setting for the supervised component was varied, including hospital-based outpatient programmes (Brocki 2014; Cavalheri 2017; Messaggi-Sartor 2018; Stigt 2013), fitness centre-based programmes (Edvardsen 2015), and inpatient programmes (Arbane 2011; Arbane 2014). In two studies (Arbane 2011; Arbane 2014), home-based exercise was the main component of the exercise training programme.

The interventions consisted of combined aerobic and resistance exercise in six studies (Arbane 2011; Arbane 2014; Brocki 2014; Cavalheri 2017; Salhi 2015; Stigt 2013); combined aerobic exercise and inspiratory muscle training in one study (MessaggiSartor 2018); and combined aerobic exercise, resistance exercise, inspiratory muscle training and balance training in one study (Edvardsen 2015). The frequency of the exercise training programme varied from twice a week to five days a week. The intensity of the aerobic exercise was variably reported, ranging between $60 \%$ to $90 \%$ of maximum heart rate or baseline peak work rate, $80 \%$ of the average speed achieved on the 6MWT, or an intensity that elicited scores between 11 to 15 on rating of perceived exertion scale. The intensity of the resistance training was not reported in three studies (Arbane 2014; Brocki 2014; Stigt 2013); was set at a specific initial weight (e.g. $2 \mathrm{lb} ; 1.5 \mathrm{~kg}$ ) in two studies (Arbane 2011; Cavalheri 2017); and was reported as 50\% 1 repetition-maximum (RM) in one study, Salhi 2015, and 6 to 12 RM in one study, Edvardsen 2015. Edvardsen 2015 did not report the intensity of inspiratory muscle training, whereas Messaggi-Sartor 2018 reported starting inspiratory muscle training at 50\% of the maximal inspiratory pressure (after one familiarisation session at $30 \%$ of the maximal inspiratory pressure).

The control groups received usual care that comprised routine outpatient appointments and pain medication prescription (Arbane 2011; Arbane 2014; Cavalheri 2017; Edvardsen 2015; Messaggi-Sartor 2018; Stigt 2013), phone calls (Arbane 2011; Cavalheri 2017), breathing exercises and mobilisation (Arbane 2014), and instructions regarding exercise (Brocki 2014). Participants in two studies were advised to perform physical activity (Brocki 2014; Messaggi-Sartor 2018), whilst those in one study were discouraged from undertaking supervised exercise training (Salhi 2015).

\section{Excluded studies}

In this update, of the 24 records for which the full texts were reviewed, 15 were excluded for the following reasons: (i) did not meet review criteria $(n=12)$; and (ii) authors did not reply to several contact attempts to obtain the specific data needed for this review $(n=3)$. These reasons are summarised in the Characteristics of excluded studies section.

\section{Risk of bias in included studies}

Three out of the seven domains included in the Cochrane Collaboration's 'Risk of bias' tool were identical across the eight included studies (random sequence generation, allocation concealment, and blinding of participants and personnel). For details regarding risk of bias in the included studies, see Characteristics of included studies; Figure 2; Figure 3. 
Figure 2. Risk of bias graph: review authors' judgements about each risk of bias item presented as percentages across all included studies.

Random sequence generation (selection bias)

Allocation concealment (selection bias)

Blinding of participants and personnel (performance bias)

Blinding of outcome assessment (detection bias)

Incomplete outcome data (attrition bias)

Selective reporting (reporting bias)

Other bias

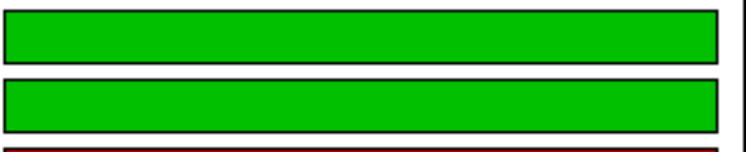

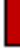

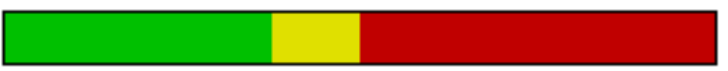

$$
\text { L }
$$
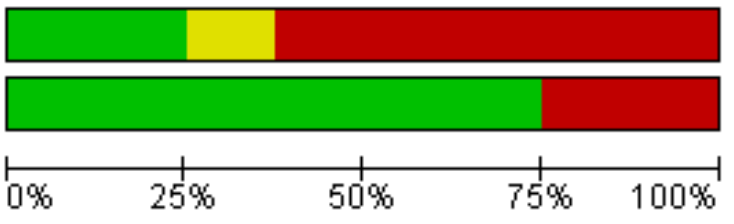

Low risk of bias

Unclear risk of bias

High risk of bias 
Figure 3. Risk of bias summary: review authors' judgements about each risk of bias item for each included study.

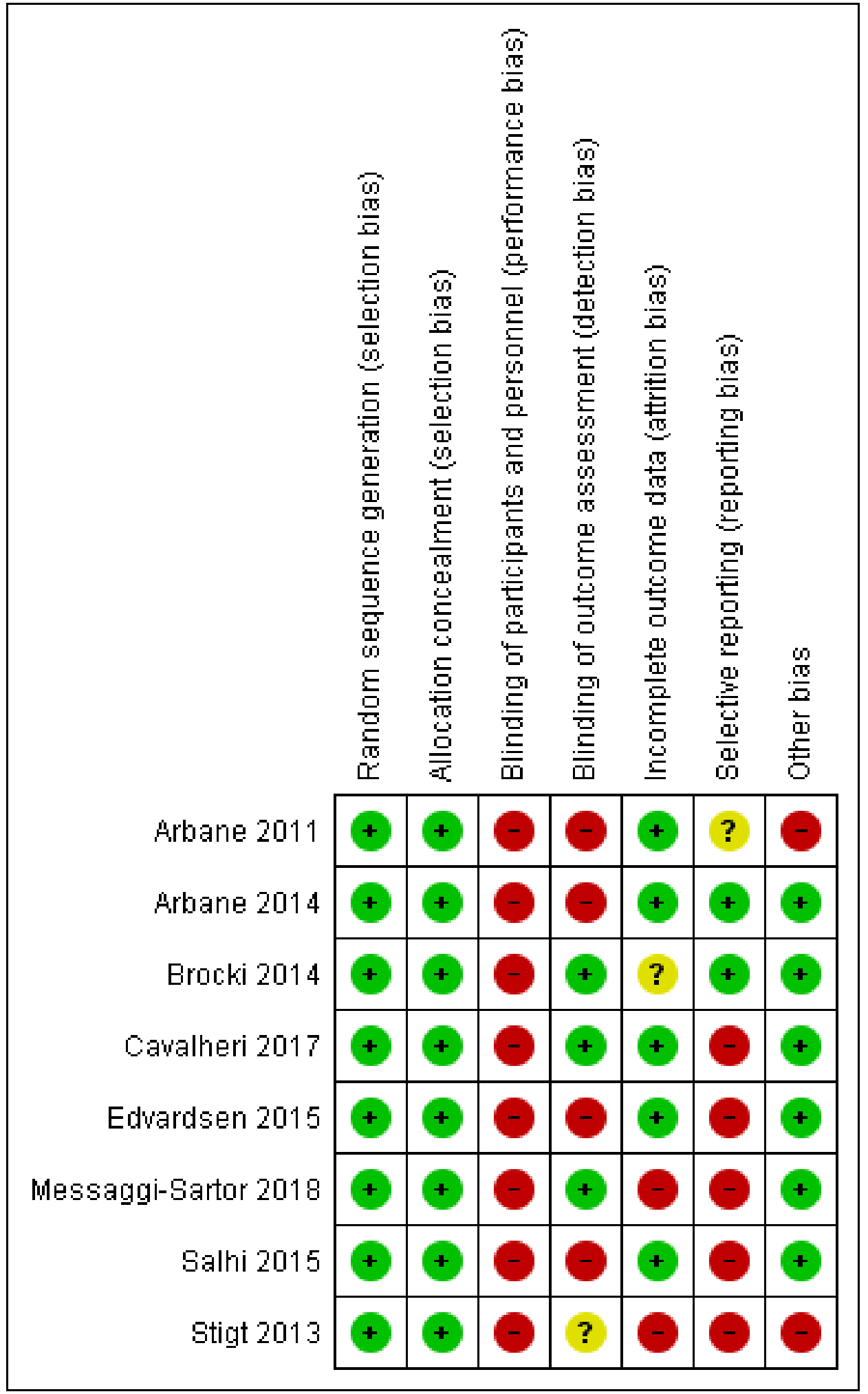

\section{Allocation}

All eight included studies reported using a process of randomly allocating participants to the two groups, and in all studies this randomisation sequence was concealed. We therefore judged all the included studies to be at low risk of selection bias. 


\section{Blinding}

Neither the participants nor the personnel responsible for implementing the intervention were blind to group allocation in any of the included studies. This lack of blinding could have influenced the results, as the participants may have been influenced by a placebo effect. Hence, we rated all the included studies as at high risk of performance bias. Regarding detection bias, in three studies blinding of the outcome assessor was fully ensured (Brocki 2014; Cavalheri 2017; Messaggi-Sartor 2018), therefore these studies were rated as at low risk of detection bias. As the study by Stigt 2013 did not describe blinding of outcome assessors, and as the authors did not reply to our email specifically asking about this issue, we rated the risk of detection bias as unclear. We rated the other four studies as at high risk of detection bias (Arbane 2011; Arbane 2014; Edvardsen 2015; Salhi 2015).

\section{Incomplete outcome data}

We rated five studies as at low risk of bias due to incomplete outcome data (Arbane 2011; Arbane 2014; Cavalheri 2017; Edvardsen 2015; Salhi 2015), as missing outcome data were balanced between the intervention and control groups in numbers, Brocki 2014 analysed their data according to the intention-totreat principle, details about the missing cases were insufficient to permit a judgement of low or high risk of bias, therefore we rated this study as at unclear risk of bias due to incomplete outcome data. We rated two studies as at high risk of bias (Messaggi-Sartor 2018; Stigt 2013), mainly due to investigators performing 'as-treated' a large loss to follow-up, with some postintervention data reported in only $40 \%$ to $60 \%$ of participants (Stigt 2013).

\section{Selective reporting}

We judged two studies as having a low risk of reporting bias (Arbane 2014; Brocki 2014). We judged one study as at unclear risk of reporting bias due to insufficient information to judge this item with similar reasons for missing data across groups. Although rather than intention-to-treat analysis, Messaggi-Sartor 2018, and

(i.e. no access to trial registration) (Arbane 2011). We reviewed the trial registration of five studies (Cavalheri 2017; Edvardsen 2015; Messaggi-Sartor 2018; Salhi 2015; Stigt 2013), and noticed that one to two prespecified outcomes were not reported in the published paper, therefore we rated these five studies as at high risk of reporting bias.

\section{Other potential sources of bias}

We rated two studies as at high risk of other potential sources of bias (Arbane 2011; Stigt 2013). The potential sources of bias were as follows: (i) both studies did not collect all outcome measures at identical time points; (ii) in Arbane 2011 the control group had five participants classified as stage IV disease, whereas the intervention group had none in this stage; and (iii) Stigt 2013 had more participants following chemotherapy randomised to the intervention group, and there was a higher attrition rate for those who had chemotherapy compared to those who did not. We rated the remaining studies as at low risk of other potential sources of bias.

\section{Effects of interventions}

See: Summary of findings for the main comparison Exercise group compared to control group for non-small cell lung cancer

We included data pertaining to exercise capacity, HRQoL, forcegenerating capacity of the peripheral muscles, dyspnoea, fatigue, and lung function in the meta-analyses.

\section{Primary outcome: exercise capacity}

Four studies reported the $\mathrm{VO}_{2}$ peak as their measure of exercise capacity (Cavalheri 2017; Edvardsen 2015; Messaggi-Sartor 2018; Salhi 2015). On completion of the intervention period, $\mathrm{VO}_{2}$ peak was significantly higher in the intervention group compared to the control group (mean difference (MD) $2.97 \mathrm{~mL} / \mathrm{kg} / \mathrm{min}, 95 \%$ confidence interval $(\mathrm{Cl}) 1.93$ to $4.02 \mathrm{~mL} / \mathrm{kg} / \mathrm{min}, \mathrm{I}^{2}=0 \%, 4$ studies, 135 participants, moderate-certainty evidence) (Analysis 1.1; Figure 4).

Figure 4. Forest plot of comparison: 1 Exercise group versus control group, outcome: 1.1 Exercise capacity $\left(\mathrm{VO}_{2} \mathrm{peak}\right.$ in $\mathrm{mL} / \mathrm{kg} / \mathrm{min})$.

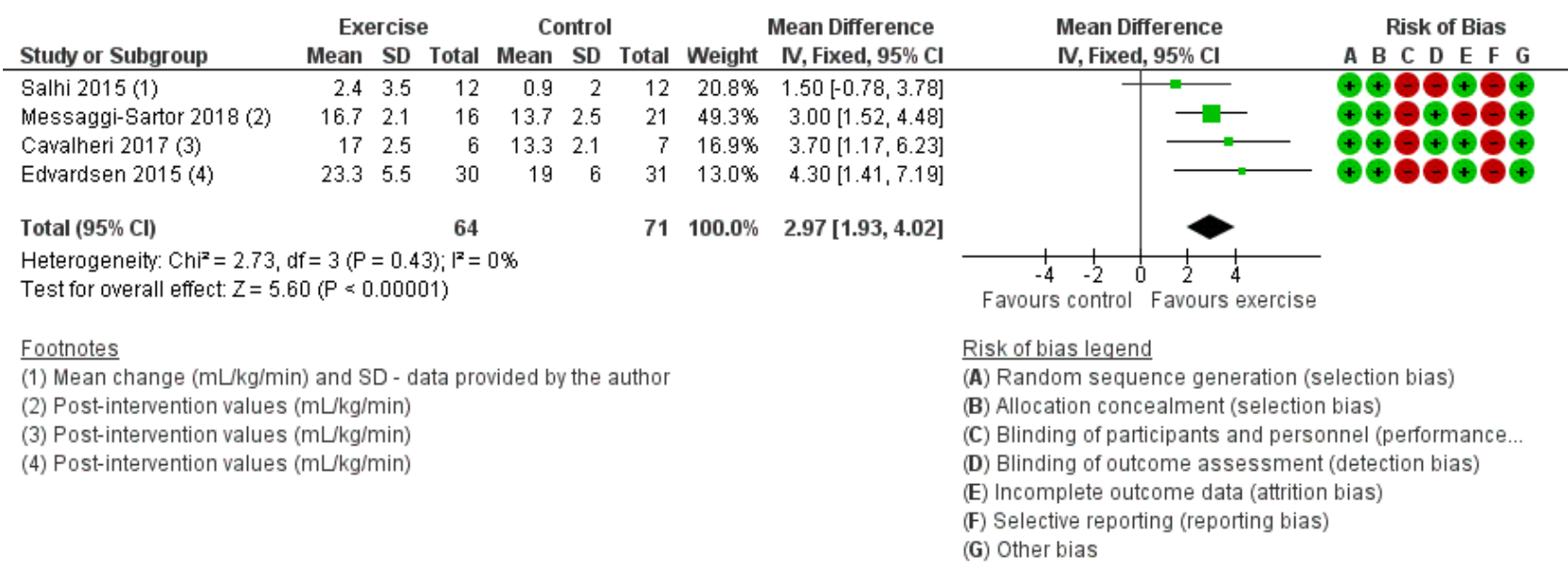

Five studies reported the 6MWD as their measure of exercise capacity (Arbane 2011; Brocki 2014; Cavalheri 2017; Salhi 2015;

Stigt 2013). On completion of the intervention period, 6MWD was significantly higher in the intervention group compared to the 
control group (MD $57 \mathrm{~m}, 95 \% \mathrm{Cl} 34$ to $80 \mathrm{~m}, \mathrm{I} 2=22 \%, 5$ studies, 182 participants, high-certainty evidence) (Analysis 1.2; Figure 5). The magnitude of the effect found ( $M D=57 \mathrm{~m}$ ) exceeded the minimal important difference (MID) of the 6MWD reported for people with lung cancer (i.e. 22 to $42 \mathrm{~m}$ ) (Granger 2015).

Figure 5. Forest plot of comparison: 1 Exercise group versus control group, outcome: 1.2 Exercise capacity (6MWD in metres).

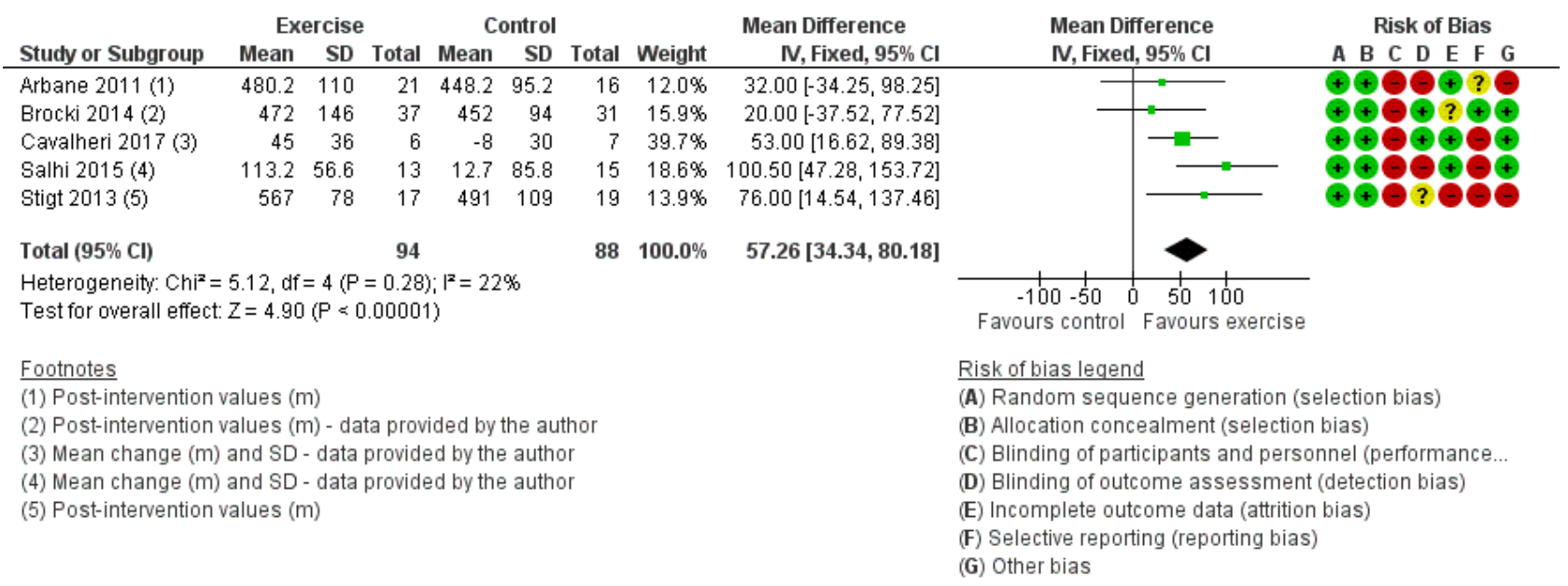

\section{Primary outcome: safety of the intervention}

Four of the eight included studies reported data on safety of the intervention (i.e. adverse events related to the intervention) (Brocki 2014; Edvardsen 2015; Messaggi-Sartor 2018; Salhi 2015). Three of these four studies reported no adverse events (Brocki 2014; Messaggi-Sartor 2018; Salhi 2015), whereas one reported a hip fracture during balance training (Edvardsen 2015).

\section{Secondary outcome: general HRQOL}

Four studies reported general HRQoL using the SF-36 (higher scores indicate better HRQoL) (Arbane 2014; Brocki 2014; Cavalheri 2017; Edvardsen 2015). On completion of the intervention period, the physical component score of the SF-36 was significantly higher in the intervention group compared to the control group (MD 5.0 points, $95 \% \mathrm{Cl} 2.3$ to 7.7 points, $\mathrm{I}^{2}=44 \%, 4$ studies, 208 participants, low-certainty evidence) (Analysis 1.3; Figure 6). On completion of the intervention period, there was an uncertain effect for the mental component score of the SF-36 (MD -2.3 points, $95 \% \mathrm{Cl}-11.3$ to 6.6 points, $\mathrm{I}^{2}=87 \%$, 4 studies, 208 participants, low-certainty evidence) (Analysis 1.4). Heterogeneity was substantial in the metaanalysis for the mental component score of the SF-36 $(12=87 \%)$, therefore we undertook sensitivity analyses. Both the uncertain effect and the substantial heterogeneity were maintained when (i) the two studies rated as having a high risk of detection bias were excluded (MD -5.3 points, $95 \% \mathrm{Cl}-12.1$ to 1.6 points, $\mathrm{I}^{2}=$ $72 \%$ ) (Arbane 2014; Edvardsen 2015); and (ii) the study rated as having an unclear risk of attrition bias was excluded (MD -3.2 points, $95 \% \mathrm{Cl}-17.9$ to 11.6 points, $\mathrm{I}^{2}=91 \%$ ) (Brocki 2014). When the two studies rated as having a high risk of reporting bias were excluded (Cavalheri 2017; Edvardsen 2015), the uncertain effect was maintained (MD -3.7 points, $95 \% \mathrm{Cl}-11.4$ to 4.0 points), and there was no substantial heterogeneity $\left(I^{2}=21 \%\right)$. 
Figure 6. Forest plot of comparison: 1 Exercise group versus control group, outcome: 1.3 General health-related quality of life (SF-36 - physical component score).

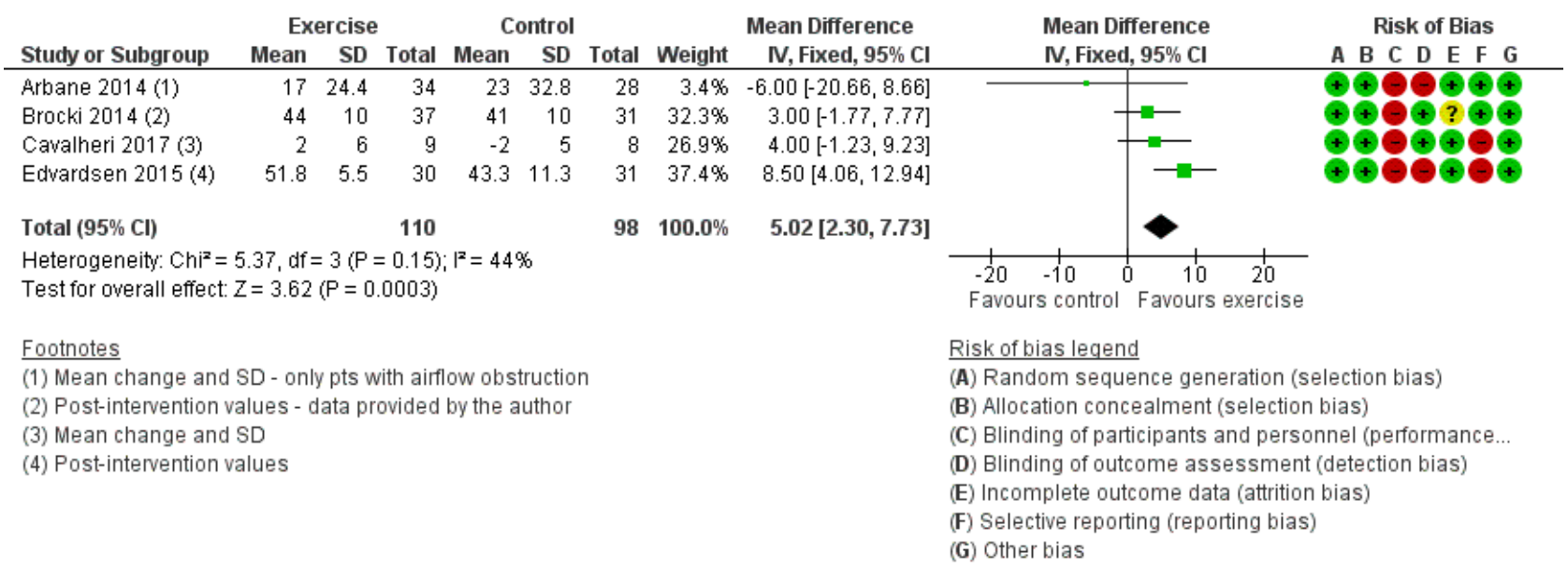

\section{Secondary outcome: disease-specific HRQOL}

Four studies reported disease-specific HRQoL using the EORTC QLQ-C30 (Arbane 2011; Cavalheri 2017; Messaggi-Sartor 2018; Salhi 2015). The four studies reported the global health component score of the EORTC QLQ-C30; two studies reported scores for the functional and symptom scales of the EORTC QLQ-C30 (Arbane 2011; Cavalheri 2017); and two studies reported the physical functioning component score of the EORTC QLQ-C30 (MessaggiSartor 2018; Salhi 2015). Higher scores indicate better HRQoL for the global health and physical functioning components. Conversely, for symptoms, higher scores indicate worse symptoms. On completion of the intervention period, there was an uncertain effect on all components of disease-specific HRQoL (global health: MD -0.14 points, $95 \% \mathrm{Cl}-7.24$ to 6.96 points, $\mathrm{I}^{2}=0 \%, 4$ studies, 111 participants (Analysis 1.5); functional scales: MD -0.82 points, $95 \% \mathrm{Cl}-8.81$ to 7.17 points, $\mathrm{I}^{2}=0 \%$, 2 studies, 60 participants (Analysis 1.6); symptom scales: MD -3.05 points, $95 \% \mathrm{Cl}-10.58$ to 4.47 points, $I^{2}=0 \%, 2$ studies, 60 participants (Analysis 1.7); physical functioning: MD 2.05 points, $95 \% \mathrm{Cl}-3.50$ to 7.59 points, $\mathrm{I}^{2}=0 \%, 2$ studies, 51 participants (Analysis 1.8)).

\section{Secondary outcome: force-generating capacity of peripheral muscles}

Four studies measured force-generating capacity of the quadriceps muscle (Arbane 2011; Cavalheri 2017; Edvardsen 2015; Salhi 2015). This outcome measure was assessed using different techniques/ measures in the four studies. Furthermore, two studies reported postintervention values (Arbane 2011; Edvardsen 2015), whereas the other two studies reported mean change values (Cavalheri 2017; Salhi 2015). Consequently, we have presented the final result as standardised mean difference (SMD), and subgroups (studies that reported postintervention values; studies that reported mean change values) were included in the meta-analysis. Overall, on completion of the intervention period, force-generating capacity of the quadriceps muscle was significantly higher in the intervention group compared to the control group (SMD $0.75,95 \% \mathrm{Cl} 0.4$ to 1.1 , $1^{2}=0 \%$, 4 studies, 133 participants, moderate-certainty evidence) (Analysis 1.9). There was no different between the results of the subgroups $\left(P=0.78 ; 1^{2}=0 \%\right)$.
Two studies measured handgrip force (Cavalheri 2017; Edvardsen 2015). On completion of the intervention period, there was an uncertain effect on handgrip force (MD $3.19 \mathrm{~kg}, 95 \% \mathrm{Cl}-1.14$ to 7.52 $\mathrm{kg}, \mathrm{I}^{2}=0 \%, 2$ studies, 75 participants) (Analysis 1.10).

\section{Secondary outcome: pressure-generating capacity of respiratory muscles}

Only one study measured the pressure-generating capacity of inspiratory and expiratory muscles (Messaggi-Sartor 2018). On completion of the intervention period, there was no significant difference between the intervention and control in both maximal inspiratory pressure (MD $13 \%$ predicted, $95 \% \mathrm{Cl}-37$ to $11 \%$ predicted) and maximal expiratory pressure (MD $10 \%$ predicted, $95 \% \mathrm{Cl}-27$ to $8 \%$ predicted).

\section{Secondary outcome: dyspnoea}

Three studies measured dyspnoea (Edvardsen 2015; MessaggiSartor 2018; Salhi 2015). Two of these studies reported the dyspnoea component score of the EORTC QLQ-C30 (Edvardsen 2015; Messaggi-Sartor 2018), whereas one used the visual analogue scale (Salhi 2015). In both tools, higher scores indicate worse dyspnoea. Furthermore, two studies reported postintervention values (Edvardsen 2015; Salhi 2015), whereas the remaining study reported mean change values (Messaggi-Sartor 2018). Consequently, we have presented the final result as SMD, and subgroups (studies that reported postintervention values; study that reported mean change values) were included in the metaanalysis. Overall, on completion of the intervention period, dyspnoea was significantly less in the intervention group compared to the control group (SMD $-0.43,95 \% \mathrm{Cl}-0.81$ to $-0.05, \mathrm{I}^{2}=37 \%$, 3 studies, 110 participants, very low-certainty evidence) (Analysis 1.11). In the subgroup of studies that reported postintervention values, dyspnoea was significantly less in the intervention group compared to the control group (SMD $-0.59,95 \% \mathrm{Cl}-1.02$ to $-0.16, \mathrm{I}^{2}$ $=0 \%, 2$ studies, 87 participants). No between-group difference was demonstrated in the study that reported mean change values (SMD $0.15,95 \% \mathrm{Cl}-0.67$ to $0.98,1$ study, 23 participants). 


\section{Secondary outcome: fatigue}

Three studies measured fatigue (Cavalheri 2017; Messaggi-Sartor 2018; Salhi 2015). Two studies measured fatigue using the FACITfatigue (Cavalheri 2017; Salhi 2015), whereas one study used the fatigue component score of the EORTC QLQ-C30 (Messaggi-Sartor 2018). For the FACIT-fatigue, lower scores indicate greater fatigue, whereas for the EORTC QLQ-C30 higher scores indicate greater fatigue. In order to pool these data, we changed the direction of the mean change in scores of the EORTC QLQ-C30 (i.e. negative values were made positive). On completion of the intervention period, there was an uncertain effect on fatigue (SMD $-0.05,95 \% \mathrm{Cl}-0.52$ to $0.43, \mathrm{I}^{2}=0 \%, 3$ studies, 68 participants) (Analysis 1.12).

\section{Secondary outcome: feelings of anxiety and depression}

Only one study measured feelings of anxiety and depression using the HADS (Cavalheri 2017). On completion of the intervention period in this study, there was no significant difference between the intervention and control groups in feelings of anxiety (mean \pm SD intervention group: $3 \pm 2$ points to $5 \pm 4$ points and control group: $2 \pm 2$ points to $4 \pm 5$ points; $P=0.17$ ) and depression (mean $\pm S D$ intervention group: $2 \pm 2$ points to $4 \pm 5$ points and control group: 3 \pm 3 points to $4 \pm 3$ points; $P=0.40$ ).

\section{Secondary outcome: lung function}

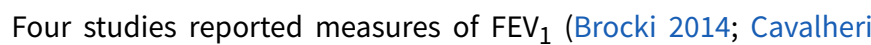
2017; Edvardsen 2015; Stigt 2013). One study reported $\mathrm{FEV}_{1}$ as a $\%$ of predicted values (Edvardsen 2015), whereas three studies reported $\mathrm{FEV}_{1}$ in absolute value (litres) (Brocki 2014; Cavalheri 2017; Stigt 2013). Furthermore, two studies reported postintervention values (Edvardsen 2015; Stigt 2013), whilst the other two studies reported mean change values (Brocki 2014; Cavalheri 2017). Consequently, we have presented the final result as SMD, and subgroups (studies that reported postintervention values; studies that reported mean change values) were included in the metaanalysis. Overall, on completion of the intervention period, there was an uncertain effect on $\mathrm{FEV}_{1}(\mathrm{SMD}-0.06,95 \% \mathrm{Cl}-0.37$ to 0.25 , $\mathrm{I}^{2}=0 \%$, 4 studies, 166 participants) (Analysis 1.13). There was no difference between the results of the subgroups $\left(P=0.59 ; 1^{2}=0 \%\right)$.

Two studies reported measures of FVC (Brocki 2014; Cavalheri 2017). On completion of the intervention period, there was an uncertain effect on FVC (MD $-0.06 \mathrm{~L}, 95 \% \mathrm{Cl}-0.26$ to $0.15 \mathrm{~L}, \mathrm{I}^{2}=0 \%$, 2 studies, 83 participants) (Analysis 1.14).

\section{Secondary outcome: mortality}

Data were not available for this outcome.

\section{DISCUSSION}

\section{Summary of main results}

This review provides moderate- to high-certainty evidence that, in people following lung resection for NSCLC, exercise training increased $\mathrm{VO}_{2}$ peak (MD $2.97 \mathrm{~mL} / \mathrm{kg} / \mathrm{min}, 95 \% \mathrm{Cl} 1.93$ to $4.02 \mathrm{~mL}$ / $\mathrm{kg} / \mathrm{min}$ ); 6MWD (MD $57 \mathrm{~m}, 95 \% \mathrm{Cl} 34$ to $80 \mathrm{~m}$ ); and quadriceps muscle force (SMD $0.75,95 \% \mathrm{Cl} 0.4$ to 1.1 ). One adverse event (hip fracture) related to the intervention was reported in one of the included studies. Low-certainty evidence also suggested that exercise training improved the physical component score of general HRQoL (MD 5.0 points, $95 \% \mathrm{Cl} 2.3$ to 7.7 points) and relieved dyspnoea (SMD $-0.43,95 \% \mathrm{Cl}-0.81$ to -0.05 ) in people following lung resection for NSCLC. We observed uncertain effects for disease-specific HRQoL, handgrip force, fatigue, and lung function. Data were insufficient to comment on the effect of exercise training on maximal inspiratory and expiratory pressures and feelings of anxiety and depression. The included studies did not report on mortality.

\section{Overall completeness and applicability of evidence}

The update of this systematic review was warranted as we were able to include five additional studies, almost tripling the number of studies in the original review (Cavalheri 2013a), and providing a 2.5 -fold increase on the number of participants (178 to 450 ). The updated meta-analyses investigating the effects of exercise training following lung resection for NSCLC on exercise capacity were able to provide novel, moderate-certainty evidence for improvements in $\mathrm{VO}_{2}$ peak as well as confirm and strengthen the certainty of the previous finding of improvements in 6MWD. Exercise capacity in people with NSCLC is adversely affected by several factors including the tumour itself, coexisting lung disease as well as treatment for the condition, which may include resection of the tumour with or without adjuvant chemotherapy or radiotherapy (Jones 2009). Of note, earlier work that assessed several outcomes such as exercise capacity, HRQoL, muscle force, lung function, and feelings of anxiety and depression reported that, compared to healthy controls, the greatest impairment demonstrated in people following lung resection for NSCLC was in exercise capacity (Cavalheri 2015). In fact, 15 of the 21 participants (i.e. 71\%) had a $\mathrm{VO}_{2}$ peak below the lower limit of normal established in healthy controls (Cavalheri 2015). Our findings of improved exercise capacity are particularly relevant because both $\mathrm{VO}_{2}$ peak and 6MWD are valuable prognostic indicators in this population (Jones 2010; Zarogoulidis 2012). For example, a longitudinal study that followed 398 participants with NSCLC for 30.8 months demonstrated that each $1 \mathrm{~mL} / \mathrm{kg} / \mathrm{min}$ increase in $\mathrm{VO}_{2}$ peak was associated with a $4 \%$ reduction in all-cause mortality (Jones 2010). Regarding the 6MWD, the magnitude of the effect found in this update (MD $=57 \mathrm{~m}$ ) exceeded the minimal important difference (MID) of the 6MWD reported for people with lung cancer (i.e. 22 to $42 \mathrm{~m}$ ) (Granger 2015). In addition to being statistically significant, the magnitude of improvement in exercise capacity was therefore also clinically important. We did not investigate maintenance of improvements in exercise capacity in this review, and future studies should investigate strategies to maintain these gains.

Three of the four included studies reporting on adverse events found no adverse events during exercise training (Brocki 2014; Messaggi-Sartor 2018; Salhi 2015). Edvardsen 2015 reported the occurrence of a hip fracture during balance training, a type of training that was only conducted in that study. When needed, balance training should therefore be performed under close supervision, and in proximity to a railing or other secure support (Beck 2017).

Our review suggests that exercise training improved the physical component score of general HRQoL, as measured by the SF-36, in people following lung resection for NSCLC. This finding is important because, compared to pre-surgical scores, people with NSCLC present with a worse physical component score for HRQoL at six months following lung resection, with little change up to two years afterwards (Poghosyan 2013). Furthermore, 
the magnitude of the between-group difference in the physical component score of $\mathrm{HRQ}$ oL found in the current review was 5 points, which exceeded the MID for the SF-36 (i.e. 3 to 5 points) (Samsa 1999). This improvement in HRQoL following a programme of exercise training is in agreement with findings of systematic reviews in people with chronic lung diseases such as COPD, McCarthy 2015; Puhan 2016, and interstitial lung disease, Dowman 2014, as well as in women with breast cancer, Lahart 2018. Conversely, improvements in the mental component score of general $\mathrm{HRQ}$ oL were not demonstrated in the current review. The meta-analysis undertaken for this outcome was the only one that presented substantial heterogeneity. However, both the lack of improvement in the mental component score of general HRQoL and the substantial heterogeneity were unresolved by sensitivity analyses. It is possible that this lack of improvement may be attributable to minimal impairment in this domain and, therefore, little scope for improvement with exercise training. However, it is also likely that exercise training alone has no effect on the mental component of $\mathrm{HRQ}$ oL, and that a combination of exercise training with other interventions provided by a multidisciplinary team including psychologists and other health professionals needs to be considered. Our finding of no between-group difference in disease-specific HRQoL, measured using the EORTC QLQ-C30, may reflect that the meta-analyses lacked statistical power to detect changes in disease-specific HRQoL, especially for the subscales of physical functioning, function, and symptoms. The number of participants in the meta-analyses for the disease-specific HRQoL subscales ranged between 51 and 60, a sample size much lower than that for the physical component score of general HRQoL ( $n$ $=208$ ). Larger RCTs are needed to further investigate the effects of exercise training on disease-specific HRQoL in people following lung resection for NSCLC.

A novel finding of the current review is that exercise training improved force-generating capacity of the quadriceps muscle. We included four studies in the meta-analysis (Arbane 2011; Cavalheri 2017; Edvardsen 2015; Salhi 2015), and, despite assessing forcegenerating capacity of the quadriceps muscle using different methods (e.g. femoral nerve stimulation, maximal isometric force, and one-repetition maximum), results were similar across the four studies, and the 12 in the meta-analysis was $0 \%$. A previous cross-sectional study in 64 people following lung resection for NSCLC demonstrated that force-generating capacity of the muscle is only modestly reduced in this population (Burtin 2017), that is the average isometric quadriceps force was $89 \pm$ $25 \%$ of predicted (Burtin 2017). However, as discussed by the authors of that study, the high SD (i.e. $25 \%$ ) suggests substantial heterogeneity in isometric quadriceps muscle force across the population, with muscle weakness being more pronounced in those patients with lower exercise capacity. Some people with NSCLC may therefore present with significant reduction in isometric quadriceps muscle force following lung resection, and the improved force-generating capacity of the quadriceps muscle after exercise training demonstrated in the current review is specifically relevant to this group.

We did not find changes in handgrip force following exercise training. This finding was expected, as one principle of exercise training is specificity, and training of the hand muscles was not part of the exercise training programmes in the two studies that measured this outcome (Cavalheri 2017; Edvardsen 2015). The only study that measured the pressure-generating capacity of inspiratory and expiratory muscles did not show improvement in these outcomes following exercise training (Messaggi-Sartor 2018). The reasons for the lack of improvement in these outcomes may relate to an ineffective training programme as well as lack of statistical power to detect small changes.

We demonstrated in this review that exercise training may reduce dyspnoea in people following lung resection for NSCLC. Dyspnoea is a common symptom amongst people with lung cancer. A previous study in 142 people following lung resection for NSCLC (median time from surgery $=10$ years) showed that $90(63 \%)$ reported chronic dyspnoea, and $45(32 \%)$ had to stop due to breathlessness when walking at their own pace (Sarna 2004). Similarly, a cross-sectional survey of 342 people following lung resection for NSCLC (assessed 1 to 6 years following the resection) demonstrated that 205 (60\%) reported significant dyspnoea at the time they responded to the survey (Feinstein 2010). The 2013 evidence-based clinical practice guidelines (CPG) of the American College of Chest Physicians (ACCP) discuss the importance of managing dyspnoea in people with lung cancer as "it creates significant worsening to a patient's HRQoL" (Simoff 2013). This CPG was based on a previous integrative review of systematic reviews related to the management of breathlessness in respiratory illnesses (Bailey 2010). It concluded that it is important to focus future research on promising non-pharmacological interventions to manage dyspnoea, as pharmacological treatments do not completely alleviate symptoms and have the added burden of side effects. Our review suggests that exercise training may be a promising non-pharmacological intervention to manage dyspnoea in people following lung resection for NSCLC.

Our meta-analysis did not show differences in fatigue following exercise training. Fatigue is a common symptom in people with early stage (i.e. stages I to IIIA) NSCLC (Huang 2015). However, the mean time taken following lung resection for people with NSCLC to recover from symptoms of fatigue is 62 days ( $95 \% \mathrm{Cl} 52$ to 72 days) (Fagundes 2015). The lack of between-group difference in fatigue demonstrated in this review is therefore likely to be related, at least in part, to a natural recovery in this outcome in both the intervention and control groups.

The only study that measured feelings of anxiety and depression did not show improvement in these outcomes following exercise training (Cavalheri 2017). However, the participants in that study presented with low scores for feelings of anxiety and depression (i.e. HADS anxiety and depression scores $\leq 7$ ) at baseline. This result is in agreement with a study of pulmonary rehabilitation in people with COPD that found that people with baseline HADS scores for feelings of anxiety and depression of $\leq 7 \mathrm{did}$ not have a significant change in symptoms following pulmonary rehabilitation (Harrison 2012). As lung resection is the treatment that offers the best chance of cure of NSCLC (Brunelli 2013), further investigation is needed to explore the extent to which feelings of anxiety and depression are present in this population, and, if so, whether they are best managed with a combination of exercise training and other interventions provided by a multidisciplinary team.

We did not demonstrate changes in lung function following exercise training in this review. This finding was expected and is in agreement with the literature on the effect of pulmonary rehabilitation on lung function for people with COPD (McCarthy 2015). 


\section{Quality of the evidence}

We rated the quality (certainty) of the evidence provided by the studies included in the analysis as moderate, ranging between very low (e.g. dyspnoea) and high (e.g. exercise capacity measure as the 6MWD). We assessed all included studies as having a high risk of performance bias. However, blinding of participants and personnel is particularly challenging in RCTs investigating the effectiveness of exercise training. The reasons for rating the evidence for the outcomes dyspnoea and HRQoL as very low and low certainty, respectively, were mainly due to high risk of detection bias and some level of inconsistency (for HRQoL and dyspnoea) and imprecision of pooled estimates (dyspnoea). We rated the evidence for the outcome exercise capacity ( $\mathrm{VO}_{2}$ peak) as moderate certainty because two of the four studies included in the metaanalysis had a high risk of detection bias (i.e. lack of blinding of the outcome assessors) for that specific outcome measure. We judged the evidence for the outcome quadriceps muscle force as of moderate certainty due to small sample size across the studies. Finally, we rated the evidence for the outcome exercise capacity (6MWD) as of high certainty due to the very large size of the effect, which showed marginal increase compared to the original version of the review (Cavalheri 2013a). We believe that further research is very unlikely to change our confidence in the estimate of effect for 6MWD.

\section{Potential biases in the review process}

Our review was strengthened by a number of methodological processes used to ensure rigour and completeness. These included an extensive electronic search, a search strategy with no language limitation, the use of two review authors to independently examine and select studies, and our success in contacting authors of the included studies to provide additional data. In the previous version of the review we attempted to contact authors of two other studies; one did not reply, and the other did not have access to the requested data. In this update, we attempted to contact the authors of another study, but we did not receive a reply to our several contact attempts. Exclusion of these three studies is a potential source of selection bias.

\section{Agreements and disagreements with other studies or reviews}

The first published systematic review on the effects of exercise training for people with NSCLC included randomised and nonrandomised controlled trials (Granger 2011). However, of 16 studies (two RCTs) included in this earlier review, only one RCT initiated exercise training following lung resection for NSCLC (Arbane 2011), whilst all the others explored the effect of preoperative exercise training. Based on the results of 11 non-RCTs, the authors concluded that in people with NSCLC exercise training in this population was safe and may confer positive benefits on exercise capacity and some domains of HRQoL. Reviews of preoperative exercise training in people with NSCLC have since been published following that first review (Cavalheri 2017a; Pouwels 2015; Sebio Garcia 2016). Only one of the three reviews reported results of a meta-analysis for the outcome 6MWD (Cavalheri 2017a), and, in agreement with the current review, demonstrated improved 6MWD in the intervention group compared with the control group (MD 18 $\mathrm{m}, 95 \% \mathrm{Cl} 9$ to $28 \mathrm{~m}$ ). Similarly, a recently published review that investigated the effects of exercise training in people with advanced lung cancer (i.e. stages IIIB to IVB) demonstrated improved 6MWD in the intervention group compared with the control group (MD $63 \mathrm{~m}, 95 \% \mathrm{Cl} 4$ to $123 \mathrm{~m}$ ) (Peddle-McIntyre 2019). Regarding reviews on exercise training following lung resection for NSCLC, the original version of our Cochrane Review, Cavalheri 2013a, as well as two other reviews, Crandall 2014; Sommer 2018, have been published. The review by Crandall 2014 included both RCTs and non-RCTs that investigated the effectiveness of exercise training for people with NSCLC before as well as after lung resection. However, the authors did not perform meta-analysis. The review by Sommer 2018 included only four RCTs (Arbane 2011; Brocki 2014; Edvardsen 2015; Salhi 2015). In agreement with our review, Sommer 2018 reported higher exercise capacity in the intervention group compared with the control group (SMD $0.48,95 \% \mathrm{Cl} 0.04$ to 0.93). However, in contrast to our review, which analysed $\mathrm{VO}_{2}$ peak and 6MWD separately, Sommer 2018 pooled results of $\mathrm{VO}_{2}$ peak and 6MWD together in the meta-analysis. Consistent with our findings, Sommer 2018 reported better scores for the physical component of HRQoL in the intervention group compared with the control group (SMD 0.50, 95\% Cl 0.19 to 0.82 ). However, instead of analysing general HRQoL and disease-specific HRQoL separately, Sommer 2018 pooled results of the SF-36 physical component score and EORTC QLQ-C30 physical functioning score together in the meta-analysis. Of note, our review is the first to report findings of meta-analysis for outcomes such as force-generating capacity of peripheral muscles, pressure-generating capacity of respiratory muscles, dyspnoea, and fatigue.

\section{AUTHORS' CONCLUSIONS}

\section{Implications for practice}

Our meta-analyses provided moderate- to high-certainty evidence that exercise training, which included aerobic and resistance exercises, improved exercise capacity and quadriceps muscle force of people following lung resection for non-small cell lung cancer (NSCLC). The improvement in exercise capacity was clinically important. Lower-certainty evidence from our meta-analyses also suggested that exercise training improved the physical component score of general health-related quality of life (HRQoL) and decreased dyspnoea in people following lung resection for NSCLC. The improvement in the physical component score of general HRQoL was clinically important. A survey that described the management of people with lung cancer across Australia and New Zealand reported that only a small proportion of people were referred to exercise training programmes following lung resection (Cavalheri 2013). Our review suggests that referrals to exercise programmes could be considered for people following lung resection for NSCLC. Exercise training has the potential to interrupt the 'deconditioning storm' induced by the disease and its treatment (Jones 2008). Importantly, balance training, when needed, should be performed under close supervision and in proximity to a railing or other secure support (Beck 2017).

\section{Implications for research}

In the original review we provided important considerations for minimising bias and methodological heterogeneity in upcoming studies. We were pleased to see that these considerations were addressed in the five studies added to this review (Arbane 2014; Cavalheri 2017; Edvardsen 2015; Messaggi-Sartor 2018; Salhi 2015). Specifically, these studies: (i) collected outcome measures immediately before and after the exercise training intervention rather than before lung resection and on completion of the 
exercise training intervention; (ii) chose disease-specific HRQoL questionnaires; and (iii) reported the values for each domain that contributed to $\mathrm{HRQ}$ oL as well as the total score obtained from HRQoL questionnaires. Reporting of data could be optimised by reporting the mean change in outcomes collected immediately before and after the exercise training intervention.

The current systematic review strengthens the message that exercise training improves exercise capacity in people following lung resection for NSCLC. It also highlights the need for larger randomised controlled trials (RCTs) to confirm or investigate the effects of exercise training following lung resection for NSCLC on outcomes other than exercise capacity, including different aspects of quality of life and symptoms. The effect of combining exercise training with other interventions provided by a multidisciplinary team (e.g. dietitians, occupational therapists, psychologists, and others) needs to be considered. Although blinding of study participants and personnel in RCTs of exercise training is very difficult, even with 'sham' training, future studies should strive to blind outcome assessors. Upcoming studies should consider intention-to-treat analysis, as well as attempts to minimise losses to follow-up. The addition of longer-term follow-up measures is also important for future trials. Furthermore, a comparison of the effects of exercise training in people who underwent videoassisted thoracoscopic surgery (VATS) and those who underwent thoracotomy could be included as an exploratory aim in future RCTs to evaluate their influence on maximal inspiratory and expiratory pressures as well as other outcomes.

\section{ACKN OWLEDGEMENTS}

The authors would like to thank Corynne Marchal (Managing Editor of the Cochrane Lung Cancer Group) and Marta Roque (Statistician of the Cochrane Lung Cancer Group) for their support and input. We also acknowledge the Editors Fergus Macbeth and Alain Bernard and the consumer André Stoop for their input into the review process.

Furthermore, we would like to acknowledge the contribution of Dr Fatim Tahirah and assistance provided by Sera Tort, Ivan Solà, Ambuj Kumar, Ramon Rami also, and Desiree West on the original version of the review. 


\section{R E F E R E N C E S}

\section{References to studies included in this review}

Arbane 2011 \{published data only\}

Arbane G, Jackson D, Summers R, Williams L, Tropman D, Garrod R. Early exercise training after thoracotomy prevents quadriceps sarcopenia for people with lung cancer. European Respiratory Society 2009 Annual Congress; 200909 12-16; Vienna. European Respiratory Society, 2009:819s.

Arbane G, Jackson D, Tropman D, Garrod R. An early exercise intervention prevents quadriceps weakness after thoracotomy for non-small cell lung cancer: randomised controlled trial. Thorax 2009;64:A20-1.

* Arbane G, Tropman D, Jackson D, Garrod R. Evaluation of an early exercise intervention after thoracotomy for non-small cell lung cancer (NSCLC), effects on quality of life, muscle strength and exercise tolerance: randomised controlled trial. Lung Cancer 2011;71(2):229-34.

\section{Arbane 2014 \{published data only\}}

Arbane G, Douiri A, Hart N, Hopkinson NS, Singh S, Speed C, et al. Effect of postoperative physical training on activity after curative surgery for non-small cell lung cancer: a multicentre randomised controlled trial. Physiotherapy 2014;100(2):100-7.

\section{Brocki 2014 \{published data only\}}

Brocki B, Rodkjaer L, Nekrasas V, Due KM, Andreasen J. Effects of an outpatient exercise training programme after lung cancer operation - a randomised single-blinded clinical trial. Physiotherapy 2011;97:eS156-7.

Brocki B, Rodkjær L, Nekrasas V, Due K, Dethlefsen C, Andreasen J. Rehabilitation after lung cancer operation- a randomised controlled study. European Respiratory Society 2010 Annual Congress; 201009 18-22; Barcelona. European Respiratory Society, 2010:331s.

* Brocki BC, Andreasen JJ, Nielsen LR, Nekrasas V, GorstRasmussen A, Westerdahl E. Short and long-term effects of supervised versus unsupervised exercise training on healthrelated quality of life and functional outcomes following lung cancer surgery - a randomized controlled trial. Lung Cancer 2014;83(1):102-8.

\section{Cavalheri 2017 \{published data only\}}

Cavalheri V, Jenkins S, Cecins N, Gain K, Phillips MJ, Sanders LH, et al. Exercise training for people following curative intent treatment for non-small cell lung cancer: a randomized controlled trial. Brazilian Journal of Physical Therapy 2017;21(1):58-68.

Edvardsen 2015 \{published data only\}

Edvardsen E, Skjønsberg OH, Holme I, Nordsletten L, Borchsenius F, Anderssen SA. High-intensity training following lung cancer surgery: a randomised controlled trial. Thorax 2015;70(3):244-50.
Messaggi-Sartor 2018 \{published data only\}

Messaggi-Sartor M, Marco E, Martínez-Téllez E, RodriguezFuster A, Palomares C, Chiarella S, et al. Combined aerobic exercise and high-intensity respiratory muscle training in patients surgically treated for non-small cell lung cancer: a pilot randomized clinical trial. European Journal of Physical and Rehabilitation Medicine 2018 Jul 6 [Epub ahead of print]. [DOI: 10.23736/S1973-9087.18.05156-0]

\section{Salhi 2015 \{published and unpublished data\}}

Meerbeeck JP, Salhi B, Haenebalcke C, Perez-Bogerd S, Nguyen MD, Malfait TLA, et al. Resistance training in patients with radically treated respiratory cancer: mature results of a multi-centre randomised phase 3 trial (reinforce). Journal of Thoracic Oncology 2013;8:S245.

* Salhi B, Haenebalcke C, Perez-Bogerd S, Nguyen MD, Ninane V, Malfait TLA, et al. Rehabilitation in patients with radically treated respiratory cancer: a randomised controlled trial comparing two training modalities. Lung Cancer 2015;89(2):167-74.

Surmont VF, Salhi B, Haenebalcke C, Bogerd SP, Dang DMN, Colman R, et al. REINFORCE: A randomized trial of resistance training in patients with radically treated respiratory cancer. Journal of Clinical Oncology 2013;31(15_suppl):7541.

\section{Stigt 2013 \{published and unpublished data\}}

Stigt JA, Uil SM, van Riesen SJ, Simons FJ, Denekamp M, Shahin GM, et al. A randomized controlled trial of postthoracotomy pulmonary rehabilitation in patients with resectable lung cancer. Journal of Thoracic Oncology 2013;8(2):214-21.

\section{References to studies excluded from this review}

Brocki 2016 \{published and unpublished data\}

Brocki BC, Andreasen JJ, Langer D, Souza DSR, Westerdahl E. Postoperative inspiratory muscle training in addition to breathing exercises and early mobilization improves oxygenation in high-risk patients after lung cancer surgery: a randomized controlled trial. European Journal of Cardiothoracic Surgery 2016;49(5):1483-91.

\section{Chen 2015 \{published data only\}}

Chen HM, Tsai CM, Wu YC, Lin KC, Lin CC. Randomised controlled trial on the effectiveness of home-based walking exercise on anxiety, depression and cancer-related symptoms in patients with lung cancer. British Journal of Cancer 2015; Vol. 112 , issue 3:438-45.

Chen HM, Tsai CM, Wu YC, Lin KC, Lin CC. Randomised controlled trial on the effectiveness of home-based walking exercise on anxiety, depression and cancer-related symptoms in patients with lung cancer. Palliative Medicine 2016;30(6):NP15-6. 
Chen 2016 \{published data only\}

Chen HM, Tsai CM, Wu YC, Lin KC, Lin CC. Effect of walking on circadian rhythms and sleep quality of patients with lung cancer: a randomised controlled trial. British Journal of Cancer 2016;115(11):1304-12.

\section{Granger 2013 \{published data only\}}

Granger CL, Chao C, McDonald CF, Berney S, Denehy L. Safety and feasibility of an exercise intervention for patients following lung resection: a pilot randomized controlled trial. Lung Cancer 2013;12(3):213-24.

\section{Hoffman 2017 \{published data only\}}

Hoffman AJ, Brintnall RA. A home-based exercise intervention for non-small cell lung cancer patients post-thoracotomy. Seminars in Oncology Nursing 2017;33(1):106-17.

\section{Hsiao 2017 \{published data only\}}

Hsiao WL. Testing efficacy of a pulmonary rehabilitation program for post lung cancer resection surgery. Journal of Thoracic Oncology 2017;12(11 Suppl 2):S2024.

\section{Jakobsen 2013 \{published data only\}}

Jakobsen E, Dan Joergensen O, Ladegaard L, Petersen S, Aagaard I, Mikkelsen P, et al. Postoperative rehabilitation and follow-up - a randomized study. Journal of Thoracic Oncology 2013;8:S390-1.

\section{Karvinen 2014 \{published data only\}}

Karvinen KH, Esposito D, Raedeke TD, Vick J, Walker PR. Effect of an exercise training intervention with resistance bands on blood cell counts during chemotherapy for lung cancer: a pilot randomized controlled trial. Annals of Rehabilitation Medicine 2014;3:15.

\section{Ledderer 2013 \{published data only\}}

Ledderer L, Cour K, Mogensen O, Jakobsen E, Depont Christensen R, Kragstrup J, et al. Feasibility of a psychosocial rehabilitation intervention to enhance the involvement of relatives in cancer rehabilitation: pilot study for a randomized controlled trial. Patient 2013; Vol. 6, issue 3:201-12.

\section{Liu 2015 \{published data only\}}

Liu J, Chen P, Wang R, Yuan Y, Wang X, Li C. Effect of Tai Chi on mononuclear cell functions in patients with non-small cell lung cancer. BMC Complementary and Alternative Medicine 2015;15(3):1-8

\section{Novoa 2017 \{published data only\}}

Novoa NM, Esteban P, Hernandez N, Gomez Hernandez MT, Varela G. Randomized trial to evaluate the beneficial effects of an unsupervised postoperative physical training protocol after lung resection: negative results. Interactive Cardiovascular and Thoracic Surgery 2017;25:i25

\section{Tenconi 2017 \{published data only\}}

Tenconi S, Galeone C, Fugazzaro S, Rapicetta C, Piro R, Formisano D. Perioperative and long-term effects of comprehensive pulmonary rehabilitation on exercise capacity, postoperative outcome and quality of life in patients undergoing lung resection: a randomized controlled trial granted by the ministry of health. Interactive Cardiovascular and Thoracic Surgery 2017;25:i25.

Wang 2013 \{published data only\}

Wang R, Liu J, Chen P, Yu D. Regular Tai Chi exercise decreases the percentage of type 2 cytokine-producing cells in postsurgical non-small cell lung cancer survivors. Cancer Nursing 2013;36(4):E27-34.

\section{Weiner 1997 \{published data only\}}

Weiner P, Man A, Weiner M, Rabner M, Waizman J, Magadle R, et al. The effect of incentive spirometry and inspiratory muscle training on pulmonary function after lung resection. Journal of Thoracic and Cardiovascular Surgery 1997; Vol. 113, issue 3:552-7.

\section{Yorke 2015 \{published data only\}}

Yorke J, Lloyd-Williams M, Smith J, Blackhall F, Harle A, Warden J, et al. Management of the respiratory distress symptom cluster in lung cancer: a randomised controlled feasibility trial. Supportive Care in Cancer 2015; Vol. 23, issue 11:3373-84.

\section{Additional references}

\section{AlHW 2017}

Australian Institute of Health and Welfare. Cancer in Australia 2017. www.aihw.gov.au/cancer/ (accessed 13 November 2018).

\section{Atkins 2004}

Atkins D, Eccles M, Flottorp S, Guyatt GH, Henry D, Hill S, et al. Systems for grading the quality of evidence and the strength of recommendations I: critical appraisal of existing approaches. The GRADE Working Group. BMC Health Services Research 2004;4(1):38.

\section{Bailey 2010}

Bailey CD, Wagland R, Dabbour R, Caress A, Smith J, Molassiotis A. An integrative review of systematic reviews related to the management of breathlessness in respiratory illnesses. BMC Pulmonary Medicine 2010;10:63. [PUBMED: 21143887]

Baracos 2010

Baracos VE, Reiman T, Mourtzakis M, Gioulbasanis I, Antoun S. Body composition in patients with non-small cell lung cancer: a contemporary view of cancer cachexia with the use of computed tomography image analysis. American Journal of Clinical Nutrition 2010;91 Suppl:1133-7.

\section{Beck 2017}

Beck BR, Daly RM, Singh MA, Taaffe DR. Exercise and Sports Science Australia (ESSA) position statement on exercise prescription for the prevention and management of osteoporosis. Journal of Science and Medicine in Sport 2017;20(5):438-45. [PUBMED: 27840033]

\section{Bendixen 2016}

Bendixen M, Jorgensen OD, Kronborg C, Andersen C, Licht PB. Postoperative pain and quality of life after lobectomy via videoassisted thoracoscopic surgery or anterolateral thoracotomy for 
early stage lung cancer: a randomised controlled trial. Lancet Oncology 2016;17(6):836-44. [PUBMED: 27160473]

\section{Bray 2018}

Bray F, Ferlay J, Soerjomataram I, Siegel RL, Torre LA, Jemal A. Global cancer statistics 2018: GLOBOCAN estimates of incidence and mortality worldwide for 36 cancers in 185 countries. CA: $a$ Cancer Journal for Clinicians 2018;68(6):394-424. [DOI: 10.3322/ caac.21492]

\section{Brunelli 2013}

Brunelli A, Kim AW, Berger KI, Addrizzo-Harris DJ. Physiologic evaluation of the patient with lung cancer being considered for resectional surgery: diagnosis and management of lung cancer, 3rd ed: American College of Chest Physicians evidence-based clinical practice guidelines. Chest 2013;143(5 Suppl):e166S-90S. [PUBMED: 23649437]

\section{Burtin 2017}

Burtin C, Franssen FME, Vanfleteren LEGW, Groenen MTJ, Wouters EFM, Spruit MA. Lower-limb muscle function is a determinant of exercise tolerance after lung resection surgery in patients with lung cancer. Respirology (Carlton, Vic.) 2017;22(6):1185-9. [PUBMED: 28370836]

\section{Carson 2013}

Carson KV, Chandratilleke MG, Picot J, Brinn MP, Esterman AJ, Smith BJ. Physical training for asthma. Cochrane Database of Systematic Reviews 2013, Issue 9. [DOI: 10.1002/14651858.CD001116.pub4]

\section{Cavalheri 2013}

Cavalheri V, Jenkins S, Hill K. Physiotherapy practice patterns for patients undergoing surgery for lung cancer: a survey of hospitals in Australia and New Zealand. Internal Medicine Journal 2013;43(4):394-401.

\section{Cavalheri 2013a}

Cavalheri V, Tahirah F, Nonoyama M, Jenkins S, Hill K. Exercise training undertaken by people within 12 months of lung resection for non-small cell lung cancer. Cochrane Database of Systematic Reviews 2013, Issue 7. [DOI: 10.1002/14651858.CD009955.pub2]

\section{Cavalheri 2015}

Cavalheri V, Jenkins S, Cecins N, Gain K, Phillips M, Sanders LH, et al. Impairments after curative intent treatment for non-small cell lung cancer: a comparison with age and gender-matched healthy controls. Respiratory Medicine 2015;109(10):1332-9. [PUBMED: 26342839]

\section{Cavalheri 2016}

Cavalheri V, Jenkins S, Cecins N, Phillips M, Sanders LH, Hill K. Patterns of sedentary behaviour and physical activity in people following curative intent treatment for non-small cell lung cancer. Chronic Respiratory Disease 2016;13(1):82-5. [DOI: 10.1177/1479972315616931]

\section{Cavalheri 2017a}

Cavalheri V, Granger C. Preoperative exercise training for patients with non-small cell lung cancer. Cochrane
Database of Systematic Reviews 2017, Issue 6. [DOI:

10.1002/14651858.CD012020.pub2]

\section{Cesario 2007}

Cesario A, Ferri L, Galetta D, Pasqua F, Bonassi S, Clini E, et al. Post-operative respiratory rehabilitation after lung resection for non-small cell lung cancer. Lung Cancer 2007;57(2):175-80. [PUBMED: 17442449]

\section{Chandler 2016}

Chandler J, Lasserson T, Higgins JPT, Tovey D, Churchill R. Standards for the planning, conduct and reporting of updates of Cochrane Intervention Reviews. Higgins JPT, Lasserson T, Chandler J, Tovey D, Churchill R. Methodological Expectations of Cochrane Intervention Reviews. Cochrane: London, 2016.

\section{Coups 2009}

Coups EJ, Park BJ, Feinstein MB, Steingart RM, Egleston BL, Wilson DJ, et al. Physical activity among lung cancer survivors: changes across the cancer trajectory and associations with quality of life. Cancer Epidemiology, Biomarkers \& Prevention 2009;18(2):664-72. [PUBMED: 19190151]

\section{Covidence 2017}

Covidence systematic review software. Veritas Health Innovation, Melbourne, Australia. Available at www.covidence.org. Veritas Health Innovation, Melbourne, Australia. Available at www.covidence.org.

\section{Crandall 2014}

Crandall K, Maguire R, Campbell A, Kearney N. Exercise intervention for patients surgically treated for non-small cell lung cancer (NSCLC): a systematic review. Surgical Oncology 2014;23(1):17-30. [PUBMED: 24529937]

\section{Cykert 2000}

Cykert S, Kissling G, Hansen CJ. Patient preferences regarding possible outcomes of lung resection: what outcomes should preoperative evaluations target?. Chest 2000;117(6):1551-9.

\section{D'Silva 2018}

D'Silva A, Gardiner PA, Boyle T, Bebb DG, Johnson ST, Vallance JK. Associations of objectively assessed physical activity and sedentary time with health-related quality of life among lung cancer survivors: a quantile regression approach. Lung Cancer 2018;119:78-84. [PUBMED: 29656757]

\section{Dagnelie 2007}

Dagnelie PC, Pijls-Johannesma MC, Lambin P, Beijer S, De Ruysscher D, Kempen GI. Impact of fatigue on overall quality of life in lung and breast cancer patients selected for high-dose radiotherapy. Annals of Oncology 2007;18(5):940-4.

\section{Danish Lung Cancer Registry 2009}

Danish Lung Cancer Registry. Yearly Report for 2009. lungecancer.dk/documents/00140.pdf (accessed 18 May 2012).

\section{Dayen 2017}

Dayen C, Debieuvre D, Molinier O, Raffy O, Paganin F, Virally J, et al. New insights into stage and prognosis in small cell lung 
cancer: an analysis of 968 cases. Journal of Thoracic Disease 2017;9(12):5101-11. [PUBMED: 29312716]

\section{DerSimonian 1986}

DerSimonian R, Laird N. Meta-analysis in clinical trials. Controlled Clinical Trials 1986;7(3):177-88.

\section{Dowman 2014}

Dowman L, Hill CJ, Holland AE. Pulmonary rehabilitation for interstitial lung disease. Cochrane Database of Systematic Reviews 2014, Issue 10. [DOI: 10.1002/14651858.CD006322.pub3]

\section{Fagundes 2015}

Fagundes CP, Shi Q, Vaporciyan AA, Rice DC, Popat KU, Cleeland CS, et al. Symptom recovery after thoracic surgery: measuring patient-reported outcomes with the MD Anderson Symptom Inventory. Journal of Thoracic and Cardiovascular Surgery 2015;150(3):613-9.e2. [PUBMED: 26088408]

\section{Feinstein 2010}

Feinstein MB, Krebs P, Coups EJ, Park BJ, Steingart RM, Burkhalter J, et al. Current dyspnea among long-term survivors of early-stage non-small cell lung cancer. Journal of Thoracic Oncology 2010;5(8):1221-6. [PUBMED: 20592631]

\section{Gopaldas 2010}

Gopaldas RR, Bakaeen FG, Dao TK, Walsh GL, Swisher SG, Chu D. Video-assisted thoracoscopic versus open thoracotomy lobectomy in a cohort of 13,619 patients. Annals of Thoracic Surgery 2010;89(5):1563-70.

\section{Granger 2011}

Granger CL, McDonald CF, Berney S, Chao C, Denehy L. Exercise intervention to improve exercise capacity and health related quality of life for patients with non-small cell lung cancer: a systematic review. Lung Cancer 2011;72(2):139-53. [PUBMED: 21316790]

\section{Granger 2014}

Granger CL, McDonald CF, Irving L, Clark RA, Gough K, Murnane A, et al. Low physical activity levels and functional decline in individuals with lung cancer. Lung Cancer 2014;83(2):292-9. [PUBMED: 24360323]

\section{Granger 2015}

Granger CL, Holland AE, Gordon IR, Denehy L. Minimal important difference of the 6-minute walk distance in lung cancer. Chronic Respiratory Disease 2015;12(2):146-54. [PUBMED: 25749346]

\section{Granger 2016}

Granger CL, Parry SM, Edbrooke L, Denehy L. Deterioration in physical activity and function differs according to treatment type in non-small cell lung cancer - future directions for physiotherapy management. Physiotherapy 2016;102(3):256-63. [PUBMED: 26597694]

\section{Guyatt 2008}

Guyatt GH, Oxman AD, Vist GE, Kunz R, Falck-Ytter Y, AlonsoCoello $P$, et al. GRADE: an emerging consensus on rating quality of evidence and strength of recommendations. $B M J$ 2008;336(7650):924-6.

\section{Harrison 2012}

Harrison SL, Greening NJ, Williams JE, Morgan MD, Steiner MC, Singh SJ. Have we underestimated the efficacy of pulmonary rehabilitation in improving mood?. Respiratory Medicine 2012;106(6):838-44. [PUBMED: 22197576]

\section{Higgins 2011}

Higgins JPT, Green S (editors). Cochrane Handbook for Systematic Reviews of Interventions Version 5.1.0 (updated March 2011). The Cochrane Collaboration, 2011. Available from handbook.cochrane.org.

\section{Huang 2015}

Huang X, Zhou W, Zhang Y. Features of fatigue in patients with early-stage non-small cell lung cancer. Journal of Research in Medical Sciences 2015;20(3):268-72. [PUBMED: 26109974]

\section{Jemal 2017}

Jemal A, Ward EM, Johnson CJ, Cronin KA, Ma J, Ryerson B, et al. Annual report to the nation on the status of cancer, 1975-2014, featuring survival. Journal of the National Cancer Institute 2017;109(9):1-22. [DOI: 10.1093/jnci/djx030]

\section{Jett 2013}

Jett JR, Schild SE, Kesler KA, Kalemkerian GP. Treatment of small cell lung cancer: diagnosis and management of lung cancer, 3rd ed: American College of Chest Physicians evidence-based clinical practice guidelines. Chest 2013;143(5 Suppl):e400S-19S. [PUBMED: 23649448]

\section{Jones 2007}

Jones LW, Peddle CJ, Eves ND, Haykowsky MJ, Courneya KS, Mackey JR, et al. Effects of presurgical exercise training on cardiorespiratory fitness among patients undergoing thoracic surgery for malignant lung lesions. Cancer 2007;110(3):590-8.

\section{Jones 2008}

Jones LW, Eves ND, Haykowsky M, Joy AA, Douglas PS. Cardiorespiratory exercise testing in clinical oncology research: systematic review and practice recommendations. Lancet Oncology 2008;9(8):757-65.

\section{Jones 2009}

Jones LW, Eves ND, Waner E, Joy AA. Exercise therapy across the lung cancer continuum. Current Oncology Reports 2009;11(4):255-62. [PUBMED: 19508829]

\section{Jones 2010}

Jones LW, Watson D, Herndon JE, Eves ND, Haithcock BE, Loewen $\mathrm{G}$, et al. Peak oxygen consumption and long-term all-cause mortality in nonsmall cell lung cancer. Cancer 2010;116(20):4825-32. [PUBMED: 20597134]

\section{Lahart 2018}

Lahart IM, Metsios GS, Nevill AM, Carmichael AR. Physical activity for women with breast cancer after adjuvant therapy. Cochrane Database of Systematic Reviews 2018, Issue 1. [DOI: 10.1002/14651858.CD011292.pub2] 


\section{Landreneau 1993}

Landreneau RJ, Hazelrigg SR, Mack MJ, Dowling RD, Burke D, Gavlick J, et al. Postoperative pain-related morbidity: videoassisted thoracic surgery versus thoracotomy. Annals of Thoracic Surgery 1993;56(6):1285-9.

\section{Maltais 2014}

Maltais F, Decramer M, Casaburi R, Barreiro E, Burelle Y, Debigare R, et al. An official American Thoracic Society/ European Respiratory Society statement: update on limb muscle dysfunction in chronic obstructive pulmonary disease. American Journal of Respiratory and Critical Care Medicine 2014;189(9):e15-62. [PUBMED: 24787074]

\section{McCarthy 2015}

McCarthy B, Casey D, Devane D, Murphy K, Murphy E, Lacasse Y. Pulmonary rehabilitation for chronic obstructive pulmonary disease. Cochrane Database of Systematic Reviews 2015, Issue 2. [DOI: 10.1002/14651858.CD003793.pub3]

\section{Mishra 2012}

Mishra SI, Scherer RW, Geigle PM, Berlanstein DR, Topaloglu O, Gotay CC, et al. Exercise interventions on health-related quality of life for cancer survivors. Cochrane Database of Systematic Reviews 2012, Issue 8. [DOI: 10.1002/14651858.CD007566.pub2]

\section{Mouronte-Roibas 2018}

Mouronte-Roibas C, Leiro-Fernandez V, Ruano-Ravina A, Ramos-Hernandez C, Abal-Arca J, Parente-Lamelas I, et al. Chronic obstructive pulmonary disease in lung cancer patients: prevalence, underdiagnosis, and clinical characterization. Respiration 2018;95(6):414-21. [PUBMED: 29587299]

\section{Murphy 2010}

Murphy RA, Mourtzakis M, Chu QS, Reiman T, Mazurak VC. Skeletal muscle depletion is associated with reduced plasma (n-3) fatty acids in non-small cell lung cancer patients. Journal of Nutrition 2010;140(9):1602-6.

\section{Myrdal 2003}

Myrdal G, Valtysdottir S, Lambe M, Stahle E. Quality of life following lung cancer surgery. Thorax 2003;58(3):194-7.

\section{Nezu 1998}

Nezu K, Kushibe K, Tojo T, Takahama M, Kitamura S. Recovery and limitation of exercise capacity after lung resection for lung cancer. Chest 1998;113(6):1511-6.

\section{O'Driscoll 1999}

O'Driscoll M, Corner J, Bailey C. The experience of breathlessness in lung cancer. European Journal of Cancer Care 1999;8(1):37-43.

\section{Office for National Statistics 2015}

Office for National Statistics 2015. Deaths registered in England and Wales (series DR): 2015. www.ons.gov.uk/releases/ deathsregisteredinenglandandwalesseriesdr2013 (accessed 13 November 2018).

\section{Peddle-McIntyre 2019}

Peddle-McIntyre CJ, Singh F, Thomas R, Newton RU, Galvao DA, Cavalheri V. Exercise training for advanced lung cancer.

Cochrane Database of Systematic Reviews 2019, Issue 2. [DOI: 10.1002/14651858.CD012685.pub2]

\section{Poghosyan 2013}

Poghosyan H, Sheldon LK, Leveille SG, Cooley ME. Healthrelated quality of life after surgical treatment in patients with non-small cell lung cancer: a systematic review. Lung Cancer 2013;81(1):11-26. [PUBMED: 23562675]

\section{Porszasz 2005}

Porszasz J, Emtner M, Goto S, Somfay A, Whipp BJ, Casaburi R. Exercise training decreases ventilatory requirements and exercise-induced hyperinflation at submaximal intensities in patients with COPD. Chest 2005;128(4):2025-34. [PUBMED: 16236851]

\section{Pouwels 2015}

Pouwels S, Fiddelaers J, Teijink JA, Woorst JF, Siebenga J, Smeenk FW. Preoperative exercise therapy in lung surgery patients: a systematic review. Respiratory Medicine 2015;109(12):1495-504. [PUBMED: 26303337]

\section{Puhan 2016}

Puhan MA, Gimeno-Santos E, Cates CJ, Troosters T. Pulmonary rehabilitation following exacerbations of chronic obstructive pulmonary disease. Cochrane Database of Systematic Reviews 2016, Issue 12. [DOI: 10.1002/14651858.CD005305.pub4]

\section{RevMan 2014 [Computer program]}

The Nordic Cochrane Centre, The Cochrane Collaboration. Review Manager (RevMan). Version 5.3. Copenhagen: The Nordic Cochrane Centre, The Cochrane Collaboration, 2014.

\section{Samsa 1999}

Samsa G, Edelman D, Rothman ML, Williams GR, Lipscomb J, Matchar D. Determining clinically important differences in health status measures: a general approach with illustration to the Health Utilities Index Mark II. PharmacoEconomics 1999;15(2):141-55. [PUBMED: 10351188]

\section{Sarna 2004}

Sarna L, Evangelista L, Tashkin D, Padilla G, Holmes C, Brecht ML, et al. Impact of respiratory symptoms and pulmonary function on quality of life of long-term survivors of non-small cell lung cancer. Chest 2004;125(2):439-45. [DOI: 10.1378/chest.125.2.439]

\section{Schneider 2007}

Schneider CM, Hsieh CC, Sprod LK, Carter SD, Hayward R. Exercise training manages cardiopulmonary function and fatigue during and following cancer treatment in male cancer survivors. Integrative Cancer Therapies 2007;6(3):235-41.

\section{Sebio Garcia 2016}

Sebio Garcia R, Yanez Brage MI, Gimenez Moolhuyzen E, Granger CL, Denehy L. Functional and postoperative outcomes after preoperative exercise training in patients with lung cancer: a systematic review and meta-analysis. Interactive 
Cardiovascular and Thoracic Surgery 2016;23(3):486-97. [PUBMED: 27226400]

\section{Sher 2008}

Sher T, Dy GK, Adjei AA. Small cell lung cancer. Mayo Clinic Proceedings 2008;83(3):355-67.

\section{Simoff 2013}

Simoff MJ, Lally B, Slade MG, Goldberg WG, Lee P, Michaud GC, et al. Symptom management in patients with lung cancer: diagnosis and management of lung cancer, 3rd ed: American College of Chest Physicians evidence-based clinical practice guidelines. Chest 2013;143(5 Suppl):e455S-97S. [PUBMED: 23649452]

\section{Sommer 2018}

Sommer MS, Staerkind MEB, Christensen J, Vibe-Petersen J, Larsen KR, Holst Pedersen J, et al. Effect of postsurgical rehabilitation programmes in patients operated for lung cancer: a systematic review and meta-analysis. Journal of Rehabilitation Medicine 2018;50(3):236-45. [PUBMED: 29392334]

\section{CHARACTERISTICS OF STUDIES}

Characteristics of included studies [ordered by study ID]

\section{Spruit 2006}

Spruit MA, Janssen PP, Willemsen SC, Hochstenbag MM, Wouters EF. Exercise capacity before and after an 8-week multidisciplinary inpatient rehabilitation program in lung cancer patients: a pilot study. Lung Cancer 2006;52(2):257-60. [PUBMED: 16529844]

\section{Sugimura 2006}

Sugimura H, Yang P. Long-term survivorship in lung cancer: a review. Chest 2006;129(4):1088-97.

\section{Zarogoulidis 2012}

Zarogoulidis P, Kerenidi T, Huang H, Kontakiotis T, Tremma O, Porpodis $\mathrm{K}$, et al. Six minute walking test and carbon monoxide diffusing capacity for non-small cell lung cancer: easy performed tests in every day practice. Journal of Thoracic Disease 2012;4(6):569-76.

* Indicates the major publication for the study

\section{Arbane 2011}

Methods Randomised controlled trial

Setting: St George's Hospital, London, UK

Study duration: 5 days (inpatient) +12 weeks of home-based intervention. Assessments were performed preoperatively, 5 days postoperatively, and after the 12 weeks of intervention following discharge.

Participants 67 participants with NSCLC, referred for lung resection via open thoracotomy or VATS, were screened. 53 agreed to participate in the study and were randomised before any formal testing. 2 were excluded. 51 participants (median (range) age 63 (32 to 87) years - control group; 65 (47 to 82) years - exercise group) completed the study.

Interventions

Control $(n=25)$ : Pain medication as relevant via patient-controlled analgesia on day 1 postoperatively, thereafter orally as needed. Usual care comprising routine inpatient physiotherapy treatment (airway clearance techniques, mobilisation as able, and upper limb activities) once daily from day 1 postsurgery to discharge and monthly phone calls after discharge.

Exercise $(n=26)$ : Same as control group plus twice-daily additional strength and mobility training from day 1 to day 5 postsurgery as well as 12 weeks of home-based non-supervised exercise programme (walking + home-adapted strengthening exercises) including 3 home visits.

Outcomes Exercise capacity (6-minute walk distance), health-related quality of life (EORTC QLQ-C30 version 2.0), maximal quadriceps force (femoral nerve stimulation), and postoperative complications

Notes Control group: stage I (10 participants), stage II ( 6 participants), stage IV (5 participants), and 4 participants described as "other".

Active group: stage I (15 participants), stage II (6 participants), stage III (2 participants), and data were unavailable for 3 participants.

Missing data provided on number of males/females in each group. 
Arbane 2011 (Continued)

Risk of bias

\begin{tabular}{lll}
\hline Bias & Authors' judgement & Support for judgement \\
\hline $\begin{array}{l}\text { Random sequence genera- } \\
\text { tion (selection bias) }\end{array}$ & Low risk & Quote: \\
& “...performed using computer generated tables ...” \\
\hline $\begin{array}{l}\text { Allocation concealment } \\
\text { (selection bias) }\end{array}$ & Low risk & Quote: \\
& $\begin{array}{l}\text { “...Randomisation codes were kept by an independent member of the team } \\
\text { and released after consent...” }\end{array}$ \\
& $\begin{array}{l}\text { Comment: } \\
\text { Investigators enrolling participants could not foresee assignment. }\end{array}$
\end{tabular}

Blinding of participants High risk

and personnel (perfor-

mance bias)

All outcomes

\section{Quote:}

"...Study was single blinded with the therapist performing assessments unaware of the randomisation although weekend treatments meant that in about 10 participants the same therapist performed the assessment and treatment..."

Comment:

No blinding of participants and personnel

\begin{tabular}{|c|c|c|}
\hline \multirow{4}{*}{$\begin{array}{l}\text { Blinding of outcome as- } \\
\text { sessment (detection bias) } \\
\text { All outcomes }\end{array}$} & \multirow[t]{4}{*}{ High risk } & Quote: \\
\hline & & $\begin{array}{l}\text { "...Study was single blinded with the therapist performing assessments un- } \\
\text { aware of the randomisation although weekend treatments meant that in } \\
\text { about } 10 \text { participants the same therapist performed the assessment and treat- } \\
\text { ment..." }\end{array}$ \\
\hline & & Comment: \\
\hline & & Partial blinding of outcome assessment \\
\hline
\end{tabular}

\begin{tabular}{ll}
\hline $\begin{array}{l}\text { Incomplete outcome data } \\
\text { (attrition bias) }\end{array}$ & Low risk \\
All outcomes & Numbers for each outcome were reported. Missing outcome data balanced \\
& $\begin{array}{l}\text { in numbers across intervention groups, with similar reasons for missing data } \\
\text { across groups. }\end{array}$ \\
\hline
\end{tabular}

\begin{tabular}{ll}
\hline $\begin{array}{l}\text { Selective reporting (re- } \\
\text { porting bias) }\end{array}$ & Unclear risk \\
& $\begin{array}{l}\text { No protocol available. Insufficient information to permit judgement of low risk } \\
\text { or high risk. }\end{array}$ \\
\hline
\end{tabular}

Other bias High risk Comment:

5-day postoperative assessment did not include quality of life questionnaire.

Also, the control group had 5 participants categorised at stage IV, whereas the exercise group had no participants with this categorisation.

Methods Randomised controlled trial


Arbane 2014 (Continued)

Setting: teaching hospital, London, UK

Study duration: 5 days (inpatient) +4 weeks of home-based intervention. Assessments were performed preoperatively, 5 days postoperatively (or sooner if discharge was earlier), and 4 weeks postoperatively.

$\begin{array}{ll}\text { Participants } & 131 \text { participants with NSCLC were randomised before lung resection (via open thoracotomy or VATS). } \\ \text { Following randomisation, } 29 \text { participants (22\%) were withdrawn according to predefined criteria, and } \\ \\ 24 \text { participants (18\%) were unavailable for assessment } 4 \text { weeks after lung resection. The mean (SD) age } \\ \text { was } 68 \text { (11) years for the control group and } 67 \text { (11) years for the exercise group. }\end{array}$

Interventions

Control $(n=67)$ : standard medical care including routine physiotherapy treatments, airway clearance techniques where indicated, mobilisation, and upper limb activities.

Exercise $(n=64)$ : structured, physiotherapy-led cycle ergometry strength-training programme once a day during inpatient stay. This training included a warm-up phase during 0 to 2 minutes consisting of unloaded pedaling at 50 to $60 \mathrm{rpm}$. Intensity of cycling was increased steadily during the third minute to achieve max $60 \%$ to $90 \%$ heart rate reserve. Participants were advised to exercise at an intensity of 3 to 4 in the Borg dyspnoea scale or 13 to 15 on the Borg Rating of Perceived Exertion (RPE). The aim was to complete $>5$ minutes on postoperative day 1 , increasing to maximal duration of 30 minutes on day 5. Furthermore, the exercise group undertook a 4-week home walking programme (with bi-weekly phone calls). The aim was to achieve 30 minutes of walking per day.

Outcomes Exercise capacity (incremental shuttle walk test), health-related quality of life (SF-36 and EORTC QLQLC13), and quadriceps force (maximum voluntary contraction)

Notes Subgroup analysis was undertaken with data from the 63 participants that had airflow obstruction (defined as $\mathrm{FEV}_{1} / \mathrm{FVC}<0.7$ ).

\section{Risk of bias}

\begin{tabular}{lll}
\hline Bias & Authors' judgement & Support for judgement \\
\hline $\begin{array}{ll}\text { Random sequence genera- } \\
\text { tion (selection bias) }\end{array}$ & Low risk & Quote: \\
& & "This was a dual centre, stratified, randomised controlled trial..." and "...da- \\
& ta were added to the online randomisation service provided by the Mental \\
& Health and Neurosciences Clinical Trials Unit supplied by King's College Lon- \\
& don (http://www.ctu.co.uk/)."
\end{tabular}

\begin{tabular}{ll}
\hline $\begin{array}{l}\text { Allocation concealment } \\
\text { (selection bias) }\end{array}$ & Quote: \\
& $\begin{array}{l}\text { "The allocation sequence was concealed from the researcher who enrolled } \\
\text { and assessed the participants." }\end{array}$
\end{tabular}

$\begin{array}{ll}\text { Blinding of participants } & \text { High risk } \\ \begin{array}{l}\text { and personnel (perfor- } \\ \text { mance bias) }\end{array} & \text { "The study was open labelled; neither the participants nor the researchers } \\ \text { All outcomes } & \text { were blinded." }\end{array}$

\section{Comment:}

No blinding or incomplete blinding, and the outcome is likely to be influenced by lack of blinding.

\begin{tabular}{|c|c|c|}
\hline $\begin{array}{l}\text { Blinding of outcome as- } \\
\text { sessment (detection bias) }\end{array}$ & High risk & Comment: \\
\hline All outcomes & & $\begin{array}{l}\text { Author contacted - "I can clarify that the person who assessed Physical Activ- } \\
\text { ity, Exercise Tolerance and Quadriceps Muscle Strength was not blinded to } \\
\text { group allocation" }\end{array}$ \\
\hline
\end{tabular}


Arbane 2014 (Continued)

$\begin{array}{ll}\begin{array}{l}\text { Incomplete outcome data Low risk } \\ \text { (attrition bias) }\end{array} & \text { Quote: } \\ \text { All outcomes } & \text { "The primary efficacy analysis was intention to treat, and imputed data were } \\ \text { included assuming no change where data were missing." } & \text { Comment: } \\ & \begin{array}{l}\text { Missing outcome data balanced in numbers across intervention groups, with } \\ \text { similar reasons for missing data across groups. }\end{array}\end{array}$

Selective reporting (re- Low risk Comment:

porting bias)

The study protocol is available, and all of the study's prespecified (primary and secondary) outcomes that are of interest in the review have been reported in the prespecified way.

\begin{tabular}{ll}
\hline Other bias & Comment: \\
& The study appears to be free of other sources of bias. \\
\hline
\end{tabular}

\section{Brocki 2014}

\begin{tabular}{ll}
\hline Methods & Randomised controlled trial \\
& Setting: Aalborg University Hospital, Denmark \\
& Study duration: 4 months. Intervention started 3 weeks following lung resection. Assessments were \\
performed 3 weeks following lung resection and after 4 and 12 months.
\end{tabular}

Control $(\mathrm{n}=37): 1$ individual instruction session on home exercises (strength training at least twice a
week and a daily 30 -minute walk or a bicycle ride with an intensity of 11 to 12 on the Borg scale) and
usual postoperative nurse counselling consisting of up to 3 individual 1-hour sessions performed in the
period of 3 weeks to 4 months after surgery.
Exercise $(n=41): 1$ individual instruction session on home exercises (as described above), usual post-
operative nurse counselling (described above), and supervised outpatient exercise training sessions,
1 hour once a week for 10 weeks. The sessions were based on aerobic exercises with target intensity of
$60 \%$ to $80 \%$ of work capacity, resistance training, and dyspnoea management.

\begin{tabular}{ll}
\hline Outcomes & Exercise capacity (6MWD), health-related quality of life SF-36, and lung function (spirometry) \\
\hline Notes & $\begin{array}{l}4 \text { of the } 41 \text { participants in the exercise group (10\%) and } 6 \text { of the } 37 \text { participants in the control group } \\
(16 \%) \text { had secondary lung cancer. } \\
\text { Author was contacted and kindly provided specific data (gender, age, type of surgical procedure, SF-36, } \\
6 \mathrm{MWD}, \mathrm{FEV}_{1} \text { and FVC) for the participants that had primary NSCLC. } \\
\text { 12-month follow-up not included in this review. }\end{array}$ \\
\hline
\end{tabular}

\section{Risk of bias}

Bias Authors' judgement Support for judgement


Brocki 2014 (Continued)

$\begin{array}{ll}\begin{array}{l}\text { Random sequence genera- } \\ \text { tion (selection bias) }\end{array} & \text { Quote: } \\ & \text { "Computer-generated randomization tables, stratified for pneumonectomy } \\ & \text { (expected low performance status) were used." }\end{array}$

\begin{tabular}{ll}
\hline $\begin{array}{l}\text { Allocation concealment } \\
\text { (selection bias) }\end{array}$ & Quote: \\
& $\begin{array}{l}\text { "Individual allocations were placed in consecutively numbered and sealed } \\
\text { opaque envelopes by an external person." }\end{array}$
\end{tabular}

\begin{tabular}{ll}
\hline $\begin{array}{l}\text { Blinding of participants } \\
\text { and personnel (perfor- }\end{array}$ & High risk \\
$\begin{array}{l}\text { mance bias) } \\
\text { All outcomes }\end{array}$ & "Group allocation was revealed to the patients by the main investigator." \\
& $\begin{array}{l}\text { Comment: } \\
\text { No blinding or incomplete blinding, and the outcome is likely to be influenced } \\
\text { by lack of blinding. }\end{array}$
\end{tabular}

\begin{tabular}{|c|c|c|}
\hline $\begin{array}{l}\text { Blinding of outcome as- } \\
\text { sessment (detection bias) } \\
\text { All outcomes }\end{array}$ & Low risk & $\begin{array}{l}\text { Quote: } \\
\text { "Assessors were blinded to the patient's group allocation." }\end{array}$ \\
\hline
\end{tabular}

$\begin{array}{ll}\begin{array}{l}\text { Incomplete outcome data } \\ \text { (attrition bias) }\end{array} & \text { Unclear risk } \\ \text { All outcomes } & \text { There are differential losses to follow-up between groups, and differences } \\ & \text { between completers/no completers that could be related to the outcomes, } \\ & \text { therefore we could not make an assessment of low risk of attrition bias. Since } \\ & \text { the main analysis results at } 4 \text { months were mostly of no effect (except for the } \\ \text { bodily pain domain), and the more conservative sensitivity analysis (the best } & \text { case for control) reached similar conclusions, it seems that the overall analy- } \\ \text { sis is robust and there is no suggestion of relevant bias derived from attrition } \\ \text { of participants. For this reason, we also could not make as assessment of high } \\ \text { risk of attrition bias. }\end{array}$

\begin{tabular}{|c|c|c|}
\hline $\begin{array}{l}\text { Selective reporting (re- } \\
\text { porting bias) }\end{array}$ & Low risk & $\begin{array}{l}\text { Comment: } \\
\text { ClinicalTrials.gov Identifier: NCT01048762 (not reported in the published pa- } \\
\text { per) - all of the study's prespecified (primary and secondary) outcomes that } \\
\text { are of interest in the review have been reported in the prespecified way. }\end{array}$ \\
\hline Other bias & Low risk & $\begin{array}{l}\text { Comment: } \\
\text { The study appears to be free of other sources of bias. }\end{array}$ \\
\hline
\end{tabular}

\section{Cavalheri 2017}

\begin{tabular}{ll}
\hline Methods & Randomised controlled trial \\
& Setting: 2 tertiary hospitals, Perth, Australia \\
& $\begin{array}{l}\text { Study duration: } 8 \text { weeks of intervention. Measurements were collected at baseline (i.e. } 6 \text { to } 10 \text { weeks } \\
\text { after lobectomy, or for those who required postoperative chemotherapy, } 4 \text { to } 8 \text { weeks after their last } \\
\text { chemotherapy cycle) and following completion of the intervention. }\end{array}$ \\
\hline Participants & $\begin{array}{l}\text { 96 patients with NSCLC undergoing lung resection (via open thoracotomy or VATS) were screened. } 17 \\
\text { patients (mean (SD) age } 68 \text { (9) years - control group; } 66 \text { (10) years - exercise group) agreed to partici- } \\
\text { pate in the study and were randomised. }\end{array}$
\end{tabular}


Cavalheri 2017 (Continued)

Interventions

Control $(n=8)$ : instructed to continue to perform their usual activities during the period of the study. Participants received weekly phone calls from a research assistant that consisted of general conversation as well as standardised questions about their health and well-being.

Exercise $(n=9)$ : participants in the exercise group underwent an 8-week exercise training programme aimed at improving aerobic capacity and muscle strength. The programme comprised individual, supervised training 3 times per week delivered by senior physical therapists. Each session was 60 minutes in duration. In the event that a participant could only attend 2 supervised sessions per week, they were provided with a cycle ergometer to use at home for 1 training session per week. Each class comprised aerobic (walking/cycling) and resistance training (upper/lower limbs). For corridor walking, the initial average speed was set at $80 \%$ of the average 6MWT speed. Cycling consisted of 10 min of endurance training (initial work rate was set at $60 \%$ of the Wmax) and 2 periods of 2 min of power training (initial work rate was set at $80 \%$ of the Wmax).

Outcomes Exercise capacity (6MWD and $\mathrm{VO}_{2}$ peak), health-related quality of life (SF-36, FACT-L, and EORTC QLQ$\mathrm{C} 30$ ), peripheral muscle force (isometric handgrip force, isometric quadriceps force), fatigue (FACIT-Fatigue), feelings of anxiety and depression (HADS), and lung function (spirometry)

Notes Stage I (14 participants), stage II (2 participants), stage III (1 participant)

\section{Risk of bias}

\begin{tabular}{lll}
\hline Bias & Authors' judgement & Support for judgement \\
\hline
\end{tabular}

$\begin{array}{ll}\begin{array}{ll}\text { Random sequence genera- } \\ \text { tion (selection bias) }\end{array} & \text { Quote: } \\ & \text { "The randomization sequence was generated and managed by an indepen- } \\ & \text { dent researcher using a computer..." }\end{array}$

\begin{tabular}{ll}
\hline $\begin{array}{l}\text { Allocation concealment } \\
\text { (selection bias) }\end{array}$ & Low risk \\
& “... concealed using sequentially numbered opaque envelopes." \\
\hline
\end{tabular}

Blinding of participants and personnel (performance bias)

All outcomes

\section{High risk}

Quote:

"This study was a pilot single-blinded..."

Comment:

No blinding or incomplete blinding, and the outcome is likely to be influenced by lack of blinding.

$\begin{array}{ll}\begin{array}{ll}\text { Blinding of outcome as- } \\ \text { sessment (detection bias) }\end{array} & \text { Low risk } \\ \begin{array}{ll}\text { All outcomes } & \text { "The primary investigator, who was responsible for the baseline and post-in } \\ & \text { tervention period assessments, was not aware of whether a participant had } \\ \text { been allocated to the EG or the CG." }\end{array}\end{array}$

\begin{tabular}{lll}
\hline $\begin{array}{l}\text { Incomplete outcome data } \\
\text { (attrition bias) } \\
\text { All outcomes }\end{array}$ & Low risk & $\begin{array}{l}\text { Quote: } \\
\text { "Intention-to-treat analysis was undertaken." }\end{array}$ \\
\hline $\begin{array}{l}\text { Selective reporting (re- } \\
\text { porting bias) }\end{array}$ & High risk & Comment: \\
& $\begin{array}{l}\text { Australian New Zealand Clinical Trials Registry Identifier: AC- } \\
\text { TRN12611000864921 - pressure-generating capacity of respiratory muscles } \\
\text { was included in the clinical trial registry but was not reported in the published } \\
\text { paper. }\end{array}$ \\
\hline
\end{tabular}

Other bias Low risk Comment:


Edvardsen 2015

\begin{tabular}{ll}
\hline Methods & Randomised controlled trial \\
& Setting: Oslo University Hospital in Norway \\
& $\begin{array}{l}\text { Study duration: } 20 \text { weeks, starting } 5 \text { to } 7 \text { weeks after surgery. Assessments were performed by exercise } \\
\text { physiologists before surgery, } 4 \text { to } 6 \text { weeks after surgery, and immediately after the 20-week interven- } \\
\text { tion. }\end{array}$ \\
\hline Participants & $\begin{array}{l}\text { A total of } 106 \text { patients were screened for participation, and } 69 \text { patients were enrolled before lung resec- } \\
\text { tion. Following lung resection, } 8 \text { participants were not randomised because of postoperative mortality } \\
\text { ( } n=3 \text { ) or unexpected events. } 61 \text { patients (mean (SD) age } 66 \text { (9) years - control group; } 64 \text { (9) years - exer- } \\
\text { cise group) agreed to participate in the study and were randomised. }\end{array}$
\end{tabular}

Interventions Control $(n=31)$ : the control group received standard postoperative care.

Exercise $(n=30)$ : the exercise programme was individualised and included a cardiovascular warm-up, interval training, progressive resistance training (PRT), and daily inspiratory muscle training. The intervention focused on high-intensity training, mainly by walking uphill on a treadmill at $80 \%$ to $95 \%$ of the maximum heart rate and by PRT in 3 series of 6- to 12-repetition maximum of the leg press, leg extension, back extension, seat row, bicep curls, and chest-and-shoulder press. Each session lasted 60 min, and exercise was performed 3 times per week for 20 weeks.

Outcomes Exercise capacity $\left(\mathrm{VO}_{2}\right.$ peak), health-related quality of life (SF-36 and EORTC QLQ-C30), and peripheral muscle force (isometric handgrip force by using a dynamometer, isometric quadriceps force by 1-repetition maximum) and lung function (spirometry)

Notes Stage I (33 participants), stage II (19 participants), stage III (10 participants), stage IV (1 participant)

\section{Risk of bias}

\begin{tabular}{lll}
\hline Bias & Authors' judgement & Support for judgement \\
\hline $\begin{array}{l}\text { Random sequence genera- } \\
\text { tion (selection bias) }\end{array}$ & Low risk & Quote: \\
& "The randomisation was done in blocks with varying block size (4-6 sub- \\
jects)..."
\end{tabular}


Edvardsen 2015 (Continued)

$\begin{array}{ll}\text { Incomplete outcome data } & \text { Low risk } \\ \text { (attrition bias) } & \text { Quote: } \\ \text { All outcomes } & \text { "Effects were evaluated on an intention-to-treat basis." }\end{array}$

All outcomes

Selective reporting (re- High risk Comment:

porting bias)

ClinicalTrials.gov Identifier: NCT01748981 - 1 prespecified outcome (physical activity) was not reported in the published study.

Other bias Low risk Comment:

The study appears to be free of other sources of bias.

Messaggi-Sartor 2018

Methods $\begin{aligned} & \text { Pilot randomised controlled trial } \\ & \text { Setting: outpatient cardiopulmonary rehabilitation unit of } 2 \text { university hospitals in Barcelona, Spain } \\ & \text { Study duration: } 8 \text { weeks of intervention and 2-year follow-up }\end{aligned}$

Participants 70 patients with NSCLC were screened to participate. 37 patients (mean (SD) age 65 (9) years - control group; 64 (8) years - exercise group) agreed to participate in the study and were randomised.

Interventions

Control ( $n=21)$ : usual postoperative care (standard medical treatment and periodic monitoring). Participants were advised to perform physical activity such as leisure time physical activity (walking, dancing, hiking, or swimming), transportation (walking or cycling), occupational (if still in the workforce), household chores, play, games and sports, or planned exercise.

Exercise $(n=16)$ : continuous aerobic training and high-intensity respiratory muscle training ( 24 supervised sessions, 3 per week, 8 weeks). Continuous aerobic training was performed on an ergometric bicycle, initial intensity was $60 \%$ of baseline peak workload and increased by 5 watts weekly if the participant was able to tolerate the set load for $30 \mathrm{~min}$. High-intensity respiratory muscle training consisted of 5 sets of 10 repetitions followed by 1 to 2 min of unloaded recovery breathing, twice a day, 3 days per week, for 8 weeks.

Outcomes Exercise capacity $\left(\mathrm{VO}_{2}\right.$ peak), health-related quality of life (EORTC QLQ-C30), and respiratory muscle strength (maximal inspiratory and expiratory pressure)

Notes

\section{Risk of bias}

Bias Authors' judgement Support for judgement

Random sequence genera- Low risk Quote:

tion (selection bias)

"Eligible patients were randomly assigned to the exercise and control groups. Randomization was performed by a staff member blinded to patient identify, who assigned the anonymized patient record to one of the study groups using a random number generator program."

$\begin{array}{ll}\begin{array}{l}\text { Allocation concealment } \\ \text { (selection bias) }\end{array} & \text { Quote: } \\ & \text { "Randomization was performed by a staff member blinded to patient identify, } \\ & \text { who assigned the anonymized patient record to one of the study groups." }\end{array}$


Messaggi-Sartor 2018 (Continued)

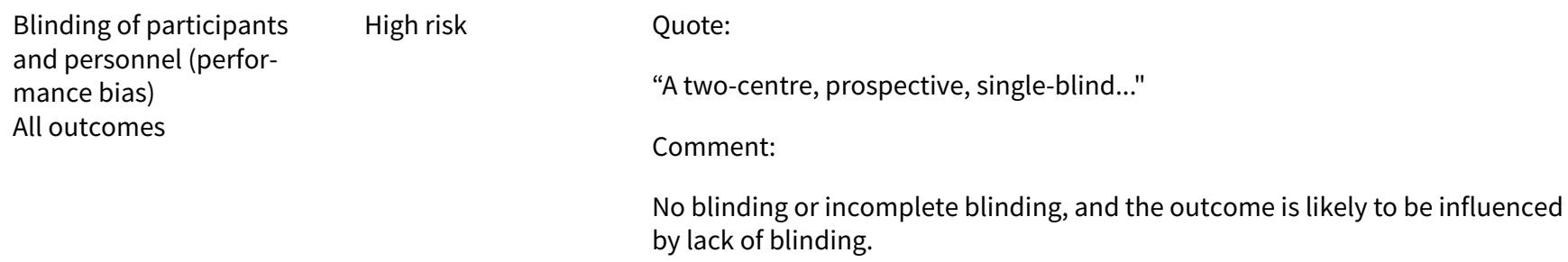

\begin{tabular}{|c|c|c|}
\hline $\begin{array}{l}\text { Blinding of outcome as- } \\
\text { sessment (detection bias) }\end{array}$ & Low risk & Quote: \\
\hline All outcomes & & $\begin{array}{l}\text { "The researchers assessing the main outcomes were blinded to the group as- } \\
\text { signments." }\end{array}$ \\
\hline
\end{tabular}

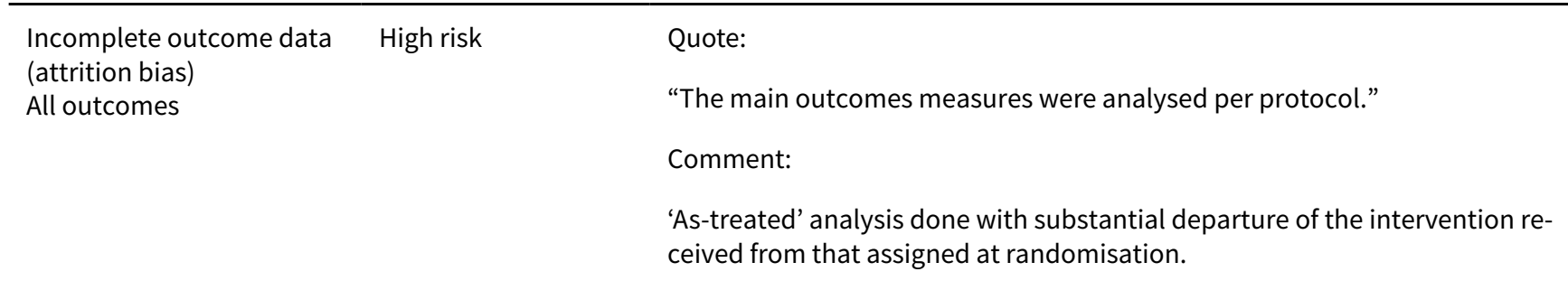

\begin{tabular}{ll}
\hline $\begin{array}{l}\text { Selective reporting (re- } \\
\text { porting bias) }\end{array}$ & High risk \\
& $\begin{array}{l}\text { Comment: } \\
\text { elinicalTrials.gov Identifier: NCT01771796 - the prespecified outcomes periph- } \\
\text { paper. Furthermore, respiratory muscle strength and quality of life are report- } \\
\text { ed in the paper but are not included in the registration. }\end{array}$
\end{tabular}

\begin{tabular}{ll}
\hline Other bias & Low risk \\
& The study appears to be free of other sources of bias. \\
\hline
\end{tabular}

\section{Salhi 2015}

\begin{tabular}{ll}
\hline Methods & Randomised controlled trial \\
& Setting: University hospital in Belgium \\
& Study duration: 12 -week intervention. Participants were evaluated before, after radical treatment, and \\
after completing the 12 -week intervention.
\end{tabular}

$\begin{array}{ll}\text { Participants } & 121 \text { consecutive patients with respiratory cancer were recruited. } 86 \text { patients completed the assess- } \\ & \text { ments before radical treatment. } 16 \text { additional patients dropped out following radical treatment. } 70 \\ & \text { radically treated patients were randomly assigned to } 1 \text { of } 3 \text { groups: control }(n=24) \text {, conventional resis- } \\ & \text { tance training }(\mathrm{CRT})(\mathrm{n}=24) \text {, or whole-body vibration training group ( } \mathrm{n}=22 \text { ). Only data pertaining to } \\ & \text { the control group (median (range) age } 64 \text { (51 to 79) years) and CRT group (63 (29 to 76) years) were used } \\ & \text { in the current review. }\end{array}$

Control $(n=24)$ : participants were discouraged from undertaking supervised exercise training.
Exercise $(\mathrm{CRT})(\mathrm{n}=24): 3$ times per week for 12 weeks. 20 min of aerobic training on the bicycle and
treadmill at $70 \%$ of the respective maximal workload (Wmax) and speed; resistance training on mul-
ti-gym equipment starting with 3 sets of 8 repetitions for each exercise at 50\% 1-repetition-maximum.

Outcomes

Exercise capacity (6MWD and $\mathrm{VO}_{2}$ peak), quadriceps muscle force (isometric handheld dynamometer), health-related quality of life (EORTC QLQ-C30), fatigue (FACIT-F), and dyspnoea (VAS dyspnoea) 
Salhi 2015 (Continued)

Notes 3-arm trial. Only data from the control and CRT groups were used in the current review.

6 of the 24 participants in the control group (25\%) and 6 of the 24 participants in the CRT group (25\%) did not undergo lung resection.

Author was contacted and kindly provided specific data for the participants that underwent lung resection (gender, age, lung cancer stage, $\mathrm{VO}_{2}$ peak, 6MWD, quadriceps force, EORTC QLQ-C30, dyspnoea, fatigue, and $\mathrm{FEV}_{1}$ ).

\section{Risk of bias}

\begin{tabular}{lll}
\hline Bias & Authors' judgement & Support for judgement \\
\hline $\begin{array}{l}\text { Random sequence genera- } \\
\text { tion (selection bias) }\end{array}$ & Low risk & Quote: \\
& & "Patient randomisation was conducted by a blinded, web-based platform us- \\
& ing a minimisation technique..." \\
\hline $\begin{array}{l}\text { Allocation concealment } \\
\text { (selection bias) }\end{array}$ & Low risk & Quote: \\
& & $\begin{array}{l}\text { "Patient randomisation was conducted by a blinded, web-based platform us- } \\
\text { ing a minimisation technique with random allocation to either a control group } \\
\text { (CON), a CRT-group and a WBVT-group." }\end{array}$ \\
& Comment: \\
& Central allocation.
\end{tabular}

\begin{tabular}{|c|c|c|}
\hline $\begin{array}{l}\text { Blinding of participants } \\
\text { and personnel (perfor- } \\
\text { mance bias) }\end{array}$ & High risk & $\begin{array}{l}\text { Comment: } \\
\text { No blinding, and the outcome is likely to be influenced by lack of blinding. }\end{array}$ \\
\hline
\end{tabular}

\begin{tabular}{|c|c|c|}
\hline $\begin{array}{l}\text { Blinding of outcome as- } \\
\text { sessment (detection bias) } \\
\text { All outcomes }\end{array}$ & High risk & $\begin{array}{l}\text { Quote: } \\
\text { "The investigator was unblinded for the intervention and its evaluation." }\end{array}$ \\
\hline $\begin{array}{l}\text { Incomplete outcome data } \\
\text { (attrition bias) } \\
\text { All outcomes }\end{array}$ & Low risk & $\begin{array}{l}\text { Comment: } \\
3 / 24 \text { (control group), } 4 / 24 \text { (resistance group), and } 5 / 22 \text { (whole-body vibration } \\
\text { training group) were lost to follow-up. Intention-to-treat and per-protocol } \\
\text { analysis performed. Missing data imputation was performed. }\end{array}$ \\
\hline $\begin{array}{l}\text { Selective reporting (re- } \\
\text { porting bias) }\end{array}$ & High risk & $\begin{array}{l}\text { Comment: } \\
\text { ClinicalTrials.gov Identifier: NCT00752700 (not included in the published pa- } \\
\text { per) - prespecified outcomes such as muscle mass, body composition, and } \\
\text { anxiety and depression were not reported in the published paper. }\end{array}$ \\
\hline Other bias & Low risk & $\begin{array}{l}\text { Comment: } \\
\text { The study appears to be free of other sources of bias. }\end{array}$ \\
\hline
\end{tabular}

Stigt 2013

$\begin{array}{ll}\text { Methods } & \text { Randomised controlled trial } \\ & \text { Setting: Teaching Hospital in Zwolle, the Netherlands }\end{array}$


Stigt 2013 (Continued)

Study duration: 12 weeks of intervention and 1-year follow-up. Assessments were performed before surgery and postoperatively at $1,3,6$, and 12 months.

Participants patients with NSCLC who were eligible for thoracotomy were invited. 60 patients accepted, but 57
were randomised before surgery. 49 participants completed (exercise group: $\mathrm{n}=23$ ( 21 males), mean
age $63.6 \pm 10.2$ years and control group: $\mathrm{n}=26$ (19 males), mean age $63.2 \pm 10.3$ years)

Interventions Control $(n=26)$ : usual care consisting of routine outpatient appointments at $1,3,6$, and 12 months following surgery. Pain medication prescribed by their pulmonologist or general practitioner.

Exercise $(n=23): 4$ weeks after discharge, twice a week, participants exercised at $60 \%$ to $80 \%$ of their peak cycling load and performed muscle training for 12 weeks. An anaesthesiologist adjusted pain treatment according to the World Health Organization (WHO) analgesic ladder.

\begin{tabular}{ll}
\hline Outcomes & $\begin{array}{l}\text { Exercise capacity (6MWD), health-related quality of life (SGRQ and SF-36), and pulmonary function } \\
\text { (spirometry) }\end{array}$ \\
\hline Notes & Only "open thoracotomy" included. \\
& $\begin{array}{l}\text { The number of participants who had adjuvant chemotherapy was } 10 \text { in the exercise group and } 6 \text { in the } \\
\text { control group. }\end{array}$ \\
\hline
\end{tabular}

\section{Risk of bias}

\begin{tabular}{|c|c|c|}
\hline Bias & Authors' judgement & Support for judgement \\
\hline $\begin{array}{l}\text { Random sequence genera- } \\
\text { tion (selection bias) }\end{array}$ & Low risk & $\begin{array}{l}\text { Quote: } \\
\text { "...patients were randomised to the active (rehabilitation) group or control } \\
\text { group using a computer minimization system..." }\end{array}$ \\
\hline $\begin{array}{l}\text { Allocation concealment } \\
\text { (selection bias) }\end{array}$ & Low risk & $\begin{array}{l}\text { Quote: } \\
\text { “...using a computer minimization system initiated by the treating chest physi- } \\
\text { cian...” } \\
\text { Comment: } \\
\text { Investigators enrolling participants could not foresee assignment. }\end{array}$ \\
\hline
\end{tabular}

$\begin{array}{ll}\text { Blinding of participants } & \text { High risk } \\ \begin{array}{l}\text { and personnel (perfor- } \\ \text { mance bias) }\end{array} & \text { No blinding of participants and personnel. }\end{array}$

All outcomes

\begin{tabular}{|c|c|c|}
\hline $\begin{array}{l}\text { Blinding of outcome as- } \\
\text { sessment (detection bias) }\end{array}$ & Unclear risk & Comment: \\
\hline
\end{tabular}

\begin{tabular}{ll}
\hline $\begin{array}{l}\text { Incomplete outcome data } \\
\text { (attrition bias) }\end{array}$ & High risk \\
All outcomes & 3 months postdischarge, 6 MWD and lung function data were reported for less \\
& $\begin{array}{l}\text { than } 40 \% \text { and } 60 \% \text { of participants, respectively. Reasons reported as follows: } \\
\text { "... because they dropped out or felt unable to perform the test..." }\end{array}$
\end{tabular}

$\begin{array}{ll}\begin{array}{l}\text { Selective reporting (re- } \\ \begin{array}{l}\text { porting bias) } \\ \text { High risk }\end{array}\end{array} & \begin{array}{l}\text { Comment: } \\ \text { The trial registration of the study (clinicaltrials.gov/show/NCT01136083) was } \\ \text { reviewed, and not all of the prespecified outcomes were reported in the pub- } \\ \text { lished paper. }\end{array} \\ \end{array}$


Stigt 2013 (Continued)
Other bias
High risk
Comment:

More participants who had chemotherapy were randomised to the training group, and Table 3 shows a higher dropout in attendance rate for participants who had chemotherapy compared to those who did not.

6MWD: 6-minute walk distance

6MWT: 6-minute walk test

EORTC QLQ-C30: European Organisation for Research and Treatment of Cancer Quality of Life Questionnaire core 30

EORTC QLQ-LC13: European Organisation for Research and Treatment of Cancer Quality of Life Questionnaire, Lung Cancer subscale

FACIT-F: Functional Assessment of Chronic Illness Therapy - Fatigue Subscale

FACT-L: Functional Assessment of Cancer Therapy - Lung

$\mathrm{FEV}_{1}$ /FVC: Forced expiratory volume in one second / Force vital capacity

HADS: Hospital Anxiety and Depression scale

NSCLC: Non-small cell lung cancer

rpm: Revolutions per minute

SD: Standard deviation

SF-36: Medical Outcomes Study Short Form 36 General Health Survey

SGRQ: St. George's Respiratory Questionnaire

VATS: Video assisted thoracotomy

Wmax: Maximum work rate

Characteristics of excluded studies [ordered by study ID]

\begin{tabular}{|c|c|}
\hline Study & Reason for exclusion \\
\hline Brocki 2016 & Not exercise training \\
\hline Chen 2015 & Mixed population. No access to specific data \\
\hline Chen 2016 & Mixed population. No access to specific data \\
\hline Granger 2013 & Not specifically NSCLC \\
\hline Hoffman 2017 & Qualitative analysis only \\
\hline Hsiao 2017 & Includes preoperative intervention \\
\hline Jakobsen 2013 & Did not reply to contact attempts \\
\hline Karvinen 2014 & Mixed population. No access to specific data \\
\hline Ledderer 2013 & Mixed population with few participants with NSCLC \\
\hline Liu 2015 & Intervention delivered more than 12 months following lung resection. \\
\hline Novoa 2017 & Conference abstract. No access to specific data \\
\hline Tenconi 2017 & Conference abstract. No access to specific data \\
\hline Wang 2013 & Intervention delivered more than 12 months following lung resection. \\
\hline Weiner 1997 & Not postoperative patients \\
\hline Yorke 2015 & Not postoperative exercise training \\
\hline
\end{tabular}


NSCLC: non-small cell lung cancer

\section{DATA AND ANALYSES}

\section{Comparison 1. Exercise group versus control group}

\begin{tabular}{|c|c|c|c|c|}
\hline Outcome or subgroup title & No. of studies & $\begin{array}{l}\text { No. of partici- } \\
\text { pants }\end{array}$ & Statistical method & Effect size \\
\hline $\begin{array}{l}1 \text { Exercise capacity }\left(\mathrm{VO}_{2} \text { peak in } \mathrm{mL} /\right. \\
\mathrm{kg} / \mathrm{min})\end{array}$ & 4 & 135 & $\begin{array}{l}\text { Mean Difference (IV, Fixed, } \\
95 \% \mathrm{CI} \text { ) }\end{array}$ & $2.97[1.93,4.02]$ \\
\hline 2 Exercise capacity (6MWD in metres) & 5 & 182 & $\begin{array}{l}\text { Mean Difference (IV, Fixed, } \\
95 \% \mathrm{CI})\end{array}$ & $\begin{array}{l}57.26[34.34 \\
80.18]\end{array}$ \\
\hline $\begin{array}{l}3 \text { General health-related quality of } \\
\text { life (SF-36 - physical component } \\
\text { score) }\end{array}$ & 4 & 208 & $\begin{array}{l}\text { Mean Difference (IV, Fixed, } \\
95 \% \mathrm{Cl} \text { ) }\end{array}$ & $5.02[2.30,7.73]$ \\
\hline $\begin{array}{l}4 \text { General health-related quality of } \\
\text { life (SF-36 - mental component score) }\end{array}$ & 4 & 208 & $\begin{array}{l}\text { Mean Difference (IV, Random, } \\
95 \% \mathrm{CI} \text { ) }\end{array}$ & $-2.32[-11.26,6.62]$ \\
\hline $\begin{array}{l}5 \text { Disease-specific health-related } \\
\text { quality of life (EORTC QLQ-C30 - glob- } \\
\text { al health) }\end{array}$ & 4 & 111 & $\begin{array}{l}\text { Mean Difference (IV, Fixed, } \\
95 \% \mathrm{Cl} \text { ) }\end{array}$ & $-0.14[-7.24,6.96]$ \\
\hline $\begin{array}{l}6 \text { Disease-specific health-related } \\
\text { quality of life (EORTC QLQ C } 30 \text { - func- } \\
\text { tional scales) }\end{array}$ & 2 & 60 & $\begin{array}{l}\text { Mean Difference (IV, Fixed, } \\
95 \% \mathrm{Cl} \text { ) }\end{array}$ & $-0.82[-8.81,7.17]$ \\
\hline $\begin{array}{l}7 \text { Disease-specific health-related } \\
\text { quality of life (EORTC QLQ-C30 - } \\
\text { symptoms scales) }\end{array}$ & 2 & 60 & $\begin{array}{l}\text { Mean Difference (IV, Fixed, } \\
95 \% \mathrm{Cl} \text { ) }\end{array}$ & $-3.05[-10.58,4.47]$ \\
\hline $\begin{array}{l}8 \text { Disease-specific health-related } \\
\text { quality of life (EORTC QLQ-C30 - phys- } \\
\text { ical functioning) }\end{array}$ & 2 & 51 & $\begin{array}{l}\text { Mean Difference (IV, Fixed, } \\
95 \% \mathrm{CI} \text { ) }\end{array}$ & $2.05[-3.50,7.59]$ \\
\hline $\begin{array}{l}9 \text { Force-generating capacity of pe- } \\
\text { ripheral muscle (quadriceps) }\end{array}$ & 4 & 133 & $\begin{array}{l}\text { Std. Mean Difference (IV, } \\
\text { Fixed, } 95 \% \mathrm{CI} \text { ) }\end{array}$ & $0.75[0.39,1.10]$ \\
\hline $\begin{array}{l}\text { 9.1 Studies that reported postinter- } \\
\text { vention values }\end{array}$ & 2 & 97 & $\begin{array}{l}\text { Std. Mean Difference (IV, } \\
\text { Fixed, } 95 \% \mathrm{CI} \text { ) }\end{array}$ & $0.72[0.30,1.13]$ \\
\hline $\begin{array}{l}\text { 9.2 Studies that reported mean } \\
\text { change values }\end{array}$ & 2 & 36 & $\begin{array}{l}\text { Std. Mean Difference (IV, } \\
\text { Fixed, } 95 \% \mathrm{CI} \text { ) }\end{array}$ & $0.83[0.14,1.52]$ \\
\hline $\begin{array}{l}10 \text { Force-generating capacity of pe- } \\
\text { ripheral muscles (handgrip) }\end{array}$ & 2 & 75 & $\begin{array}{l}\text { Mean Difference (IV, Fixed, } \\
95 \% \mathrm{CI} \text { ) }\end{array}$ & $3.19[-1.14,7.52]$ \\
\hline 11 Dyspnoea & 3 & 110 & $\begin{array}{l}\text { Std. Mean Difference (IV, } \\
\text { Fixed, } 95 \% \mathrm{CI} \text { ) }\end{array}$ & $-0.43[-0.81,-0.05]$ \\
\hline $\begin{array}{l}11.1 \text { Studies that reported postinter- } \\
\text { vention values }\end{array}$ & 2 & 87 & $\begin{array}{l}\text { Std. Mean Difference (IV, } \\
\text { Fixed, } 95 \% \mathrm{CI} \text { ) }\end{array}$ & $-0.59[-1.02,-0.16]$ \\
\hline
\end{tabular}




\begin{tabular}{|c|c|c|c|c|}
\hline Outcome or subgroup title & No. of studies & $\begin{array}{l}\text { No. of partici- } \\
\text { pants }\end{array}$ & Statistical method & Effect size \\
\hline $\begin{array}{l}11.2 \text { Study that reported mean } \\
\text { change value }\end{array}$ & 1 & 23 & $\begin{array}{l}\text { Std. Mean Difference (IV, } \\
\text { Fixed, } 95 \% \mathrm{CI} \text { ) }\end{array}$ & $0.15[-0.67,0.98]$ \\
\hline 12 Fatigue & 3 & 68 & $\begin{array}{l}\text { Std. Mean Difference (IV, } \\
\text { Fixed, } 95 \% \mathrm{CI} \text { ) }\end{array}$ & $-0.05[-0.52,0.43]$ \\
\hline 13 Lung function $\left(\mathrm{FEV}_{1}\right)$ & 4 & 166 & $\begin{array}{l}\text { Std. Mean Difference (IV, } \\
\text { Fixed, } 95 \% \mathrm{CI} \text { ) }\end{array}$ & $-0.06[-0.37,0.25]$ \\
\hline $\begin{array}{l}\text { 13.1 Studies that reported postinter- } \\
\text { vention values }\end{array}$ & 2 & 83 & $\begin{array}{l}\text { Std. Mean Difference (IV, } \\
\text { Fixed, } 95 \% \mathrm{CI} \text { ) }\end{array}$ & $0.02[-0.41,0.46]$ \\
\hline $\begin{array}{l}\text { 13.2 Studies that reported mean } \\
\text { change values }\end{array}$ & 2 & 83 & $\begin{array}{l}\text { Std. Mean Difference (IV, } \\
\text { Fixed, } 95 \% \mathrm{CI} \text { ) }\end{array}$ & $-0.14[-0.58,0.29]$ \\
\hline 14 Lung function (FVC) & 2 & 83 & $\begin{array}{l}\text { Mean Difference (IV, Fixed, } \\
95 \% \mathrm{CI})\end{array}$ & $-0.06[-0.26,0.15]$ \\
\hline
\end{tabular}

Analysis 1.1. Comparison 1 Exercise group versus control group, Outcome 1 Exercise capacity $\left(\mathrm{VO}_{2}\right.$ peak in $\left.\mathrm{mL} / \mathrm{kg} / \mathrm{min}\right)$.

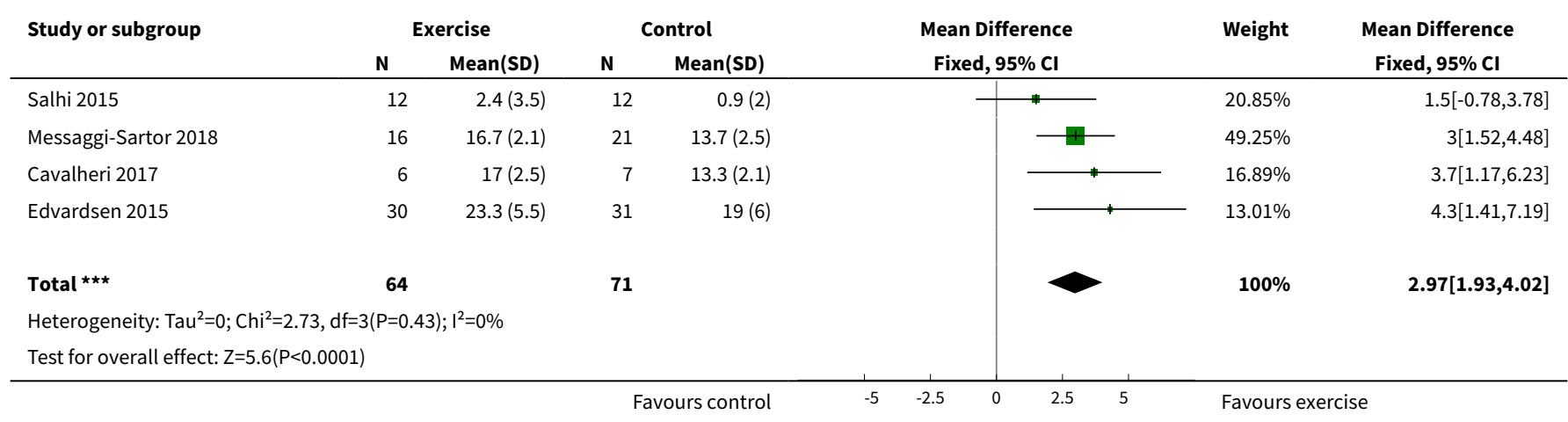

Analysis 1.2. Comparison 1 Exercise group versus control group, Outcome 2 Exercise capacity (6MWD in metres).

\begin{tabular}{|c|c|c|c|c|c|c|c|c|}
\hline \multirow{3}{*}{$\begin{array}{l}\text { Study or subgroup } \\
\text { Arbane } 2011\end{array}$} & \multicolumn{2}{|c|}{ Exercise } & \multicolumn{2}{|c|}{ Control } & \multirow{2}{*}{\multicolumn{2}{|c|}{$\begin{array}{c}\text { Mean Difference } \\
\text { Fixed, } 95 \% \mathrm{Cl}\end{array}$}} & \multirow[t]{2}{*}{ Weight } & \multirow{2}{*}{$\begin{array}{c}\text { Mean Difference } \\
\text { Fixed, } 95 \% \mathrm{Cl}\end{array}$} \\
\hline & $\mathbf{N}$ & $\operatorname{Mean}(S D)$ & $\mathbf{N}$ & $\operatorname{Mean}(S D)$ & & & & \\
\hline & 21 & $480.2(110)$ & 16 & $448.2(95.2)$ & & , & $11.97 \%$ & $32[-34.25,98.25]$ \\
\hline Brocki 2014 & 37 & $472(146)$ & 31 & $452(94)$ & & $\rightarrow$ & $15.88 \%$ & $20[-37.52,77.52]$ \\
\hline Cavalheri 2017 & 6 & $45(36)$ & 7 & $-8(30)$ & & $\longrightarrow$ & $39.69 \%$ & $53[16.62,89.38]$ \\
\hline Salhi 2015 & 13 & $113.2(56.6)$ & 15 & $12.7(85.8)$ & & 7 & $18.55 \%$ & $100.5[47.28,153.72]$ \\
\hline Stigt 2013 & 17 & $567(78)$ & 19 & 491 (109) & & 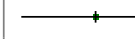 & $13.91 \%$ & $76[14.54,137.46]$ \\
\hline 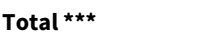 & 94 & & 88 & & & & $100 \%$ & $57.26[34.34,80.18]$ \\
\hline \multicolumn{9}{|c|}{ Heterogeneity: $\mathrm{Tau}^{2}=0 ; \mathrm{Chi}^{2}=5.12, \mathrm{df}=4(\mathrm{P}=0.28) ; \mathrm{I}^{2}=21.82 \%$} \\
\hline \multicolumn{9}{|c|}{ Test for overall effect: $Z=4.9(P<0.0001)$} \\
\hline
\end{tabular}


Analysis 1.3. Comparison 1 Exercise group versus control group, Outcome 3 General health-related quality of life (SF-36 - physical component score).

\begin{tabular}{|c|c|c|c|c|c|c|c|}
\hline \multirow[t]{2}{*}{ Study or subgroup } & \multicolumn{2}{|c|}{ Exercise } & \multicolumn{2}{|c|}{ Control } & \multirow{2}{*}{$\begin{array}{c}\text { Mean Difference } \\
\text { Fixed, } 95 \% \mathrm{Cl} \\
\end{array}$} & \multirow[t]{2}{*}{ Weight } & \multirow{2}{*}{$\begin{array}{c}\text { Mean Difference } \\
\text { Fixed, } 95 \% \mathrm{Cl} \\
\end{array}$} \\
\hline & $\mathbf{N}$ & $\operatorname{Mean}(S D)$ & $\mathbf{N}$ & $\operatorname{Mean}(S D)$ & & & \\
\hline Arbane 2014 & 34 & $17(24.4)$ & 28 & $23(32.8)$ & 1 & $3.43 \%$ & $-6[-20.66,8.66]$ \\
\hline Brocki 2014 & 37 & $44(10)$ & 31 & $41(10)$ & - & $32.32 \%$ & $3[-1.77,7.77]$ \\
\hline Cavalheri 2017 & 9 & $2(6)$ & 8 & $-2(5)$ & —- & $26.89 \%$ & $4[-1.23,9.23]$ \\
\hline Edvardsen 2015 & 30 & $51.8(5.5)$ & 31 & $43.3(11.3)$ & 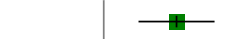 & $37.37 \%$ & $8.5[4.06,12.94]$ \\
\hline \multicolumn{8}{|c|}{ Heterogeneity: $\mathrm{Tau}^{2}=0 ; \mathrm{Chi}^{2}=5.37, \mathrm{df}=3(\mathrm{P}=0.15) ; \mathrm{I}^{2}=44.11 \%$} \\
\hline Test for overall effec & & & & & & & \\
\hline
\end{tabular}

Analysis 1.4. Comparison 1 Exercise group versus control group, Outcome 4 General health-related quality of life (SF-36 - mental component score).

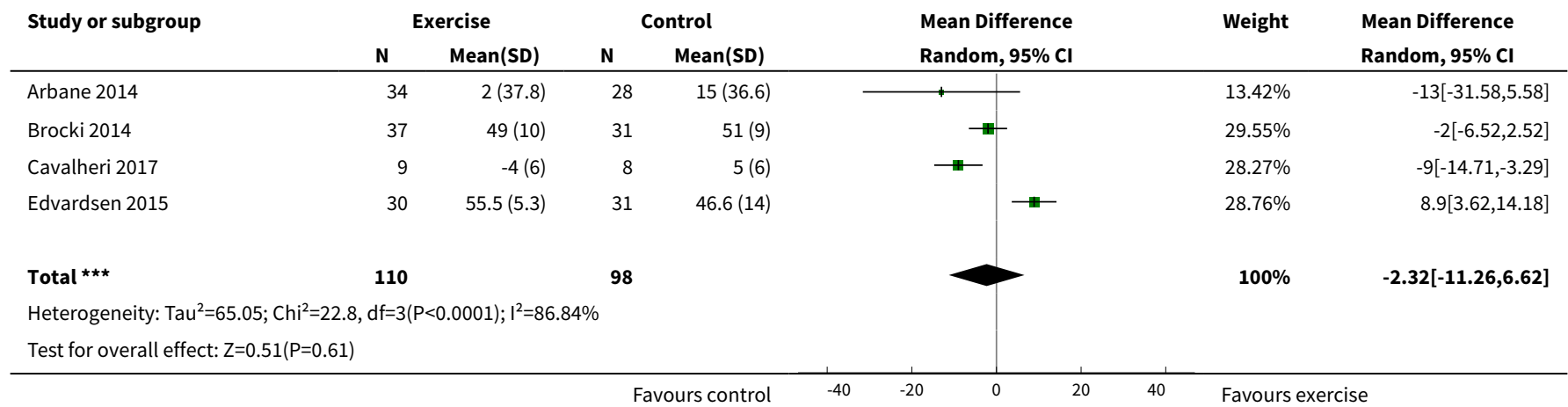

Analysis 1.5. Comparison 1 Exercise group versus control group, Outcome 5 Disease-specific health-related quality of life (EORTC QLQ-C30 - global health).

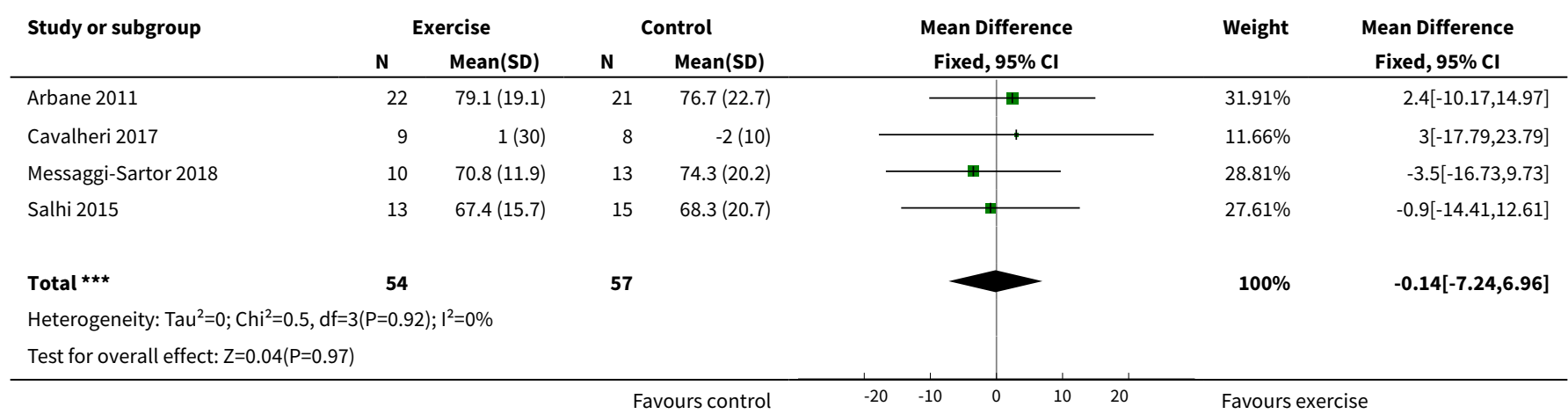


Analysis 1.6. Comparison 1 Exercise group versus control group, Outcome 6 Disease-specific health-related quality of life (EORTC QLQ C30 - functional scales).

\begin{tabular}{|c|c|c|c|c|c|c|c|}
\hline \multirow[t]{2}{*}{ Study or subgroup } & \multicolumn{2}{|c|}{ Exercise } & \multicolumn{2}{|c|}{ Control } & \multirow{2}{*}{$\begin{array}{c}\text { Mean Difference } \\
\text { Fixed, } 95 \% \mathrm{Cl}\end{array}$} & \multirow[t]{2}{*}{ Weight } & \multirow{2}{*}{$\begin{array}{c}\text { Mean Difference } \\
\text { Fixed, } 95 \% \mathrm{Cl}\end{array}$} \\
\hline & $\mathbf{N}$ & $\operatorname{Mean}(S D)$ & $\mathbf{N}$ & $\operatorname{Mean}(S D)$ & & & \\
\hline Arbane 2011 & 22 & $79.1(19.1)$ & 21 & $76.7(22.7)$ & 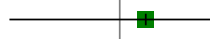 & $40.43 \%$ & $2.4[-10.17,14.97]$ \\
\hline Cavalheri 2017 & 9 & $0(14)$ & 8 & $3(7)$ & + & $59.57 \%$ & $-3[-13.35,7.35]$ \\
\hline 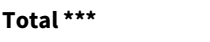 & 31 & & 29 & & & $100 \%$ & $-0.82[-8.81,7.17]$ \\
\hline \multicolumn{8}{|c|}{ Heterogeneity: $\mathrm{Tau}^{2}=0 ; \mathrm{Chi}^{2}=0.42, \mathrm{df}=1(\mathrm{P}=0.52) ; \mathrm{I}^{2}=0 \%$} \\
\hline
\end{tabular}

Analysis 1.7. Comparison 1 Exercise group versus control group, Outcome 7 Disease-specific health-related quality of life (EORTC QLQ-C30 - symptoms scales).

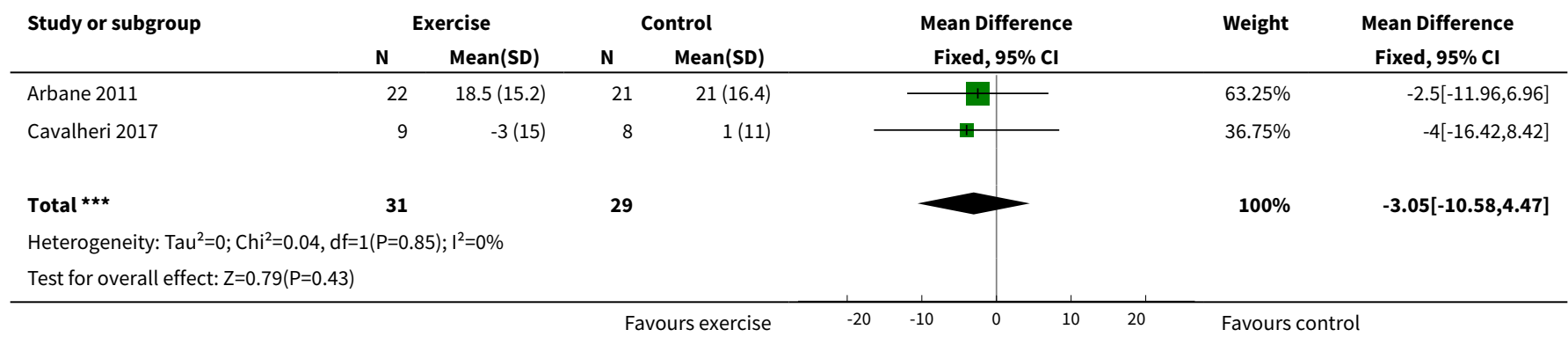

Analysis 1.8. Comparison 1 Exercise group versus control group, Outcome 8 Diseasespecific health-related quality of life (EORTC QLQ-C30 - physical functioning).

\begin{tabular}{|c|c|c|c|c|c|c|c|}
\hline \multirow[t]{2}{*}{ Study or subgroup } & \multicolumn{2}{|c|}{ Exercise } & \multicolumn{2}{|c|}{ Control } & \multirow{2}{*}{$\begin{array}{c}\text { Mean Difference } \\
\text { Fixed, } 95 \% \mathrm{Cl}\end{array}$} & \multirow[t]{2}{*}{ Weight } & \multirow{2}{*}{$\begin{array}{c}\text { Mean Difference } \\
\text { Fixed, } 95 \% \mathrm{Cl}\end{array}$} \\
\hline & $\mathbf{N}$ & $\operatorname{Mean}(S D)$ & $\mathbf{N}$ & $\operatorname{Mean}(S D)$ & & & \\
\hline Messaggi-Sartor 2018 & 10 & $96(5.6)$ & 13 & $93.8(9.2)$ & & $82.97 \%$ & $2.2[-3.89,8.29]$ \\
\hline Salhi 2015 & 15 & $3.5(15.3)$ & 13 & $2.2(20.2)$ & & $17.03 \%$ & $1.3[-12.14,14.74]$ \\
\hline Total $* \star \star$ & 25 & & 26 & & & $100 \%$ & $2.05[-3.5,7.59]$ \\
\hline \multicolumn{8}{|c|}{ Heterogeneity: $\mathrm{Tau}^{2}=0 ; \mathrm{Chi}^{2}=0.01, \mathrm{df}=1(\mathrm{P}=0.9) ; \mathrm{I}^{2}=0 \%$} \\
\hline
\end{tabular}

Analysis 1.9. Comparison 1 Exercise group versus control group, Outcome 9 Force-generating capacity of peripheral muscle (quadriceps).

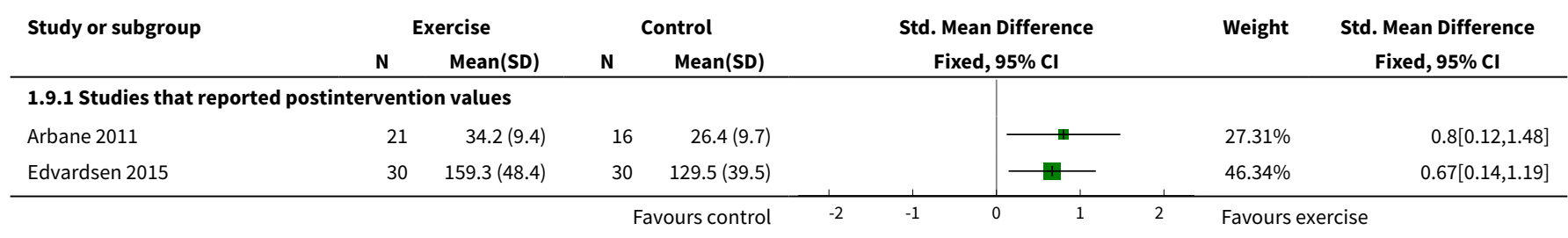




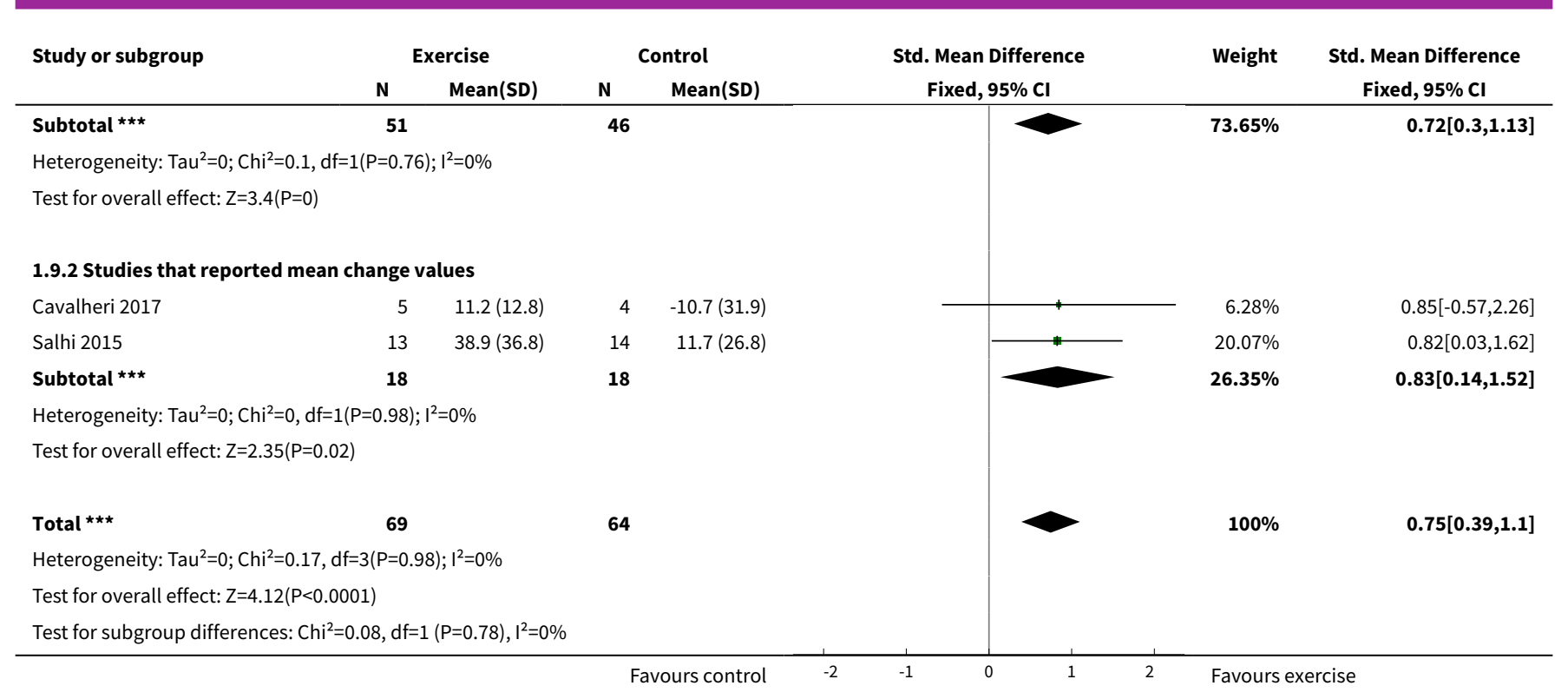

Analysis 1.10. Comparison 1 Exercise group versus control group, Outcome 10 Force-generating capacity of peripheral muscles (handgrip).

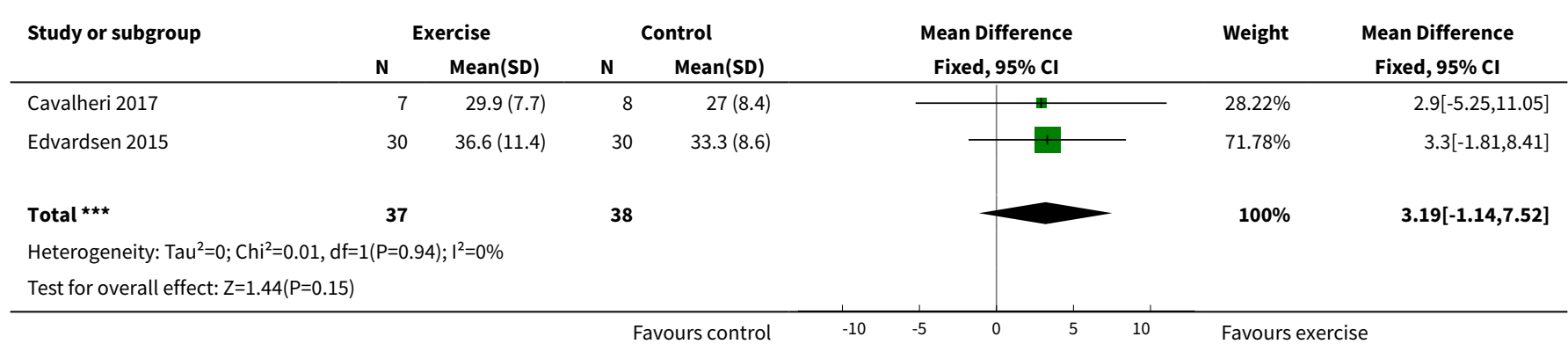

\section{Analysis 1.11. Comparison 1 Exercise group versus control group, Outcome 11 Dyspnoea.}

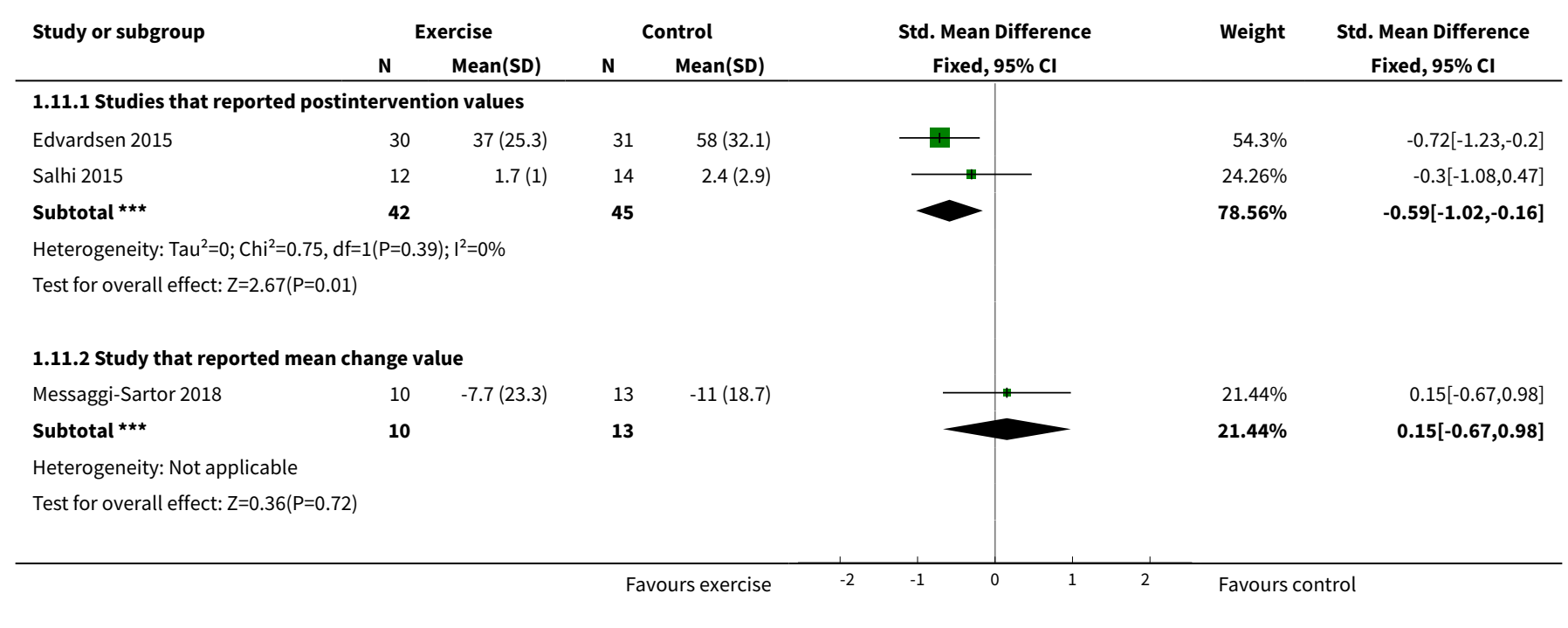




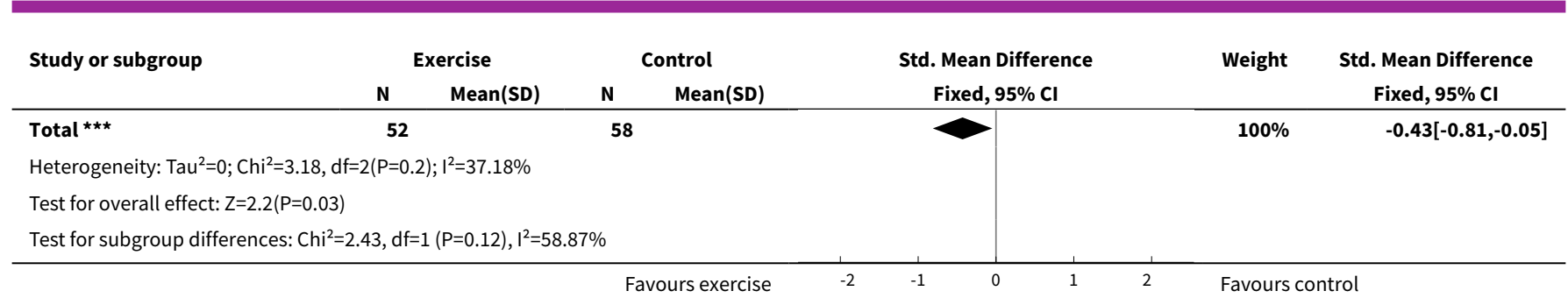

\section{Analysis 1.12. Comparison 1 Exercise group versus control group, Outcome 12 Fatigue.}

\begin{tabular}{|c|c|c|c|c|c|c|c|}
\hline \multirow[t]{2}{*}{ Study or subgroup } & \multicolumn{2}{|c|}{ Exercise } & \multicolumn{2}{|c|}{ Control } & \multirow{2}{*}{$\begin{array}{c}\text { Std. Mean Difference } \\
\text { Fixed, } 95 \% \mathrm{Cl}\end{array}$} & \multirow[t]{2}{*}{ Weight } & \multirow{2}{*}{$\begin{array}{c}\text { Std. Mean Difference } \\
\text { Fixed, } 95 \% \mathrm{Cl} \\
\end{array}$} \\
\hline & $\mathbf{N}$ & $\operatorname{Mean}(S D)$ & $\mathbf{N}$ & $\operatorname{Mean}(S D)$ & & & \\
\hline Cavalheri 2017 & 9 & $-1.2(7.6)$ & 8 & $1.6(7.9)$ & 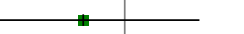 & $24.8 \%$ & $-0.34[-1.3,0.62]$ \\
\hline Messaggi-Sartor 2018 & 10 & $4.4(16.3)$ & 13 & $1.4(22.6)$ & - & $33.63 \%$ & $0.14[-0.68,0.97]$ \\
\hline Salhi 2015 & 13 & $-2.2(7.7)$ & 15 & $-2(9.8)$ & & $41.56 \%$ & $-0.02[-0.76,0.72]$ \\
\hline Total $* \star \star$ & 32 & & 36 & & & $100 \%$ & $-0.05[-0.52,0.43]$ \\
\hline Test for overall effect: & & & & & & & \\
\hline
\end{tabular}

Analysis 1.13. Comparison 1 Exercise group versus control group, Outcome 13 Lung function (FEV 1 ).

\begin{tabular}{|c|c|c|c|c|c|c|c|}
\hline \multirow[t]{2}{*}{ Study or subgroup } & \multicolumn{2}{|c|}{ Exercise } & \multicolumn{2}{|c|}{ Control } & \multirow{2}{*}{$\begin{array}{c}\text { Std. Mean Difference } \\
\text { Fixed, } 95 \% \mathrm{Cl} \\
\end{array}$} & \multirow[t]{2}{*}{ Weight } & \multirow{2}{*}{$\begin{array}{c}\text { Std. Mean Difference } \\
\text { Fixed, } 95 \% \mathrm{Cl} \\
\end{array}$} \\
\hline & $\mathbf{N}$ & $\operatorname{Mean}(S D)$ & $\mathbf{N}$ & Mean(SD) & & & \\
\hline \multicolumn{8}{|c|}{ 1.13.1 Studies that reported postintervention values } \\
\hline Edvardsen 2015 & 30 & $77.9(16.2)$ & 30 & $78.4(22.8)$ & & $36.84 \%$ & $-0.02[-0.53,0.48]$ \\
\hline Stigt 2013 & 9 & $2.1(0.6)$ & 14 & $2(0.6)$ & & $13.41 \%$ & $0.16[-0.68,1]$ \\
\hline Subtotal $\star \star \star$ & 39 & & 44 & & & $50.24 \%$ & $0.02[-0.41,0.46]$ \\
\hline \multicolumn{8}{|c|}{ Heterogeneity: $\operatorname{Tau}^{2}=0 ; \mathrm{Chi}^{2}=0.14, \mathrm{df}=1(\mathrm{P}=0.71) ; \mathrm{I}^{2}=0 \%$} \\
\hline \multicolumn{8}{|c|}{ 1.13.2 Studies that reported mean change values } \\
\hline Brocki 2014 & 37 & $0.1(0.5)$ & 31 & $0.1(0.6)$ & & $41.43 \%$ & $-0.02[-0.5,0.46]$ \\
\hline Cavalheri 2017 & 7 & $0(0.1)$ & 8 & $0.1(0.1)$ & & $8.33 \%$ & $-0.77[-1.84,0.29]$ \\
\hline Subtotal $\star \star \star ~$ & 44 & & 39 & & & $49.76 \%$ & $-0.14[-0.58,0.29]$ \\
\hline \multicolumn{8}{|c|}{ Heterogeneity: $\mathrm{Tau}^{2}=0 ; \mathrm{Chi}^{2}=1.6, \mathrm{df}=1(\mathrm{P}=0.21) ; \mathrm{I}^{2}=37.64 \%$} \\
\hline 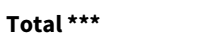 & 83 & & 83 & & & $100 \%$ & $-0.06[-0.37,0.25]$ \\
\hline \multicolumn{8}{|c|}{ Heterogeneity: $\operatorname{Tau}^{2}=0 ; \mathrm{Chi}^{2}=2.03, \mathrm{df}=3(\mathrm{P}=0.57) ; \mathrm{I}^{2}=0 \%$} \\
\hline \multicolumn{8}{|c|}{ Test for overall effect: $Z=0.38(P=0.7)$} \\
\hline \multicolumn{8}{|c|}{ Test for subgroup differences: $\mathrm{Chi}^{2}=0.29, \mathrm{df}=1(\mathrm{P}=0.59), \mathrm{I}^{2}=0 \%$} \\
\hline & & & & s control & -1 & Favours & \\
\hline
\end{tabular}


Analysis 1.14. Comparison 1 Exercise group versus control group, Outcome 14 Lung function (FVC).

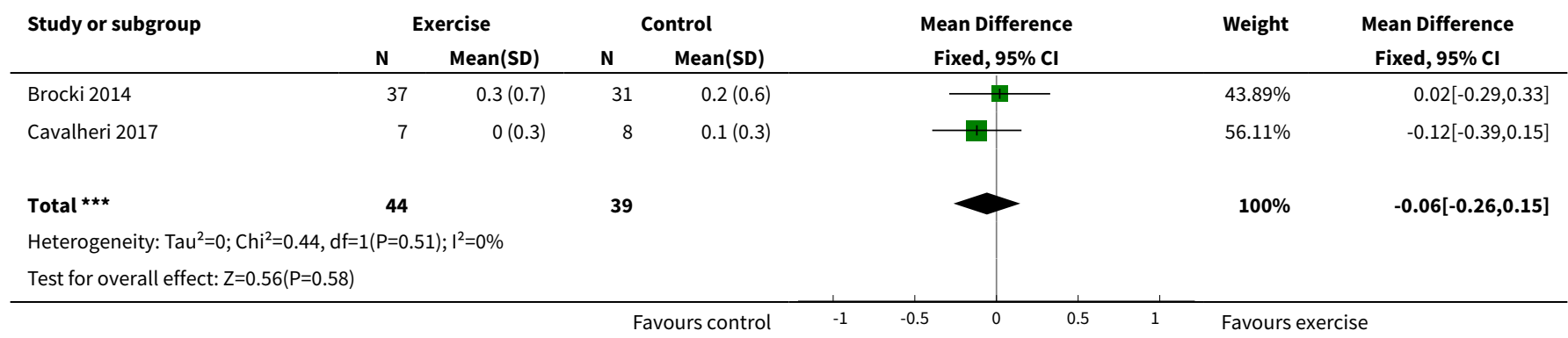

\section{APPENDICES}

\section{Appendix 1. MEDLINE (via PubMed) search strategy}

\#1 ((((lung cancer*[Title/Abstract]) OR non-small cell[Title/Abstract]) OR non small cell[Title/Abstract]) OR Lung Neoplasms[MeSH Terms]) OR Carcinoma, Non-Small-Cell Lung[MeSH Terms]

\#2 ((()((((exercis*[Title/Abstract]) OR rehabilitat*[Title/Abstract]) OR aerobic*[Title/Abstract]) OR endurance[Title/Abstract]) OR strength*[Title/Abstract]) OR inspiratory muscle*[Title/Abstract]) OR respiratory muscle*[Title/Abstract]) OR treadmill[Title/Abstract]) OR walking[Title/Abstract]) OR cycl*[Title/Abstract]

\#3 (training*[Title/Abstract]) OR program*[Title/Abstract]

\#4 ((\#1) AND \#2) AND \#3

\section{Appendix 2. CENTRAL search strategy}

\#1 (lung cancer*):ti,ab,kw in Clinical Trials

\#2 (non-small cell):ti,ab,kw in Clinical Trials

\#3 (non small cell):ti,ab,kw in Clinical Trials

\#4 MeSH descriptor Lung Neoplasms, this term only

\#5 MeSH descriptor Carcinoma, Non-Small-Cell Lung, this term only

\#6 (\#1 OR \#2 OR \#3 OR \#4 OR \#5)

\#7 (exercis*):ti,ab,kw in Clinical Trials

\#8 (rehabilitat*):ti,ab,kw in Clinical Trials

\#9 (aerobic*):ti,ab,kw in Clinical Trials

\#10 (endurance):ti,ab,kw in Clinical Trials

\#11 (strength*):ti,ab,kw in Clinical Trials

\#12 (inspiratory muscle*):ti,ab,kw in Clinical Trials

\#13 (respiratory muscle*):ti,ab,kw in Clinical Trials

\#14 (treadmill):ti,ab,kw in Clinical Trials

\#15 (walking):ti,ab,kw in Clinical Trials

$\# 16$ (cycl*):ti,ab,kw in Clinical Trials

\#17 (\#7 OR \#8 OR \#9 OR \#10 OR \#11 OR \#12 OR \#13 OR \#14 OR \#15 OR \#16)

Exercise training undertaken by people within 12 months of lung resection for non-small cell lung cancer (Review) 
\#18 (training*):ti,ab,kw in Clinical Trials

\#19 (program*):ti,ab,kw in Clinical Trials

\#20 (\#18 OR \#19)

\#21 (\#6 AND \#17 AND \#20)

\section{Appendix 3. Embase (via Ovid) search strategy}

1. "lung cancer*".m_titl.

2. limit 1 to human

3. non-small cell.mp.

4. limit 3 to human

5. non small cell.mp.

6. limit 5 to human

7. Lung Neoplasms.mp.

8. limit 7 to human

9. Carcinoma, Non-Small-Cell Lung.mp.

10. limit 9 to human

11.1 or 2 or 3 or 4 or 5 or 6 or 7 or 8 or 9 or 10

12. exercis ${ }^{\star} \cdot \mathrm{mp}$.

13. limit 12 to human

14. rehabilitat*.mp.

15. limit 14 to human

16. aerobic $^{\star} . \mathrm{mp}$.

17. limit 16 to human

18. endurance/

19. limit 18 to human

20. strength ${ }^{\star} \cdot \mathrm{mp}$.

21. limit 20 to human

22. inspiratory muscle ${ }^{\star} . \mathrm{mp}$.

23. limit 22 to human

24. respiratory muscle ${ }^{\star} . \mathrm{mp}$.

25. limit 24 to human

26. treadmill/

27. limit 26 to human

28. walking/

29. limit 28 to human

30. cycling/

Exercise training undertaken by people within $\mathbf{1 2}$ months of lung resection for non-small cell lung cancer (Review) 
31. limit 30 to human

32. 12 or 13 or 14 or 15 or 16 or 17 or 18 or 19 or 20 or 21 or 22 or 23 or 24 or 25 or 26 or 27 or 28 or 29 or 30 or 31

33. training/

34. limit 33 to human

35. $\operatorname{program}^{\star} \cdot \mathrm{mp}$.

36. limit 35 to human

37.33 or 34 or 35 or 36

38. 11 and 32 and 37

\section{FEEDBACK}

\section{Lack of reporting on adverse events, 4 April 2019}

\section{Summary}

The Cochrane Lung Cancer consumer (André Stoop) as well as the Statistitian (Marta Roque) the lack of reporting on adverse effects or harms related to the intervention.

\section{Reply}

We added "safety of the intervention" as a primary outcome as suggested in the document "Standards for planning, conduct and reporting of UPDATES of Cochrane Intervention reviews (U1-11, UR1-7)".

\section{Contributors}

All authors.

\section{WHAT'S NEW}

\begin{tabular}{lll}
\hline Date & Event & Description \\
\hline 10 April 2019 & Feedback has been incorporated & $\begin{array}{l}\text { New primary outcome included: safety of the intervention (i.e. } \\
\text { adverse events related to the intervention). }\end{array}$ \\
\hline 11 February 2019 & New search has been performed & Literature search ran on 11 February 2019. \\
\hline 11 February 2019 & New citation required but conclusions & $\begin{array}{l}\text { Five new studies included (Arbane 2014; Cavalheri 2017; Edvard- } \\
\text { sen 2015; Messaggi-Sartor 2018; Salhi 2015), resulting in a total } \\
\text { of eight included studies. Background, analysis, 'Summary of } \\
\text { findings' table, and conclusions updated. We have excluded the } \\
\text { outcome 'development of a postoperative pulmonary complica- } \\
\text { tion' from the 2019 update. Two news authors added. }\end{array}$ \\
\hline
\end{tabular}

\section{H I S T ORY}

Protocol first published: Issue 7, 2012

Review first published: Issue 7, 2013

\begin{tabular}{lll}
\hline Date & Event & Description \\
\hline 21 July 2015 & Amended & Contact details updated. \\
\hline
\end{tabular}




\section{CONTRIBUTIONS OF AUTHORS}

Vinicius Cavalheri: selection of studies, 'Risk of bias' assessment, data extraction, conduct of the analysis, and writing the final review paper.

Chris Burtin: selection of studies, 'Risk of bias' assessment, and writing the final review paper.

Vittoria R Formico: selection of studies, 'Risk of bias' assessment, data extraction, conduct of the analysis, and critical appraisal of the final review paper.

Mika L Nonoyama: methodological topics and critical appraisal of the final review paper.

Sue Jenkins: critical appraisal of the final review paper.

Martijn A Spruit: critical appraisal of the final review paper.

Kylie Hill: critical appraisal of the final review paper.

\section{DECLARATIONS OF INTEREST}

VC, KH, and SJ conducted a study that was included in this review (Cavalheri 2017). Consequently, the 'Risk of bias' assessment for that study was performed by $\mathrm{CB}$ and VRF.

Vinicius Cavalheri: none known

Chris Burtin: none known

Vittoria R Formico: none known

Mika L Nonoyama: none known

Sue Jenkins: none known

Martijn A Spruit: Prof Spruit discloses receiving personal remuneration for consultancy and/or lectures from Boehringer Ingelheim, AstraZeneca, and GSK outside the submitted work.

Kylie Hill: is a member of the Editorial Board for the Journal of Physiotherapy.

\section{SOURCES OF SUPPORT}

\section{Internal sources}

- Curtin University, Perth, Australia.

\section{External sources}

- Cancer Council Western Australia, Australia.

This research was supported by a Cancer Council Western Australia Postdoctoral Fellowship (VC).

\section{DIFFERENCES BETWEEN PROTOCOLANDREVIEW}

We presented the results of the primary outcome 'exercise capacity' in a separate meta-analysis: one that included peak rate of oxygen uptake $\left(\mathrm{VO}_{2}\right.$ peak) and a second one that included six-minute walk distance (6MWD). We added 'safety of the intervention' as a primary outcome as suggested in the document 'Standards for planning, conduct and reporting of UPDATES of Cochrane Intervention reviews (U1-11, UR1-7)' (Chandler 2016). We did not calculate risk difference, as no meta-analysis of dichotomous data was performed. We excluded the outcome 'development of a post-operative pulmonary complication' from the 2019 update, as we understand that postoperative exercise training in this population commences days or weeks after hospital discharge and hence cannot have an effect on the development of postoperative pulmonary complications. We added the visual analogue scale as a measure of dyspnoea. We divided the outcome health-related quality of life (HRQoL) into 'general HRQoL' and 'disease-specific HRQoL'. Due to changes such as separate meta-analysis for $\mathrm{VO}_{2}$ peak and 6MWD; the inclusion of 'safety of the intervention' as a primary outcome; the division of HRQoL into general HRQoL and disease-specific HRQoL; and the new findings of significant between-group difference in force-generating capacity of the peripheral muscles (quadriceps) and dyspnoea, new outcomes have been included in the 'Summary of findings' table. These include: (i) exercise capacity (both as $\mathrm{VO}_{2}$ peak and 6MWD); (ii) safety of the intervention; (iii) general HRQoL; (iv) force-generating capacity of the peripheral muscles (quadriceps); and (v) dyspnoea. 


\section{N D EX TERMS}

\section{Medical Subject Headings (MeSH)}

`Exercise Therapy; Breathing Exercises; Carcinoma, Non-Small-Cell Lung [rehabilitation] [surgery]; Exercise Tolerance [ ${ }^{\star}$ physiology]; Forced Expiratory Volume [physiology]; Health Status; Lung Neoplasms [rehabilitation] [surgery]; Muscle Strength [physiology]; Oxygen Consumption; Postoperative Care [methods]; Quadriceps Muscle [physiology]; Quality of Life; Randomized Controlled Trials as Topic; Resistance Training; Time Factors

\section{MeSH check words}

Female; Humans; Male 